\title{
A QUALITATIVE STUDY EXPLORING THE EXPERIENCES OF MINDFULNESS TRAINING IN PEOPLE WITH ACQUIRED BRAIN INJURY
}

by

Shruti Niraj

A Thesis Submitted in Partial Fulfilment of the Registration for the Degree of Doctor of Clinical Psychology in the University of Birmingham

\section{Volume I: Research Component}

Department of Clinical Psychology

School of Psychology

The University of Birmingham June 2017 


\section{UNIVERSITYOF BIRMINGHAM}

\section{University of Birmingham Research Archive \\ e-theses repository}

This unpublished thesis/dissertation is copyright of the author and/or third parties. The intellectual property rights of the author or third parties in respect of this work are as defined by The Copyright Designs and Patents Act 1988 or as modified by any successor legislation.

Any use made of information contained in this thesis/dissertation must be in accordance with that legislation and must be properly acknowledged. Further distribution or reproduction in any format is prohibited without the permission of the copyright holder. 


\section{Overview}

This thesis is submitted in partial fulfilment of the requirements for the degree of Doctor of Clinical Psychology (Clin.Psy.D) at the University of Birmingham. The thesis consists of two volumes.

\section{Volume I}

Volume I consists of three parts. The first part presents a systematic review evaluating the evidence for the use of mindfulness-based interventions in people with neurodegenerative disorders. The second part is an empirical paper, which focuses on how individuals with acquired brain injury make sense of their experiences of learning and practicing mindfulness skills. The third part is a public domain paper outlining the research undertaken in the empirical paper suitable for a public audience.

\section{Volume II}

Volume II contains five Clinical Practice Reports completed over the course of training. They represent clinical work carried out during placements in the specialties of Learning Disabilities, Child, Adult, Older and Adult. The first report presents cognitivebehavioural and psychodynamic formulation of problems presented by a client with mild learning difficulty. The second report presents a service evaluation of a community learning disability service. The third report presents single case study describing results of a traumafocused cognitive-behavioural intervention with a child with trauma symptoms following a road traffic accident. The forth report is a case study of a compassion-focused intervention provided for a 68 years old lady with depression. Finally, CPR5 was presented as an oral presentation of psychodynamic work conducted with a 31 years old lady. The abstract of this work is presented. 



\section{Acknowledgements}

Firstly, I would like to thank my supervisor Dr. Theresa Powell for her advice, guidance and support throughout the completion of this thesis. I would like to express my appreciation to Dr. Michael Larkin and Dr. Andrew Fox for their valuable advice regarding my analysis and to Dr. Sue Wright for her support with recruitment.

Secondly, I would like to offer my sincerest thanks to all the participants who have given up their personal time to contribute to the research.

Finally, I would like to express my heartfelt gratitude to all my friends and family for their words of encouragement; and to my husband Niraj, who sustained me through this process with love, inspiration and incredible patience. 


\section{CONTENTS}

\section{VOLUME I: RESEARCH COMPONENT}

\section{Literature Review}

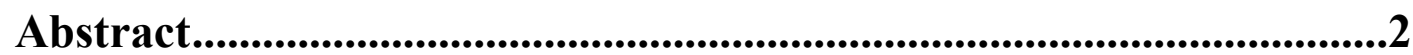

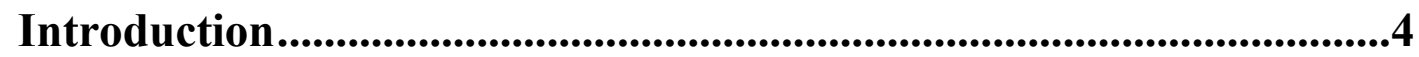

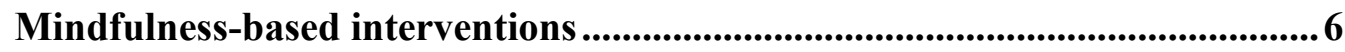

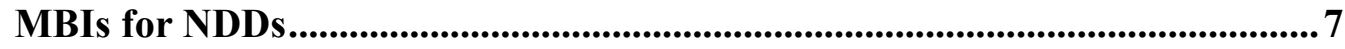

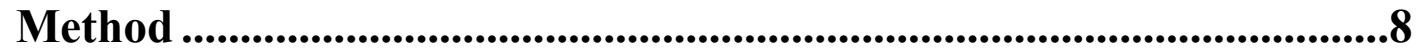

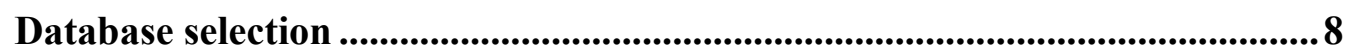

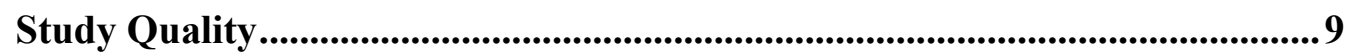

Data extraction and synthesis .................................................................11

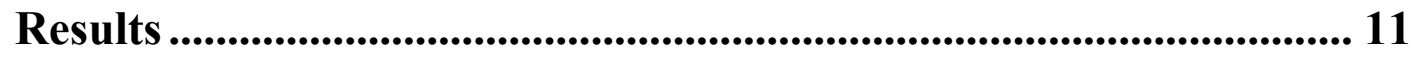

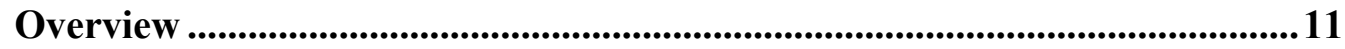

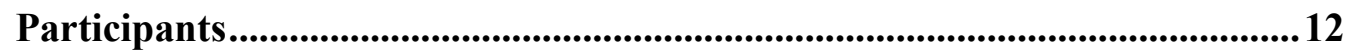

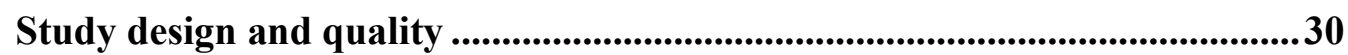

Intervention characteristics ................................................................................35

Primary and secondary outcome measures ..............................................................38

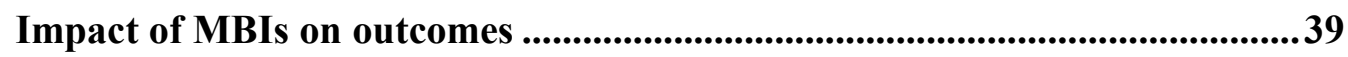

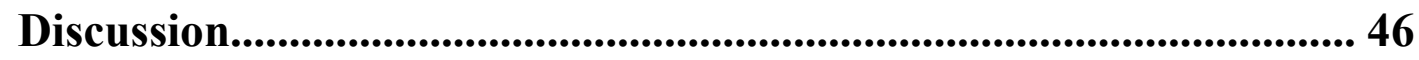

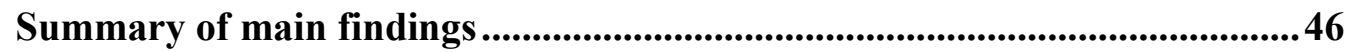

Intervention content and delivery ......................................................................48

Methodological issues ...........................................................................................50

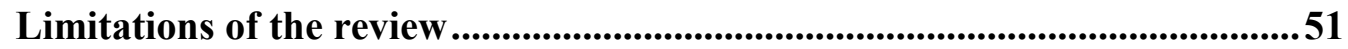

Implications for clinical practice and future research ....................................51

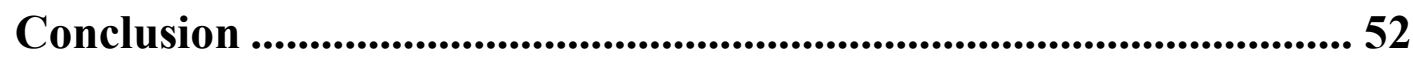

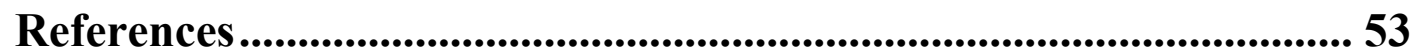




\section{Empirical Paper}

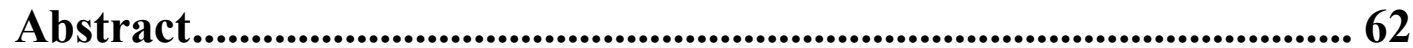

Introduction................................................................................................. 63

What is Mindfulness? .............................................................................................64

Impact of mindfulness in people with ABI .........................................................65

Qualitative studies in mindfulness...................................................................67

Present study ........................................................................................................68

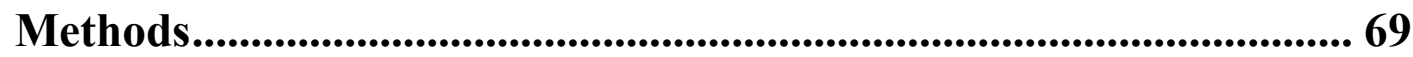

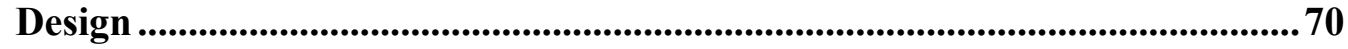

Data collection ............................................................................................ 73

Data Analysis...............................................................................................

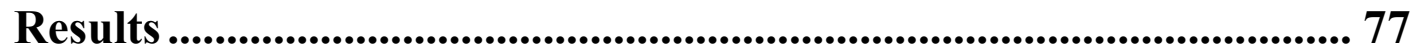

Focus Groups............................................................................................................................ 77

Individual In-vivo Recordings ................................................................................99

Themes from in-vivo recordings ..................................................................................101

Discussion......................................................................................................... 105

Main findings.............................................................................................................. 105

Strengths and limitations ................................................................................... 111

Future research ............................................................................................112

Implications for clinical practice .........................................................................112

Conclusion ........................................................................................................... 114

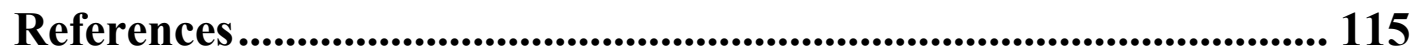

\section{Public Domain Briefing Paper}

Overview

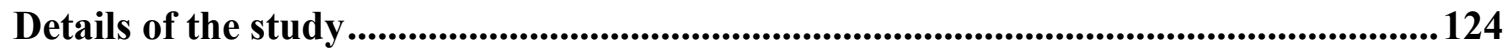

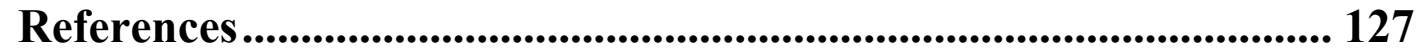




\section{VOLUME I: APPENDICES}

\section{Appendices - Literature review}

Appendix 1. Search Strategy 130

Appendix 2. NICE quality framework (Revised version) 132

Appendix 3. Results of the outcome measures used in the studies 134

\section{Appendices - Empirical Paper}

Appendix 1. Local Research Ethics Committee Approval Letter 136

Appendix 2. Brief programme of the 8 weeks mindfulness group 139

Appendix 3. Participant Information Sheet

Appendix 4. Consent Form - For clients participating in Voice recordings and

Focus group of the study

Appendix 5. Consent Form - For clients participating in Focus Group of the study

Appendix 6. Consent Form - - Voice recordings of the study 146

Appendix 7. Focus group interview schedule 147

Appendix 8. Total length of each focus group and participants attending each group

Appendix 9. Instructions for the Participants. 149

Appendix 10. An Example of a Worked-out Transcript from Focus Group - 2 ....150

Appendix 11. Emergent Themes from Focus Group - 2 ................................................. 152

Appendix 12. Master Table of Themes by Focus Groups 154

Appendix 13. Master Table of Themes and Location by Participant in Each Focus Group 


\section{VOLUME I: TABLES}

\section{Literature Review}

Table 1: Inclusion criteria for the review........................................9

Table 2: Exclusion criteria for the review....................................10

Table 3: Description of Multiple Sclerosis studies..................................14

Table 4: Description of Parkinson's disease studies.................................18

Table 5: Description of Dementia or MCI studies................................23

Table 6: Quality ratings for studies reviewed using the NICE quality framework.. 32

\section{Empirical Paper}

Table 1: Inclusion criteria for the present study $\ldots . \ldots \ldots \ldots \ldots \ldots \ldots \ldots \ldots \ldots \ldots \ldots \ldots \ldots . . . . \ldots 1$

Table 2: Participant demographics.............................................72

Table 3: Key stages followed during IPA.......................................76

Table 4: Master table of Themes for the Focus Groups..............................77

Table 5: Annotation of changes introduced to verbatim extracts ...................79

Table 6: Total number and length of recordings for each participant................98

Table 7: Revised template of Themes from interpreting the in-vivo recordings of current participants .........................................................100

Table 8: Reasons given by participants for practicing mindfulness ................101

\section{VOLUME I: FIGURES}

\section{Literature Review}

Figure 1: Summary of the review process. . .13

\section{Empirical Paper}

Figure 1: Diagrammatical representation of superordinate and subthemes from the focus group transcripts. 


\section{CONTENTS \\ VOLUME II: CLINICAL PRACTICE REPORTS}

\section{Clinical Practice Report 1: Models}

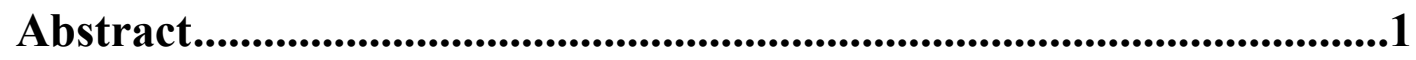

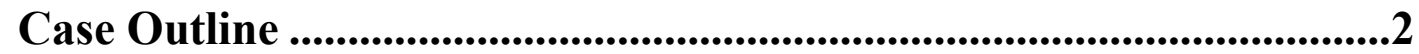

Formulation From A Cognitive Perspective ............................................6

Psychodynamic Formulation ............................................................................ 13

Critical Appraisal \& Personal Reflections ............................................. 21

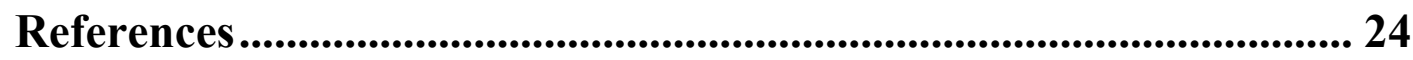

Clinical Practice Report 2: Service Evaluation

Abstract...................................................................................................................... 26

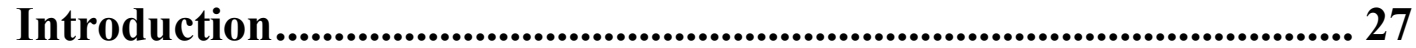

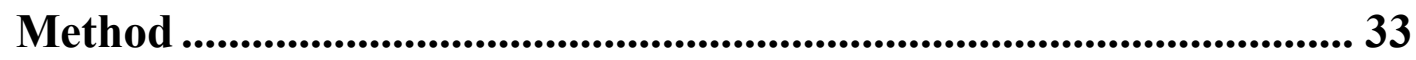

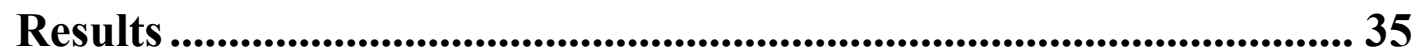

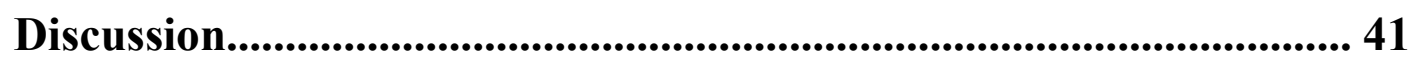

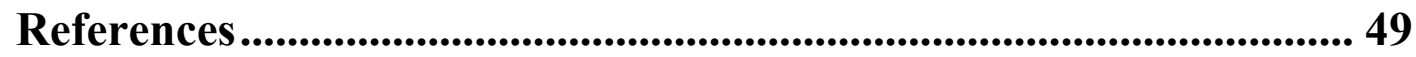

Clinical Practice Report 3: Single-case Study

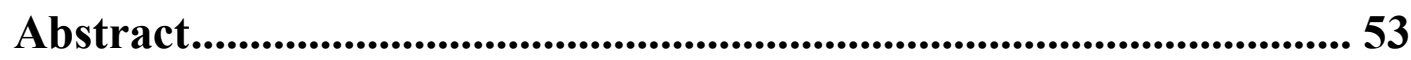

Case Summary ...................................................................................................... 55

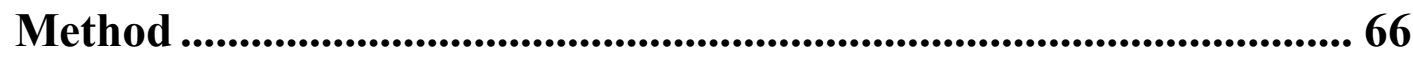

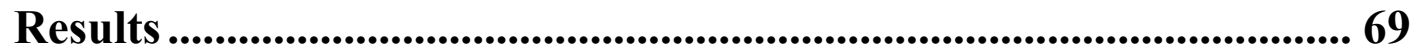

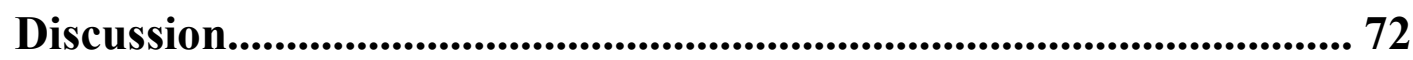

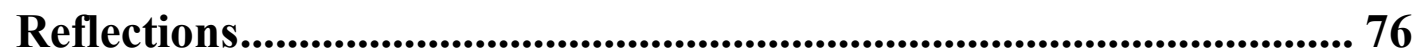

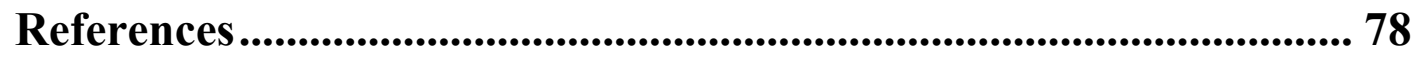

Clinical Practice Report 4: Case Study

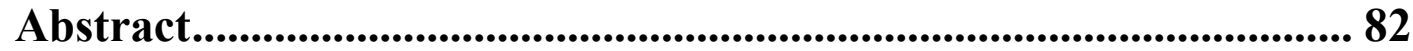

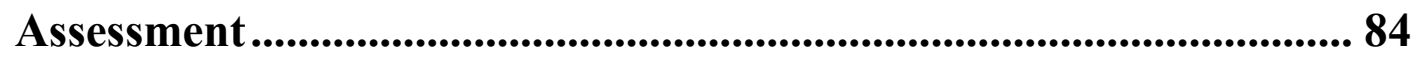




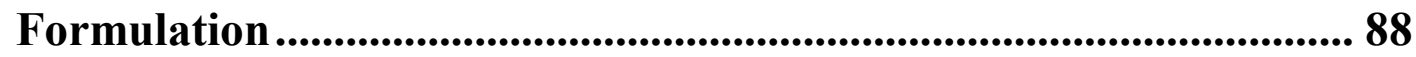

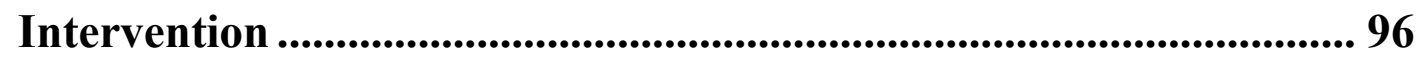

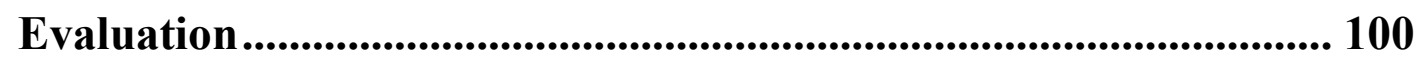

Reflections.............................................................................................................. 102

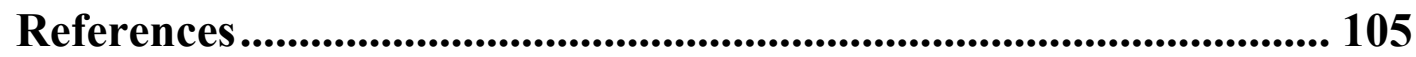

Clinical Practice Report 5: Case Study .................................................. 108

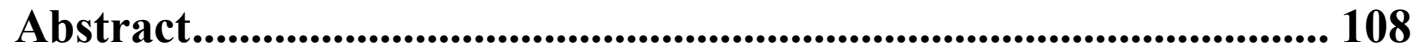

\section{VOLUME II: APPENDICES}

\section{Clinical Practice Report 2}

Appendix 1. National Research Ethics Service Guidance Sheet.......................... 111

Appendix 2. Health Research Authority (HRA) Decision Tool .......................... 114

Appendix 3. Client Information leaflet .............................................................. 115

Appendix 4. Comprehension Test........................................................................... 122

Appendix 5. Ethics approval application to Local R\&D ................................... 124

Appendix 6. Approval from Local Safety \& Quality Group...................... 127

Appendix 7: Questionnaire: Service User Understanding of Confidentiality/Privacy and Consent............................................................. 128

Appendix 8. Participant Information Sheet (Accessible Version)............... 131

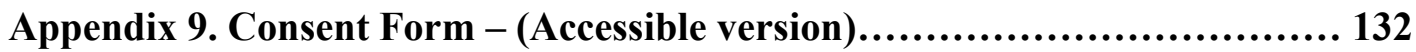

\section{Clinical Practice Report 3}

Appendix 1. Genogram .................................................. 134

Appendix 2. The Linen Cupboard Metaphor ................................. 135

Appendix 3. Thought records to update memory .............................. 136

Appendix 4. Ellie's diary for rating intensity of Scary feelings and Feelings thermometer .................................................................. 137

Appendix 5. Ellie's diary for rating level of avoidance $\quad$..........................138

\section{Clinical Practice Report 4}

Appendix 1. Self Compassion Scale (adapted from Neff, 2003) .................. 139

Appendix 2. Genogram .................................................... 140

Appendix 3. Handouts to understand CFT ideas and concepts ................... 141

Appendix 4. Diary sheet to 'develop your own story' ........................... 143 


\section{VOLUME II: TABLES}

\section{Clinical Practice Report: Service Evaluation}

Table 1. Frequencies of the quantitative responses ............................. 36

Table 2. Summary of questions asked and main theme ........................ 37

Table 3. Categories of responses .............................................. 40

Clinical Practice Report 3: Single-case Study

Table 4. The lag-1 autocorrelation coefficients, slope and significance value, and type of test applied for measures used in this study . 69

\section{Clinical Practice Report 4: Case Study}

Table 5. Quantitative indicators of intervention outcome 101

\section{VOLUME II: FIGURES}

\section{Clinical Practice Report 1: Models}

Figure 1: A genogram depicting Carl's family structure ............................7

Figure 2. A cognitive formulation of the development of Carl's difficulties ........10

Figure 3. A cross-sectional formulation of Carl's maintenance cycle of his presenting difficulties (adapted from Dudley and Kuyken, 2006)

Figure 4. An example of the interaction between the triangle of person and the triangle of conflict (adapted from Molnos, 1984) .............................. 14

Figure 5. Carl's Triangle of Conflict and Triangle of Person (Malan, 2001) ..... 18

Clinical Practice Report 3: Single-case Study

Figure 1. Formulation of Ellie's reaction to the trauma of her accident (based on Ehlers and Clark's (2000) cognitive model; adapted from Smith et al., 2014) ... 61 Figure 2. Formulation of Ellie's phobia of crossing a road following her accident (adapted from Townend, 2003) 62

Figure 3. Graph showing Ellie's level of Scary Feelings (SUDS) scores over time. (Baseline and intervention phases are shown in different colours) 70 
Figure 4. Graph showing Ellie's level of avoidance of feared situations scores over time. (Baseline and intervention phases are shown in different colours)

Figure 5. A graph showing number of flashbacks experienced over a week long period at baseline and post-intervention 71

Figure 6. A graph showing the difference between baseline (measurements 1 and 2), mid-treatment (measurement 3), and end of treatment (measurement 4) scores of

CRIES-8 72

\section{Clinical Practice Report 4: Case Study}

Figure 1. Three-Circle model depicting three types of affect regulation system (adapted from Gilbert, 2009) 91

Figure 2. Zarina's formulation based on the Three-Circle model depicting the imbalance in three types of affect regulation system 93

Figure 3. Zarina's formulation based on threat/safety strategy formulation for shame and self-criticism (adapted from Gilbert, 2007) 


\section{List of abbreviations (In alphabetical order)}

ABI

ACT

$\mathrm{AD}$

ALS

BA

DBT

DES

GATE

HD

HRQoL

IPA

MBI

MBCT

MBSR

MCI

MND

MRC

MS

NDDs

NICE

NRCT

PD

QoL

$\mathrm{RCT}$

TA

TBI
Acquired Brain Injury

Acceptance and Commitment Therapy

Alzheimer's Disease

Amyotrophic Lateral Sclerosis

Before-and-After

Dialectical Behavioural Therapy

Descriptive Experience Sampling

Graphical appraisal tool for epidemiological studies

Huntington's Disease

Health-related Quality of Life

Interpretative Phenomenological Analysis

Mindfulness-Based Interventions

Mindfulness-Based Cognitive Therapy

Mindfulness-Based Stress Reduction

Mild Cognitive Impairment

Motor Neuron disease

Medical Research Council

Multiple Sclerosis

Neurodegenerative Disorders

National Institute of Clinical Excellence

Non-randomised Controlled Trial

Parkinson's disease

Quality of Life

Randomised Controlled Trial

Template Analysis

Traumatic Brain Injury 


\section{Literature Review}

Effectiveness of Mindfulness-Based Interventions on Neurodegenerative Disorders: A Systematic Review 


\begin{abstract}
Aims: This review systematically evaluated the evidence for the use of mindfulness-based interventions (MBIs) in people with neurodegenerative disorders (NDDs). More specifically, the review appraised the current literature on the benefits of MBIs on psychological, social, symptom-specific, behavioural, and cognitive functioning in individuals with NDDs.
\end{abstract}

Method: PsycINFO, EMBASE, Ovid MEDLINE, CINAHL Plus and the Cochrane Library were searched for papers published in all years up to July 2016. The methodological quality of the papers was assessed using the NICE quality appraisal checklist for quantitative intervention studies.

Results: 13 papers detailing 12 studies met inclusion criteria. The studies involved people with three disorders, Multiple Sclerosis (MS), Parkinson's disease (PD) and Dementia/Mild Cognitive Impairment (MCI). Most MS studies found that anxiety and depression was reduced following MBIs. No conclusions were possible for PD or Dementia/MCI in terms of effectiveness of MBIs for reducing anxiety and depression. Nor could any firm conclusions be drawn regarding the impact of MBIs on quality of life, behavioural symptoms and cognitive symptoms in MS and PD. However, one good quality study provided some evidence for its effectiveness in maintaining cognitive function in people with a diagnosis of Alzheimer's disease. The long-term impact of MBIs was also difficult to evaluate due to lack of follow-up in half of the studies.

Conclusion: There is some encouraging evidence that MBIs reduce symptoms of anxiety and depression in people with NDD, which is mainly in people with MS. More high quality studies employing robust methodology such as RCTs with adequate statistical power are 
needed to explore this and other outcomes in people with PD, dementia/MCI and other NDDs that have not yet been explored. 


\section{Introduction}

The present review aims to systematically evaluate the evidence for the effectiveness of mindfulness-based interventions (MBIs) in neurodegenerative disorders (NDDs). Neurodegenerative disorders (NDDs) result from a progressive degeneration or death of nerve cells (Cummings \& Pillai, 2016). These disorders are often associated with deterioration of the central or peripheral nervous system (Chen, Zhang, \& Huang, 2016). They include diseases such as Alzheimer's disease (AD) and other dementias, Parkinson's disease (PD), Multiple Sclerosis (MS), Amyotrophic Lateral Sclerosis (ALS), Huntington's disease and Prion Diseases (Medical Research Council: MRC, 2017).

All NDDs are gradually progressive and disabling, and have major implications for wider social and economic resources (Cummings \& Pillai, 2016). NDDs are strongly linked with age (Przedborski, Vila, \& Jackson-Lewis, 2003). The economic impact of these diseases is likely to increase at an exponential rate because of an increasingly ageing population in the UK (Medical Research Council: MRC, 2016). The number of people aged 65 or over is projected to rise by over $40 \%$ in the next 17 years (Age UK, 2017). In the UK, it has been estimated that dementia alone costs the economy $£ 17$ billion a year (MRC, 2017). Furthermore, years lived with disability attributed to PD and AD, for example, has increased by more than 70\% between 1990 and 2010 (Anon. 2013). It is therefore paramount to focus on different ways to manage the challenges resulting from this group of disorders.

NDDs are linked to a significant reduction in quality of life (QoL) and have a major impact on patients and their carers (Batista \& Pereira, 2016). As the disease progresses, it can impact on an individual's professional, personal and social life leading to a complete inability to carry out any type of daily activity (Batista \& Pereira, 2016). The psychological 
impact of NDDs has common features across conditions. Individuals with PD for example, often report that their non-motor difficulties, such as sleep disturbance, depression, anxiety and symptoms of psychosis such as hallucinations can be more disabling than the motor symptoms (Davie, 2008; Truong, Bhidayasiri, \& Wolters, 2008). Similarly, almost $90 \%$ of people with dementia suffer from various psychological and behavioural difficulties over the course of their illness (Richly, Manes, \& Bustin, 2012). The most common symptoms include anxiety, depression, apathy, psychotic symptoms, agitation, aggression and appetite and sleep changes (Richly, et al., 2012). Patients with frontal-temporal dementia can suffer from pervasive changes in personality and social behaviour, including disinhibition (Cummings \& Pillai, 2016). Similar to individuals with dementia and PD, patients diagnosed with Huntington's disease also suffer from apathy, depression, anxiety, symptoms of psychosis and behavioural difficulties (Jauhar \& Ritchie, 2010). Depression is diagnosed in $40 \%$ of individuals with Huntington's disease and they are over four times more likely to commit suicide than those of the general population (Baquero \& Martín, 2015; Di Maio et al., 1993).

The difficulties noted above also lead to a reduced health-related QoL (HRQoL). For example, HRQoL was significantly lower on both physical and mental aspects of the Short-Form 36 (SF-36) in recently diagnosed people with MS when compared with controls (Klevan et al., 2014). The physical symptoms associated with NDDs are very disabling and further reduce QoL. For example, physical symptoms in MS may include visual impairment, weakness of one or more extremities, ataxia, bladder or bowel malfunction, pain and fatigue (Henze, Rieckmann \& Tokya, 2006). Cognitive impairment is also common across the NDDs. Cognitive impairment in MS for example, has been considered 
as the leading cause of unemployment amongst people with MS (Heesen et al., 2010; Langdon, 2011).

Mental health symptoms are often under-reported in people with NDDs (Marrie et al., 2009; Patten, Beck, Williams, Barbui, \& Metz, 2003). One of the reasons for this could be the overlap between signs and symptoms of the psychiatric state and those of the neurological disorder itself (Goldstein \& McNeil, 2012). However, the psychological and behavioural symptoms are often reported to be the most debilitating manifestations of NDDs and if left untreated can have an adverse effect on QoL (Chaudhuri, Healy, \& Schapira, 2006; Cummings \& Pillai, 2016; Schrag, Jahanshahi, \& Quinn, 2000). Therefore, there is a need to explore psychological interventions to manage the symptoms of emotional distress effectively and to improve well-being in this population.

\section{Mindfulness-based interventions}

Mindfulness has been defined as "paying attention in a particular way: on purpose, in the present moment and non-judgementally" (Kabat-Zinn, 2009). This ability to direct one's attention can be developed by practicing mindfulness meditation (Baer, 2003). The most common mindfulness interventions are Mindfulness Based Stress Reduction (MBSR) and Mindfulness-based Cognitive Therapy (MBCT).

MBSR was originally designed for people to manage stress associated with chronic pain (Kabat-Zinn, 1982). However, since its inception, MBSR has been successfully applied to a large variety of emotional or chronic health problems (Baer, 2003). Metaanalytic and systematic reviews suggest that MBIs are effective in improving psychological health of individuals living with a chronic physical health condition, such as cancer, psoriasis, chronic pain, fibromyalgia and chronic obstructive pulmonary disease (Bohlmeijer, Prenger, Taal, \& Cuijpers, 2010; Paul Grossman, Niemann, Schmidt, \& Walach, 2004; Keng, Smoski, \& Robins, 2011). There is also evidence suggesting that 
MBIs, such as MBSR and MBCT are effective in reducing anxiety and depressive symptoms in individuals with a diagnosable psychological or medical disorder (Hofmann, Sawyer, Witt, \& Oh, 2010) and the MBCT programme is recommended by NICE guidelines (2009) to prevent relapse in recurrent depressive illness.

There is emerging preliminary evidence to suggest that MBIs have a role to play in improving cognitive functioning in healthy individuals and in people with age-related cognitive decline (Chiesa \& Serretti, 2010; Gard, Hölzel, \& Lazar, 2014). For example, a few studies have shown that long-term mindfulness training enhances attentional and visuospatial processes in that population (Jha, Krompinger, \& Baime, 2007; Kozhevnikov, Louchakova, Josipovic, \& Motes, 2009). Furthermore, a few studies have shown that mindfulness training can change brain structures associated with sensory processing, emotional regulation, memory and self-referential processing in people who participated in MBSR programme compared to controls (Hölzel, et al., 2011; Lazar et al., 2005).

\section{MBIs for NDDs}

Given the findings above, it has been suggested that MBIs may have a role to play in managing the psychological and cognitive symptoms associated with NDDs. So far, there is only one systematic review on MBIs and this only includes individuals with MS (Simpson et al., 2014). This review included only three studies, of which only one was a randomised controlled trial. The review concluded that although there were a number of methodological limitations, MBIs might benefit some individuals with MS in terms of QoL, mental health and some physical health symptoms. Since then, three further studies have been published investigating the effectiveness of MBIs in this population.

Given the few studies in this area and because NDDs share similar psychological symptoms, the present review has taken a broader view of the evidence. A review of MBIs for individuals with NDDs as a group of conditions will help to clarify the evidence-base in 
this area, which is in its infancy. The main aim of this review is to systematically evaluate the effectiveness of MBIs in the management of NDDs. More specifically, the aim is to appraise the current literature on the benefits of MBIs to improve psychological, social, symptom-specific, behavioural, and cognitive functioning in individuals with NDDs. This will hopefully help to clarify whether further investigation of MBIs in NDDs is likely to be a fruitful line of research.

\section{Method}

\section{Database selection}

In order to establish whether previous reviews existed on this topic, the Cochrane reviews database was searched using the terms "mindfulness/mindfulness-based interventions" and "neurodegenerative disorders/diseases". The search did not produce any pre-existing Cochrane reviews evaluating the effectiveness of MBIs for people with NDDS.

A systematic search was therefore undertaken to look for research articles evaluating the effectiveness of MBIs for individuals with NDDs. The following databases were searched in July 2016: PsycINFO, EMBASE, Ovid MEDLINE, CINAHL Plus and the Cochrane Library. The search was limited to peer-reviewed articles written in English. Search terms specified the population under study ('neurodegenerative disorders') and the interventions being examined ('mindfulness' or 'meditation' or 'MBCT'/'MBSR'). The full search strategy can be seen in Appendix 1. Titles and abstracts were reviewed and any potentially relevant papers retrieved for full review, according to the inclusion and exclusion criteria (see Table 1\& 2). 
Table 1: Inclusion criteria for the review

\section{Inclusion criteria}

1. Studies with adult population (aged $\geq 18$ years).

2. Participants with a diagnosis of: Neurodegenerative disorders including mild cognitive impairments, or dementia (including all types and stages), or Parkinson's disease, or Multiple Sclerosis, or Motor Neuron disease (MND), or amyotrophic lateral sclerosis (ALS), or Huntington's disease.

3. Studies describing intervention as Mindfulness-based Stress Reduction (MBSR), Mindfulness-based Cognitive Therapy (MBCT), or an adapted version of either of these two.

4. Studies focusing on improving psychological, social, symptom-specific, behavioural or cognitive functioning of individuals with NDDs.

5. Studies that report a quantifiable measure of the impact that mindfulness had on at least one of these aspects.

6. Randomised controlled trials (RCT), non-randomised controlled trials (NRCT) or before-and-after (BA) only studies with or without a control group.

7. Studies that included caregivers or couples where only patient data could be extracted.

8. Full papers published in English before June 2016 in peer-reviewed journals.

\section{Study Quality}

Methodological quality was assessed using the NICE quality appraisal checklist for quantitative intervention studies (NICE, 2012). This checklist is based on the 'Graphical appraisal tool for epidemiological studies (GATE)', originally developed by Jackson et al. (2006). Although this was originally tailored for public health interventions, the advantage of this quality framework in the present context is that it provides very detailed and clear guidelines appropriate for this review, thus reducing the potential for bias and increasing inter-rater reliability. The checklist has five sections (Appendix 2) with 25 questions across four sections: key population criteria for assessing the study's external validity (3 
questions), method of allocation to intervention or comparison (10 questions), reliability of outcome measures (6 questions) and reporting of analyses (6 questions). The final section awards separate overall quality grading for internal validity and external validity.

Table 2: Exclusion criteria for the review

\section{Exclusion criteria}

1. Articles that only discuss a theoretical position or opinion.

2. Studies with a mixed group where NDDs data cannot be extracted.

3. Studies using an intervention in which mindfulness training is not the dominant aspect such as Dialectical Behaviour Therapy (Linehan, 1993), and Acceptance and Commitment Therapy (Hayes et al., 1999).

4. Integrated interventions e.g. lifestyle modifications, where mindfulness is one of the components and the effect of intervention cannot be attributed to mindfulness training.

5. Interventions based primarily on physical training and/or mindfulness in movement, i.e., Tai Chi, Qi Gong, and yoga.

6. Intensive meditation retreats.

7. Case studies and qualitative research.

8. Conference and dissertation abstracts

9. Studies which only report biological outcome measures.

Two important additional questions pertinent to MBIs were added to section 3, i.e. whether the study includes a mindfulness measure as an outcome and whether home practice was monitored. Information regarding improvements in mindfulness could clarify whether the mindfulness component of the MBI contributed to any treatment effect. Home practice of up to 40 minutes twice weekly is recommended in the original MBSR program and has been considered as a crucial factor in the cultivation of mindfulness skills (KabatZinn, 2013). 
A second reviewer independently rated five papers in order to assure inter-rater reliability and disagreements in ratings were resolved through discussion and noted for future rating. A traffic light system was used for overall ratings (Green $=$ all or most of the checklist criteria fulfilled; Amber $=$ some of the criteria fulfilled; Red $=$ few or no criteria fulfilled). Whilst a final rating can provide information about the overall quality of the study, certain checklist criteria can be more important than others. Thus, a narrative summary describing the strengths and weaknesses of each study has also been provided.

\section{Data extraction and synthesis}

The data extraction tool was consistent with the York Centre for Systematic Review guidelines (University of York, 2009) and included: the characteristics of the study, design and methodology, number and characteristics of participants, the interventions, outcomes and results. A meta-analysis was not possible because of the heterogeneous nature the populations studied and the variation in the type of MBI used. Hence, the findings are presented in a narrative format.

\section{Results}

\section{Overview}

Figure 1 illustrates the search process breakdown. A total of 2028 papers were identified from five databases. Two additional papers were identified through searching the reference lists of potential papers. After filtering, 114 abstracts were screened and 31 potential papers appeared to meet the inclusion criteria. A full-text reading resulted in 13 papers. Two articles reported results from the same study (Wells et al., 2013a, 2013b). Therefore, 13 papers detailing 12 studies were included and these involved people with 
three disorders, Multiple Sclerosis (MS), Parkinson's disease (PD) and Dementia/Mild Cognitive Impairment (MCI). Tables 3-5 summarise the 12 studies.

Three studies recruited both individuals with a NDD and their carers (Cash, et al., 2016; Litherland \& Robertson, 2014; Paller et al., 2015); only the data of individuals with a NDD will be reported here. Two studies used mixed methods (Lantz, Buchalter, \& McBee, 1997; Litherland \& Robertson, 2014) but only the quantitative findings will be reported.

\section{Participants}

Four studies examined the effectiveness of MBIs in 278 participants with a confirmed diagnosis of MS. One study originated from United Kingdom (Bogosian et al., 2015), one from Switzerland (Grossman et al., 2010) and two studies were from Iran (Amiri, Rabiei, \& Donyavi, 2016; Kolahkaj \& Zargar, 2015).

Three studies investigated the effectiveness of MBIs in 78 participants with PD. Thirty four participants were from United States (Cash et al., 2016), 17 from Australia (Dissanayaka et al., 2016) and 27 from Belgium (Pickut et al., 2015).

The remaining five studies included people with either dementia or MCI. The severity and type of dementia varied within and across the studies. Only one study specifically recruited participants with Alzheimer's disease (Quintana-Hernandez et al., 2015). The majority of these studies were conducted in United States (Lantz et al., 1997; Paller et al., 2015; Wells et al., 2013a; Wells et al., 2013b), one in United Kingdom (Litherland \& Robertson, 2014) and one in Spain (Quintana-Hernandez et al., 2015). 


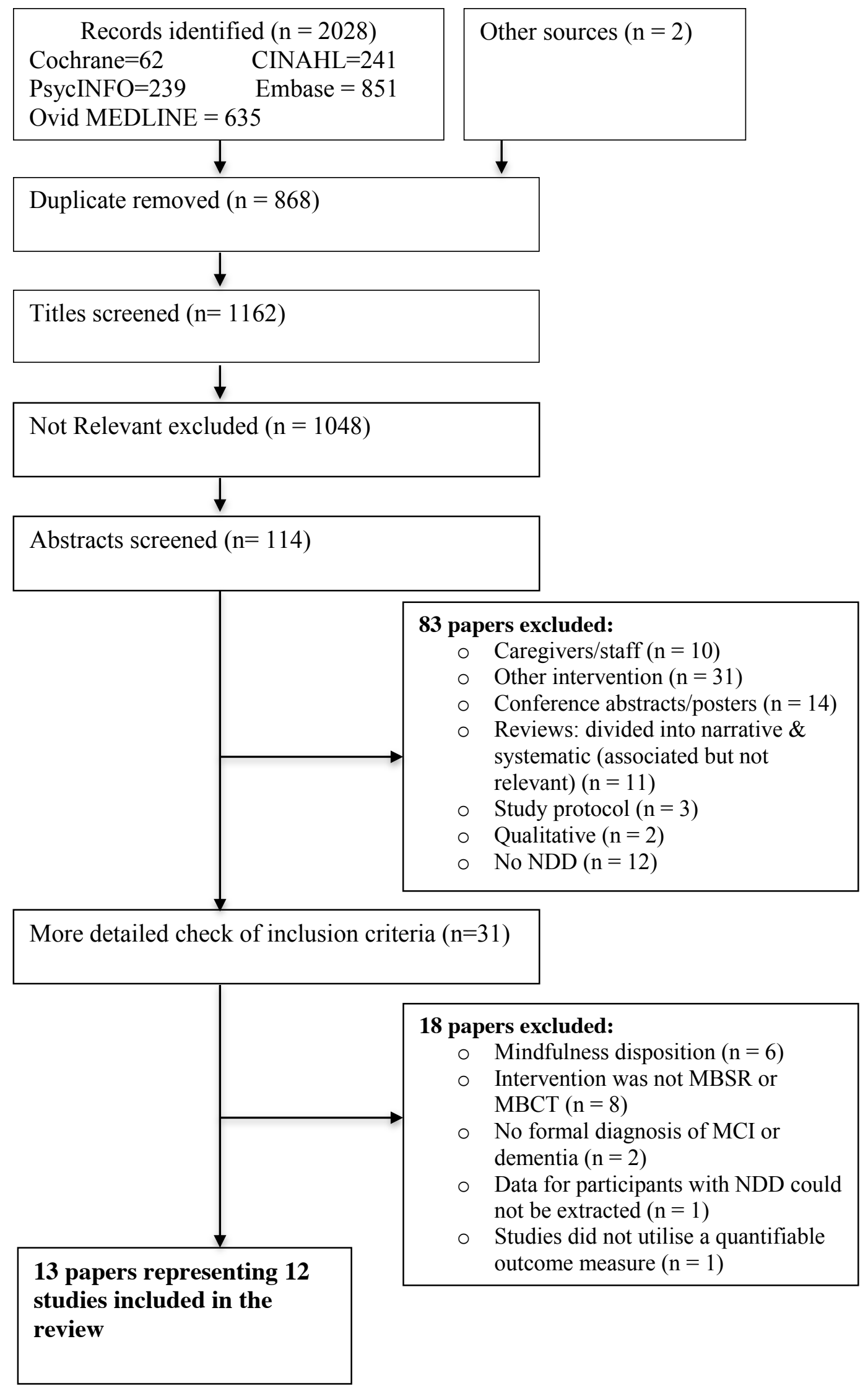

Figure 1: Summary of review process 
Table 3: Description of Multiple Sclerosis studies

\begin{tabular}{|c|c|c|c|c|c|c|c|}
\hline $\begin{array}{l}\text { Authors } \\
\text { (Country) }\end{array}$ & Study design & Participants & $\begin{array}{l}\text { Description of } \\
\text { intervention }\end{array}$ & Homework & Follow-up & $\begin{array}{l}\text { Outcome } \\
\text { measures }\end{array}$ & Results \\
\hline $\begin{array}{l}\text { Amiri et al., } \\
2016 \\
\text { (Iran) }\end{array}$ & $\begin{array}{l}\text { Non- } \\
\text { randomised } \\
\text { controlled trial }\end{array}$ & $\begin{array}{l}40 \text { adults } \\
\text { diagnosed with } \\
\text { MS between } \\
20-40 \text { years of } \\
\text { age. } \\
\text { EXP group: } \\
\mathrm{N}=20(0 \% \\
\text { attrition) } \\
\text { Mean age (SD): } \\
25.2(4.5) \\
\text { Gender: } \\
\text { Females=47.5\% } \\
\text { CTL group: } \\
\mathrm{N}=20(0 \% \\
\text { attrition) } \\
\text { Mean age (SD): } \\
25.2(4.5) \\
\text { Gender: } \\
\text { Females }=47.5 \%\end{array}$ & $\begin{array}{l}\text { EXP=MBCT } \\
\text { Intervention } \\
\text { details: group- } \\
\text { based MBCT; } \\
\text { weekly 120- } \\
\text { minutes sessions } \\
\text { for } 8 \text { weeks, no } \\
\text { retreat day. } \\
\text { Facilitator: No } \\
\text { details given. }\end{array}$ & $\begin{array}{l}\text { Home practice: } \\
\text { included but no } \\
\text { details given. }\end{array}$ & Not recorded & $\begin{array}{l}\text { Psychological: } \\
\text { Anxiety } \\
\text { (STAI), } \\
\text { Depression } \\
\text { (BDI-II) } \\
\text { Cognitive: } \\
\text { executive } \\
\text { functioning } \\
\text { (WCST) }\end{array}$ & $\begin{array}{l}\text { In comparison } \\
\text { to the CTL } \\
\text { group, mean } \\
\text { anxiety and } \\
\text { depression } \\
\text { scores } \\
\text { significantly } \\
\text { reduced in EXP } \\
\text { group at post- } \\
\text { intervention } \\
\text { when compared } \\
\text { to baseline } \\
\text { scores. } \\
\text { No significant } \\
\text { change noted in } \\
\text { executive } \\
\text { functioning in } \\
\text { either group. }\end{array}$ \\
\hline
\end{tabular}




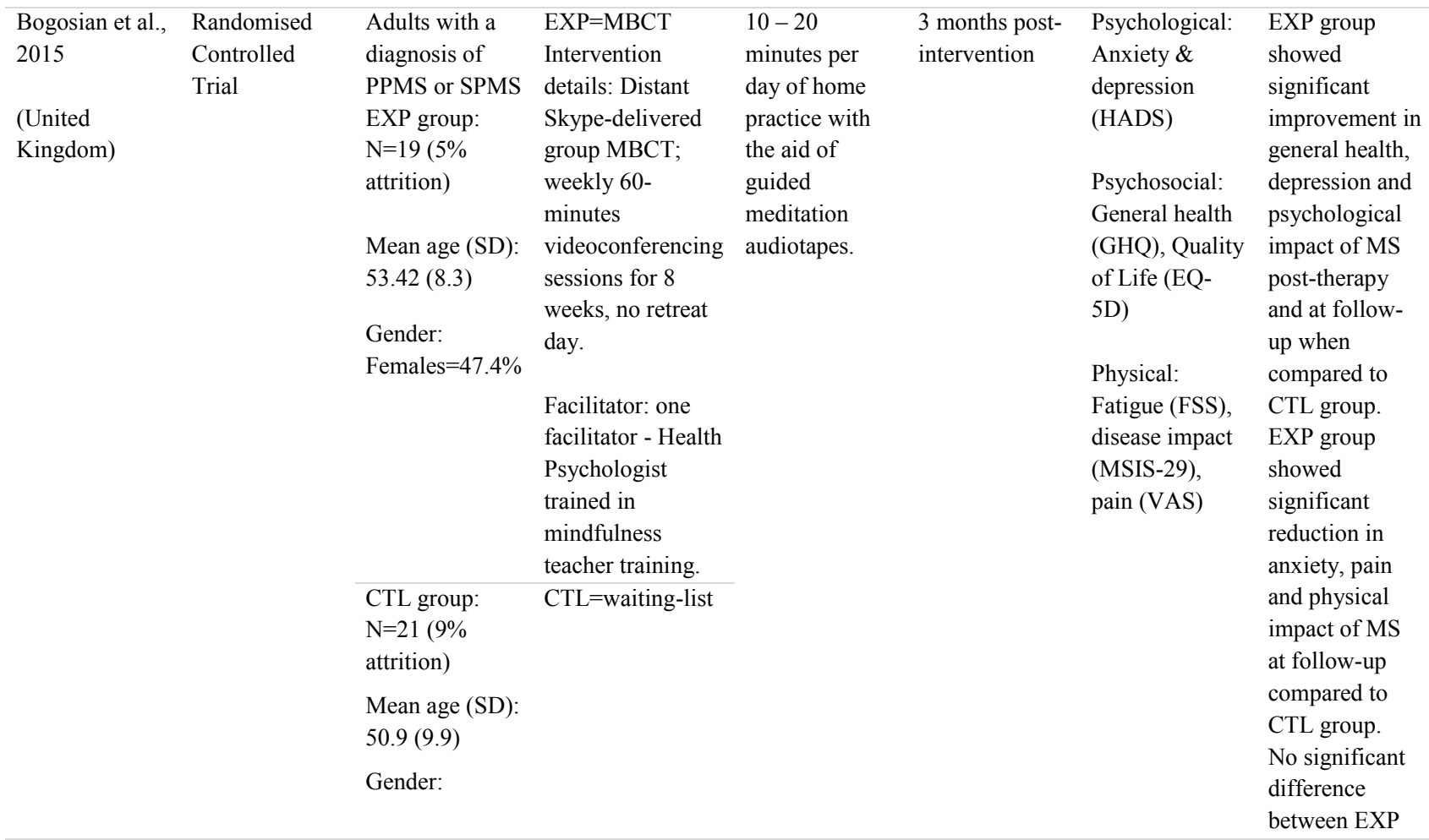


scores.

\begin{tabular}{|c|c|c|c|c|c|c|c|}
\hline $\begin{array}{l}\text { Grossman et } \\
\text { al., } 2010\end{array}$ & $\begin{array}{l}\text { Randomised } \\
\text { controlled trial }\end{array}$ & $\begin{array}{l}\text { Adults meeting } \\
\text { criteria for } \\
\text { diagnosis of } \\
\text { RRMS or } \\
\text { PPMS } \\
\text { EXP group: } \\
\text { N=76 (5\% } \\
\text { attrition) } \\
\text { Mean age (SD): } \\
45.93 \text { (10) } \\
\text { Gender: } \\
\text { Females=78\% }\end{array}$ & $\begin{array}{l}\text { EXP=MBSR } \\
\text { Intervention } \\
\text { details: Group- } \\
\text { based MBI based } \\
\text { on MBSR; } \\
\text { weekly 150- } \\
\text { minutes sessions } \\
\text { over } 8 \text { weeks, } \\
\text { one-day retreat } \\
\text { session. }\end{array}$ & $\begin{array}{l}40 \text { minutes per } \\
\text { day of home } \\
\text { practice } \\
\text { emphasised as } \\
\text { essential. }\end{array}$ & $\begin{array}{l}6 \text { months post- } \\
\text { intervention }\end{array}$ & $\begin{array}{l}\text { Psychosocial: } \\
\text { Health-related } \\
\text { Quality of Life } \\
\text { (PQOLC, } \\
\text { HAQUAMS) }\end{array}$ & $\begin{array}{l}\text { In comparison } \\
\text { to CTL group, } \\
\text { EXP group } \\
\text { showed } \\
\text { significant } \\
\text { reduction in } \\
\text { depression, } \\
\text { anxiety and } \\
\text { fatigue post- } \\
\text { intervention } \\
\text { and at follow- } \\
\text { up when } \\
\text { compared to } \\
\text { baseline scores. } \\
\text { Significant } \\
\text { improvement in } \\
\text { health-related } \\
\text { quality of life } \\
\text { post- } \\
\text { intervention } \\
\text { and at follow- } \\
\text { up compared to } \\
\text { baseline scores }\end{array}$ \\
\hline
\end{tabular}


in the EXP

group.

Kolahkaj \&

Zargar, 2015

(Iran)

\section{Randomised controlled trial}

Female patients diagnosed with

MS aged

between 20-50

years

EXP group:

$\mathrm{N}=24(16 \%$

attrition)

Mean age (SD)

$=25.70$ (5.77)

CTL group:

$\mathrm{N}=24(16 \%$

attrition)

Mean age (SD):

24.85 (2.39)
Home practice: 2 months post- Psychological: Compared to not described intervention Depression, CTL group,

Anxiety and EXP group

Stress (DASS- showed

21)

significant

reduction in

mean

depression,

anxiety and

stress scores

post-

intervention

and at follow-

up compared to

the baseline

scores.

Abbreviations: CES-D=Centre for Epidemiological Studies Depression Scale; BDI-II=The Beck Depression Inventory; DASS-21=Depression, Anxiety and Stress Scale; EQ-5D=EuroQol; GHQ=General Health Questionnaire; HADS: Hospital Anxiety and Depression Scale; HAQUAMS=Hamburg Quality of Life Questionnaire in Multiple Sclerosis; MBI= mindfulness-based intervention; MFIS=Modified Fatigue Index Scale; MSIS: Multiple Sclerosis Impact Scale; PDDS=Patient Determined Disease Steps; POMS=Profile of Mood States; PQOLC= Profile of Health-Related Quality of Life in Chronic Disorders; STAI=The State-Trait Anxiety Inventory; VAS=Visual Analogue Scale for pain; WCST $=$ The Wisconsin Card Sorting Test 
Table 4: Description of Parkinson's disease studies

\begin{tabular}{|c|c|c|c|c|c|c|c|}
\hline $\begin{array}{l}\text { Authors } \\
\text { (Country) }\end{array}$ & $\begin{array}{l}\text { Study } \\
\text { design }\end{array}$ & Participants & $\begin{array}{l}\text { Description of } \\
\text { intervention }\end{array}$ & Homework & $\begin{array}{l}\text { Follow- } \\
\text { up }\end{array}$ & $\begin{array}{l}\text { Outcome } \\
\text { measures }\end{array}$ & Results \\
\hline $\begin{array}{l}\text { Cash et al., } \\
2016 \\
\text { (United } \\
\text { States) }\end{array}$ & $\begin{array}{l}\text { Before-and- } \\
\text { after study. }\end{array}$ & $\begin{array}{l}\text { Adults over } 18 \\
\text { with a confirmed } \\
\text { diagnosis of PD by } \\
\text { a neurologist and } \\
\text { their carers of } \\
\text { family members*. } \\
\text { Patients only } \mathrm{N}= \\
34 \\
(14 \% \text { attrition) } \\
\text { Mean age (SD): not } \\
\text { provided separately } \\
\text { Gender: not } \\
\text { provided separately }\end{array}$ & $\begin{array}{l}\text { Intervention } \\
\text { details: Group- } \\
\text { based MBSR } \\
\text { (adapted for } \\
\text { people with PD), } \\
\text { weekly 90- } \\
\text { minutes sessions } \\
\text { over } 8 \text { weeks, } \\
\text { half-day silent } \\
\text { retreat after week- } \\
8 . \\
\text { Facilitator: one } \\
\text { facilitator } \\
\text { (doctoral-level } \\
\text { clinical } \\
\text { psychology } \\
\text { student) after } \\
\text { completing } \\
\text { mindfulness } \\
\text { training program }\end{array}$ & $\begin{array}{l}\text { Home } \\
\text { practice of } \\
45 \text { minutes } \\
\text { per day. }\end{array}$ & $\begin{array}{l}\text { No } \\
\text { follow- } \\
\text { ups. }\end{array}$ & $\begin{array}{l}\text { Psychological: } \\
\text { Anxiety (GAI), } \\
\text { Depression } \\
\text { (PHQ-9), Apathy } \\
\text { (Apathy scale), } \\
\text { mindfulness } \\
\text { (FFMQ-39) } \\
\text { Cognitive: } \\
\text { Memory, working } \\
\text { memory, } \\
\text { attention, mental } \\
\text { flexibility, } \\
\text { executing } \\
\text { function and } \\
\text { visuospatial } \\
\text { (ECQ, TMT, } \\
\text { Digit span, } \\
\text { COWAT) } \\
\text { Psychosocial: } \\
\text { Quality of life } \\
\text { (PDQ-39) }\end{array}$ & $\begin{array}{l}\text { Significant } \\
\text { reduction in } \\
\text { depressive } \\
\text { symptoms; } \\
\text { improvement in } \\
\text { emotional } \\
\text { functioning and } \\
\text { cognitive } \\
\text { functioning } \\
\text { domains on PDQ- } \\
39 \text { and } \\
\text { improvement on } \\
\text { cognitive tasks } \\
\text { measuring mental } \\
\text { flexibility, } \\
\text { semantic fluency, } \\
\text { complex attention } \\
\text { and sequencing } \\
\text { ability after the } \\
\text { intervention. } \\
\text { No significant } \\
\text { change in non- } \\
\text { motor symptoms }\end{array}$ \\
\hline
\end{tabular}




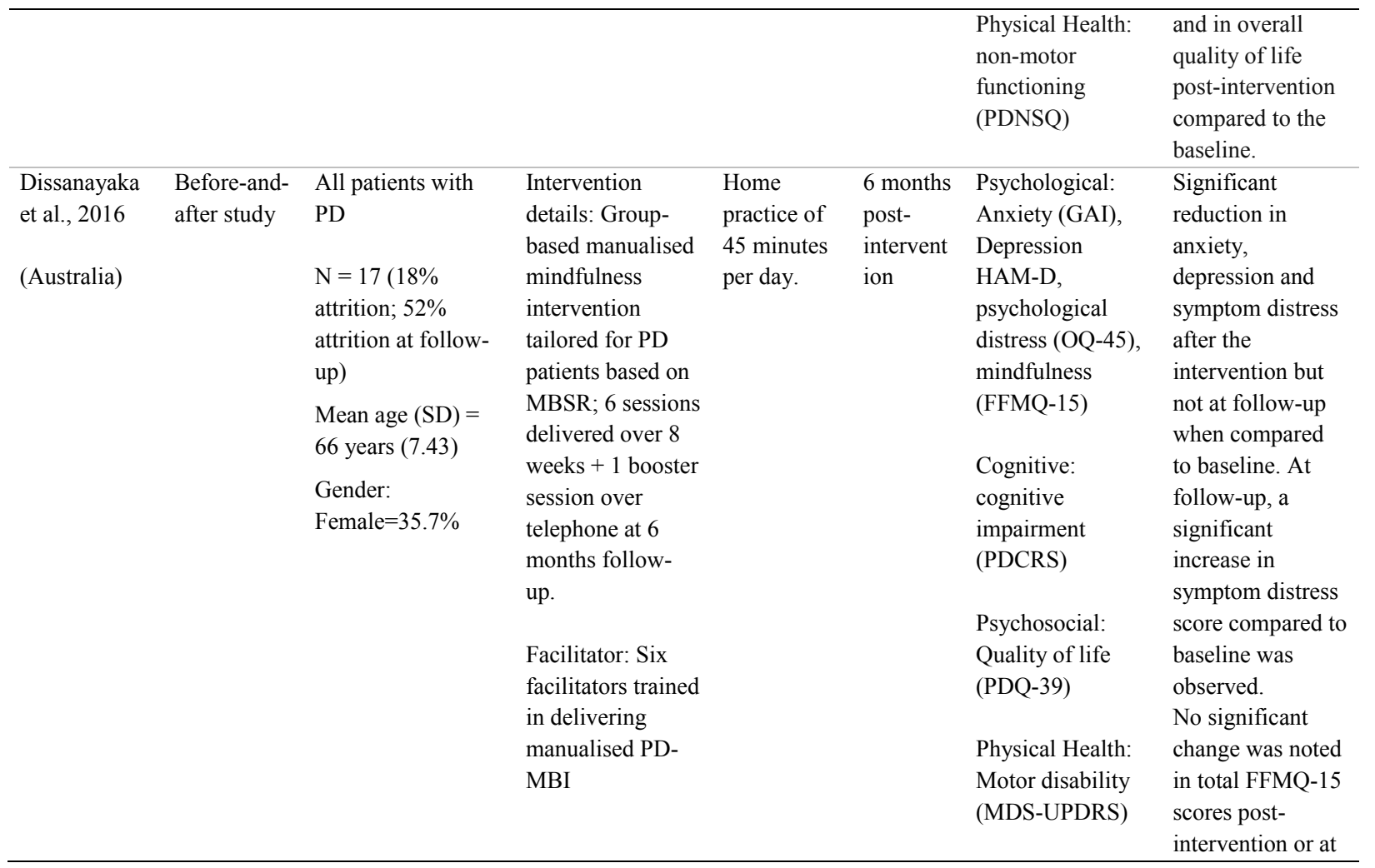


follow-up.

Significant

improvement in

Observing

subscale of

FFMQ-15 only

post-intervention.

Performance

improved on total

PDCRS and

subcortical

domain after the

intervention and

at follow-up

compared to the

baseline. No

significant

improvement in

motor disability

but a significant

improvement in

postural

instability (PIGD

on MDS-UPDRS)

compared to

baseline.

No significant 


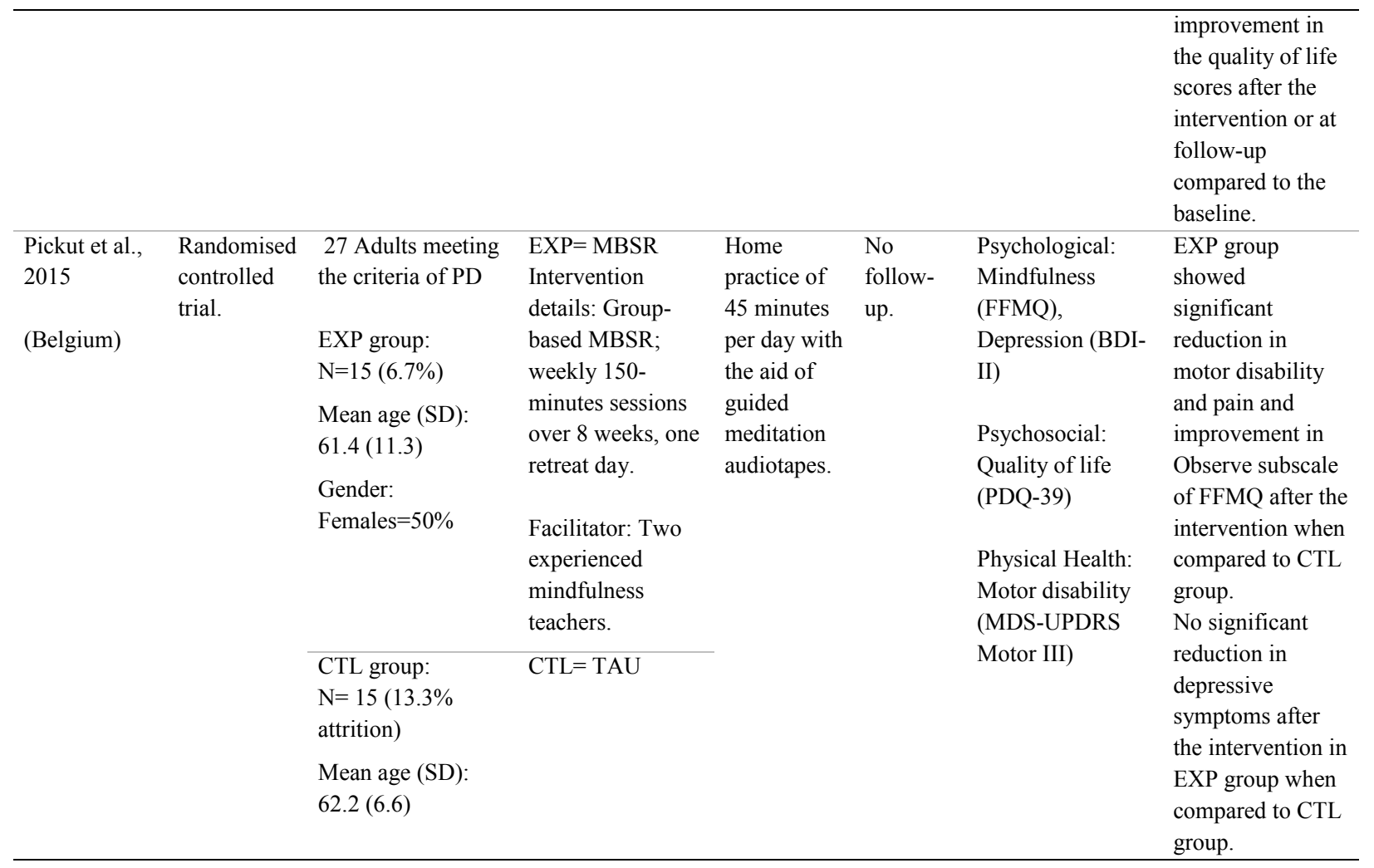




\begin{tabular}{l} 
Gender: \\
Females $=46 \%$ \\
\hline * Patient only measures are reported.
\end{tabular}

Abbreviations: BDI-II $=$ Beck Depression Inventory; COWAT $=$ Controlled Oral Word Association Test; $\mathrm{CTL}=$ Control group; $\mathrm{ECQ}=$ Everyday cognition questionnaire; EXP = Experimental group; FFMQ=Five Facet Mindfulness Questionnaire; GAI=Geriatric Anxiety Inventory; HAM-D=Hamilton Depression Rating Scale; MBI = Mindfulness-based intervention; MDS-UPDRS=Movement Disorders Society Unified Parkinson's Disease Rating Scale; PDCRS = Parkinson's Disease Cognitive Rating Scale; PDNSQ = Parkinson's Disease Non-motor Symptoms Questionnaire; PDQ=Parkinson's Disease Quality of Life Questionnaire; PHQ-9 = Patient Health Questionnaire; $\mathrm{OQ}=$ Outcome Questionnaire; TMT=Trail Making Test 
Table 5: Description of Dementia or MCI studies

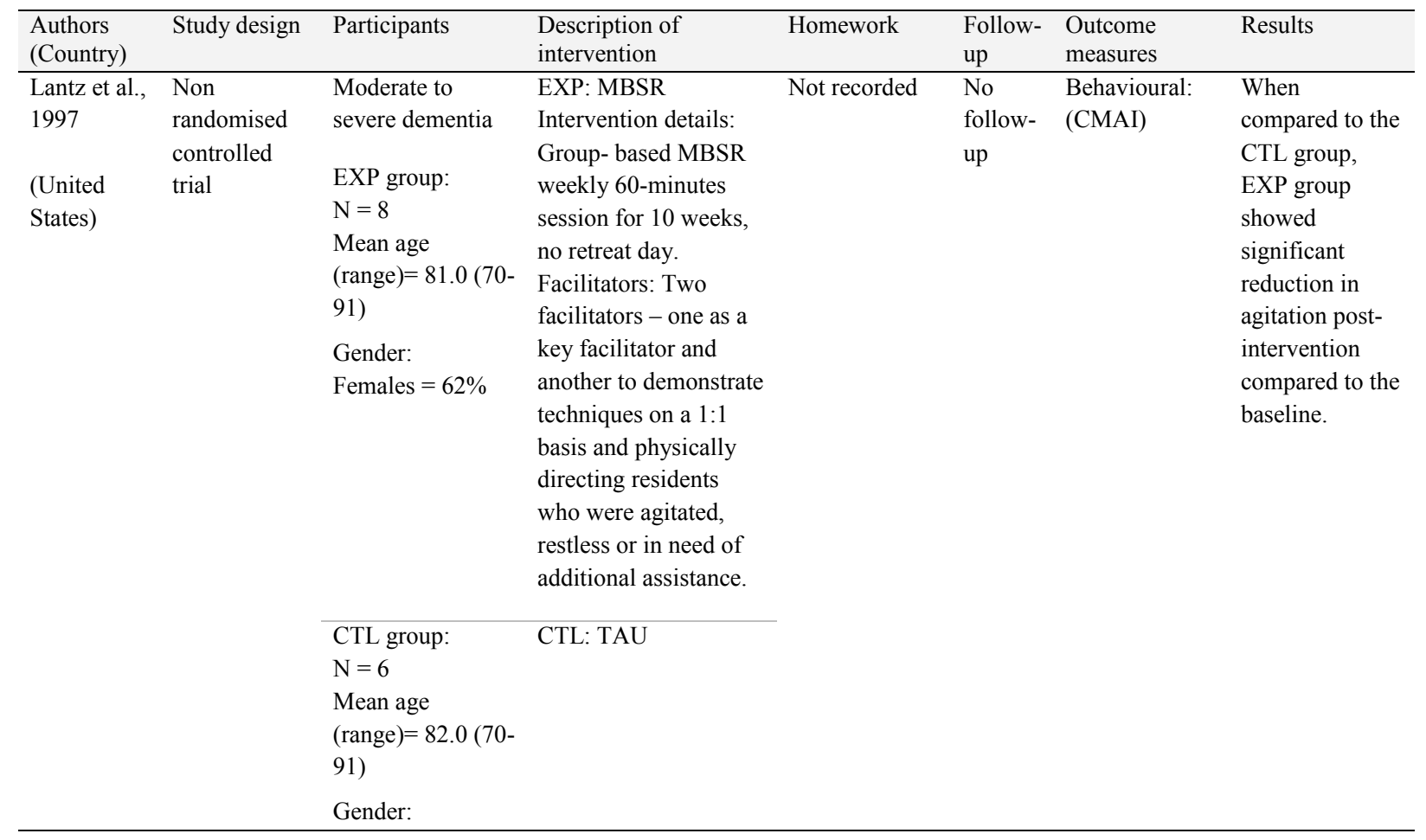




\begin{tabular}{|c|c|c|c|c|c|c|c|}
\hline & & Females $=84 \%$ & & & & & \\
\hline $\begin{array}{l}\text { Litherland } \\
\& \\
\text { Robertson, } \\
2014 \\
\text { (United } \\
\text { Kingdom) }\end{array}$ & $\begin{array}{l}\text { Single group } \\
\text { Before-and- } \\
\text { After study }\end{array}$ & $\begin{array}{l}\text { Patients with } \\
\text { dementia of } \\
\text { mixed severity } \\
\text { and their carers* } \\
\mathrm{N}=12(33 \% \\
\text { attrition) }\end{array}$ & $\begin{array}{l}\text { Intervention details: } \\
\text { Group-based MBSR; } \\
\text { weekly } 150 \text {-min } \\
\text { session for } 8 \text { weeks, } \\
\text { no retreat session. } \\
\text { Facilitator: One } \\
\text { facilitator experienced } \\
\text { in mindfulness- based } \\
\text { approaches. }\end{array}$ & $\begin{array}{l}\text { Home practice } \\
\text { recommended. }\end{array}$ & $\begin{array}{l}3 \\
\text { months }\end{array}$ & $\begin{array}{l}\text { Psychosocial: } \\
\text { Well-being } \\
\text { (WEMWBS) }\end{array}$ & $\begin{array}{l}\text { No significant } \\
\text { findings on well } \\
\text { being. }\end{array}$ \\
\hline $\begin{array}{l}\text { Paller et al., } \\
2015 \\
\text { (United } \\
\text { States) }\end{array}$ & $\begin{array}{l}\text { Single group } \\
\text { Before-and- } \\
\text { After study }\end{array}$ & $\begin{array}{l}\text { Patients } \\
\text { diagnosed with } \\
\text { dementia (AD, } \\
\text { FTD) or MCI or } \\
\text { memory problems } \\
\text { due to multiple } \\
\text { strokes and } \\
\text { family carers* } \\
\mathrm{N}=17 \\
\text { Mean age (range) } \\
=72.0 \text { ( } 55-81) \\
\text { Gender: }\end{array}$ & $\begin{array}{l}\text { Intervention details: } \\
\text { Group-based MBSR } \\
\text { (adapted for people } \\
\text { with cognitive } \\
\text { impairment); weekly } \\
\text { 90-minutes sessions } \\
\text { over } 8 \text { weeks, no } \\
\text { retreat session. }\end{array}$ & $\begin{array}{l}30-60 \\
\text { minutes of } \\
\text { home practice } \\
\text { recommended }\end{array}$ & $\begin{array}{l}\text { No } \\
\text { follow- } \\
\text { up }\end{array}$ & $\begin{array}{l}\text { Psychological: } \\
\text { Depression } \\
\text { (GDS), } \\
\text { Anxiety } \\
\text { ( BAI) } \\
\text { Physical } \\
\text { Health: Sleep } \\
\text { (PSQI) }\end{array}$ & $\begin{array}{l}\text { Significant } \\
\text { reduction in } \\
\text { depression and } \\
\text { improvement in } \\
\text { quality of life } \\
\text { after the } \\
\text { intervention } \\
\text { compared to the } \\
\text { baseline. } \\
\text { Significant } \\
\text { performance } \\
\text { improvement } \\
\text { on TMT part B } \\
\text { after the }\end{array}$ \\
\hline
\end{tabular}




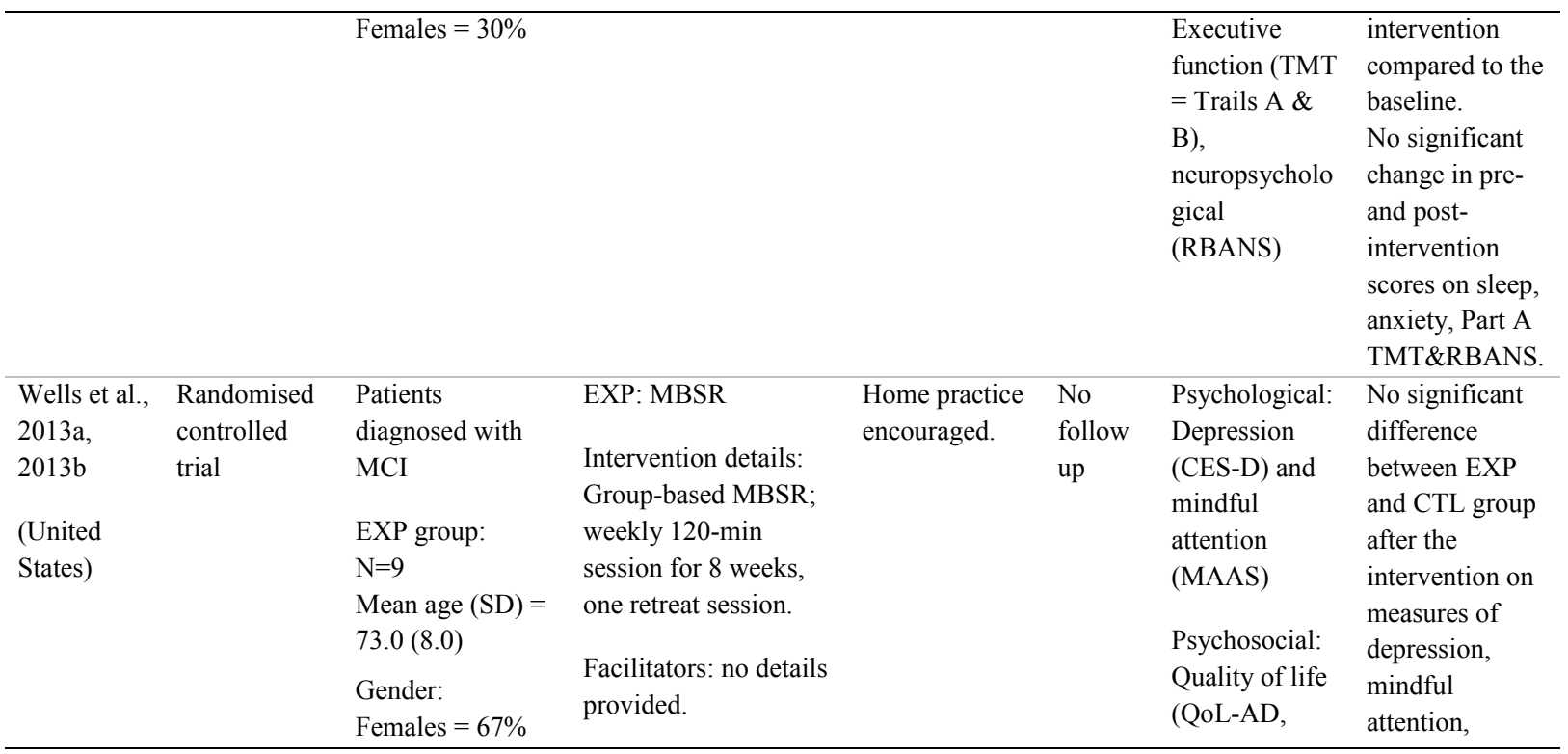




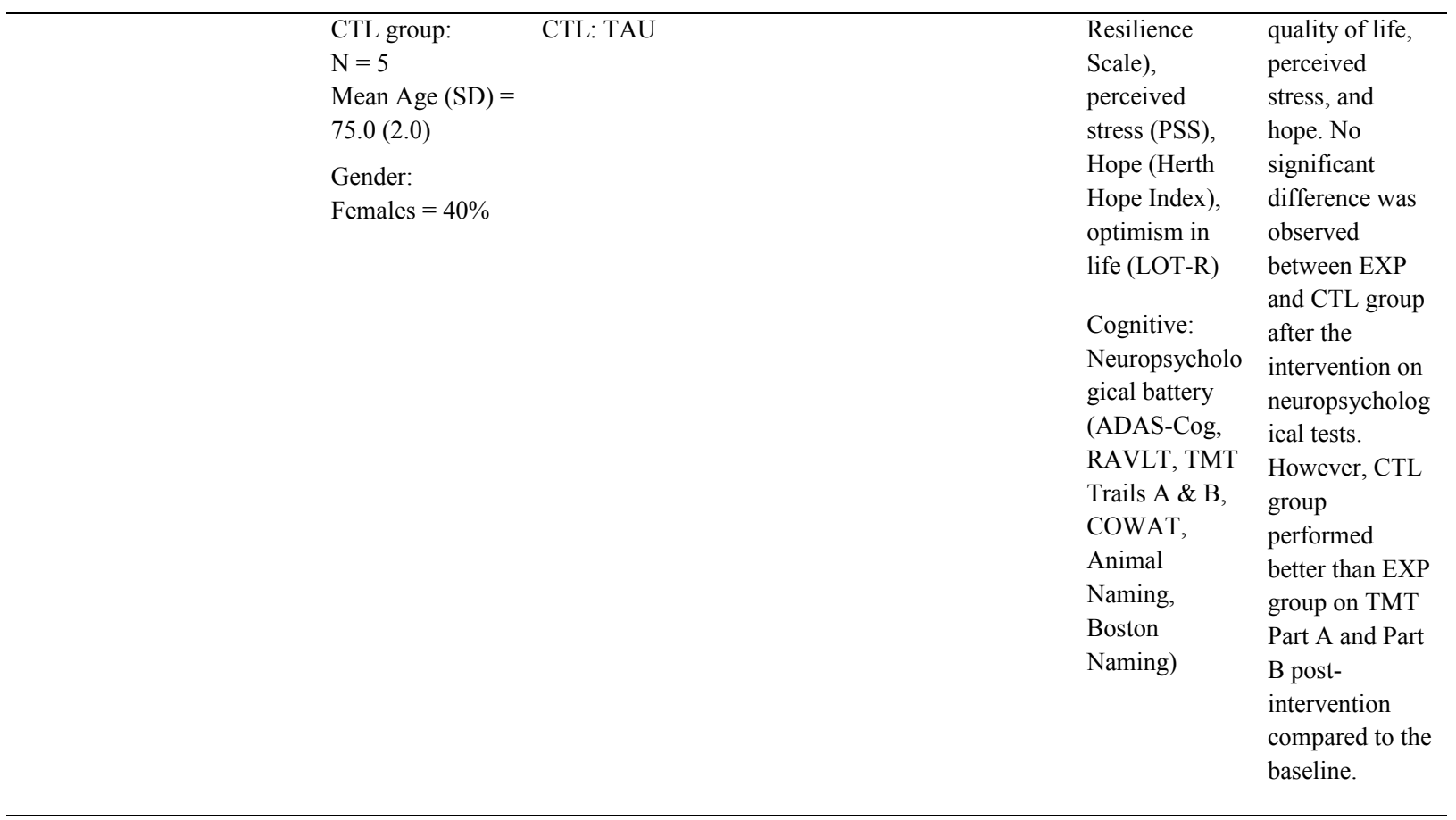




\begin{tabular}{|c|c|c|c|c|c|c|c|}
\hline $\begin{array}{l}\text { Quintana- } \\
\text { Hernandez } \\
\text { et al., } 2016 \\
\text { (Spain) }\end{array}$ & $\begin{array}{l}\text { Longitudinal } \\
\text { Randomised } \\
\text { Controlled } \\
\text { Trial }\end{array}$ & $\begin{array}{l}\text { Spanish-speaking } \\
\text { patients over } 65 \\
\text { years of age, } \\
\text { diagnosed with } \\
\text { probable AD and } \\
\text { on donepezil for } \\
\text { AD } \\
\text { Total N = } 168 \\
\text { Age n }(\%)= \\
65-75=28 \\
(23.3) \\
76-85=65 \\
(54.2) \\
\text { Gender: } \\
\text { Females }=55 \% \\
\text { EXP group } 1: \\
N=42(2.4 \% \\
\text { attrition) }\end{array}$ & $\begin{array}{l}\text { EXP 1: MBAS } \\
\text { Intervention details: } \\
\text { Group based on } \\
\text { MBSR, MBEC, } \\
\text { KirtanKriya, chair } \\
\text { yoga and multi- } \\
\text { sensorial exercises; } \\
\text { three weekly 90- } \\
\text { minutes sessions over } \\
\text { two-year period, no }\end{array}$ & $\begin{array}{l}\text { Home practice } \\
\text { of at least } 10 \\
\text { minutes of per } \\
\text { day } \\
\text { recommended. }\end{array}$ & $\begin{array}{l}6,12 \\
\text { and } 24 \\
\text { months. }\end{array}$ & $\begin{array}{l}\text { Cognitive: } \\
\text { CAMDEX-R } \\
\text { (MMSE and } \\
\text { CAMCOG) }\end{array}$ & $\begin{array}{l}\text { MBAS and } \\
\text { CST groups } \\
\text { significantly } \\
\text { preserved their } \\
\text { cognitive } \\
\text { functioning on } \\
\text { the MMSE and } \\
\text { CAMCOG } \\
\text { better than } \\
\text { those receiving } \\
\text { medication } \\
\text { alone after the } \\
\text { intervention and } \\
\text { at follow-up } \\
\text { compared to the } \\
\text { baseline. } \\
\text { MBAS and } \\
\text { CST were noted } \\
\text { as more } \\
\text { effective than } \\
\text { PMR. MBAS } \\
\text { and CST } \\
\text { treatments were } \\
\text { equivalent. }\end{array}$ \\
\hline
\end{tabular}


retreat session.

\section{Facilitator: One}

clinical psychologist

who had 5 years

personal experience as

a meditation

practitioner.

EXP group 2:

EXP 2: PMR

$\mathrm{N}=45(15.5 \%$

Intervention details:

attrition)

Standard program of

tensing and releasing

of 16 muscle groups;

three weekly 90-

minutes sessions over

two-year period.

Facilitator: 1 clinical

psychologist.

EXP group 3:

$\mathrm{N}=38(13.1 \%$

attrition)

\section{EXP 3: CST}

Intervention details:

Psychostimulation

program consisted of

visual imagery,

errorless learning,

dyadic approaches, 


\section{spaced retrieval, \\ encoding specificity \\ and external memory \\ aides; three weekly \\ 90-minutes sessions \\ over two-year period.}

Facilitator: 1

neuropsychologist

CTL group: Usual CTL: TAU

care

$\mathrm{N}=43(32.5 \%$

attrition)

* Patient only measures are reported.

Abbreviations: ADAS-Cog=Alzheimer's Disease Assessment Scale cognitive subscale; BAI $=$ Beck Anxiety Inventory; $\mathrm{CESD}=\mathrm{Center}$ of Epidemiologic Studies Depression Scale; CMAI=Cohen-Mansfield Agitation Inventory; COWAT $=$ Controlled Oral Word Association Test; $\mathrm{CTL}=$ Control group; EXP $=$ Experimental group, GDS=Geriatric Depression Scale LOT-R=Life Orientation Test- Revised, MAAS=Mindfulness Attention Awareness Scale, MCI=mild cognitive impairments, PSQI=Pittsburg Sleep Quality Inventory; PSS= Perceived Stress Scale, QoL-AD=Quality of Life- Alzheimer's Disease, RAVLT=Rey Auditory Verbal Learning Test, RBANS=Repeatable Battery for the Assessment of Neuropsychological Status TMT=Trail Making Test, WEMWBS=Warwick Edinburgh Mental Well-being Scale 


\section{Study design and quality \\ Internal Validity}

Table 6 shows quality ratings of the studies. Three studies were rated green (two MS and one dementia/MCI). Three were rated amber (one MS, one PD and one dementia/MCI). Six studies were rated red (one MS, two PD and three dementia/MCI). Thus, the studies with the best internal validity were in people with MS.

Six of the studies were RCTs (three MS, one PD and two dementia/MCI) and two of the studies were NRCTs (one MS and one dementia/MCI). Four remaining studies (two PD and two dementia/MCI) were single group before-and-after (BA) studies. All of the BA studies used convenience sampling for recruitment. Only one study (dementia/MCI) used an active comparison group in their RCT, whereas, six studies used 'usual care' (three MS, one PD and two dementia/MCI) as their control group and one study (MS) had waitlist as their control group. The randomisation for four studies (two MS, one PD and one dementia/MCI) was concealed from the investigators and the assessors carrying out statistical analysis were blinded of the group allocation to reduce the risk of detection bias. But only one of the RCTs (Quintana-Hernandez et al., 2016) used a double blinding procedure to minimise bias.

Only two of the studies (both MS) carried out power calculations and three of the studies (two MS and one dementia/MCI) justified the sample size for their pilot study. Attrition rates ranged from $0 \%-52 \%$, the highest being in one of the PD studies (Dissanayaka et al., 2016). Although all studies provided reasons for dropout, none compared the demographics of those who dropped out with those who did not. Only four studies (three MS and one dementia/MCI) carried out an intention-to-treat 
analysis. None of studies used the Bonferroni adjustment for multiple comparisons of outcomes to reduce the risk of type one error.

Two studies (both dementia/MCI) had poor reporting quality and lacked details about selection process and statistical analysis (Lantz et al., 1997; Litherland \& Robertson, 2014). Seven studies (four MS, one PD and two dementia/MCI) included follow-up, ranging from 3 - 24 months. Only four studies (three PD and one dementia/MCI) included a mindfulness measure to investigate changes in mindfulness before and after the intervention. Home practice was monitored in seven studies (two MS, three PD and two dementia/MCI).

\section{External Validity}

Overall external validity ratings ranged from moderate to poor, none merited an overall rating of green. Four studies (two MS and two dementia/MCI) received amber rating, whereas the remaining eight (i.e. two MS, three PD and three dementia/MCI) studies were rated red. Most of the studies provided limited details regarding source population and intervention settings. There were also other factors that made it difficult to generalise the study findings. For instance, one study only recruited female patients and another study recruited patients between the ages of $20-$ 40 years. 
Table 6: Quality ratings for studies reviewed using the NICE quality framework

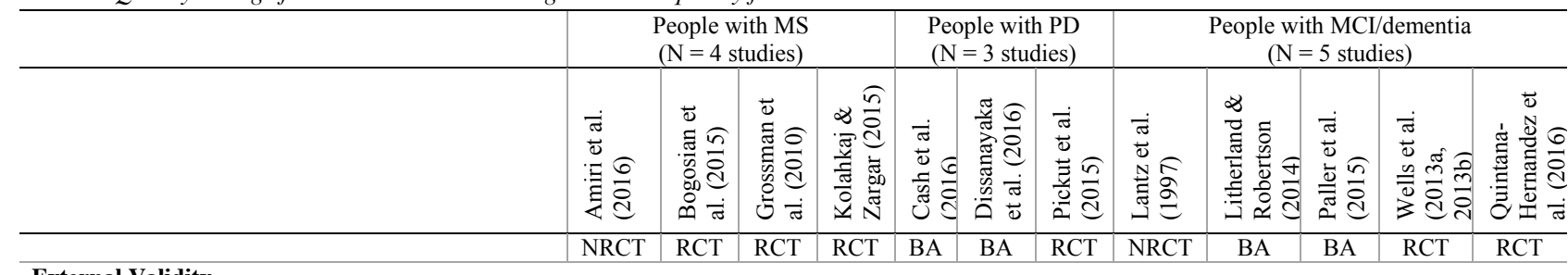

External Validity

1. Population

1.1 Is the source population/area well described?

1.2 Is the eligible population representative of the source population?

1.3 Do the selected participants represent the eligible population?

Internal Validity

2. Method of allocation to intervention

2.1 Allocation to intervention (comparison)/How was Selection bias minimised?

2.2 Were Intervention/Comparison well described and appropriate?

2.3 Was the allocation concealed?

2.4 Were participants or investigators blind to exposure and comparison?

2.5 Was the exposure to the intervention and

comparison adequate?

\begin{tabular}{|l|l|l|l|l|l|l|l|l|l|l|l|l|l}
+ & + & + & + & + & + & - & - & + & + & + & + \\
\hline+ & + & ++ & + & + & + & - & - & - & + & + & + \\
- & + & ++ & - & - & + & + & - & - & - & - & +
\end{tabular}
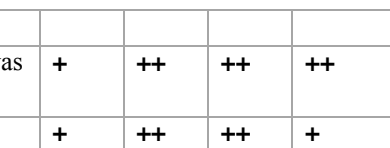

$+\quad+$

\begin{tabular}{l|l|l|l|l|l|}
+ & ++ & ++ & - & NA
\end{tabular}

\begin{tabular}{|c|c|c|c|c|c|c|}
\hline & & & & & & \\
\hline- & + & - & - & - & ++ & ++ \\
\hline++ & + & + & ++ & ++ & + & ++ \\
\hline NA & ++ & - & NA & NA & - & ++ \\
\hline NA & + & - & NA & + & + & ++ \\
\hline+ & + & NR & NR & NR & + & + \\
\hline
\end{tabular}




\begin{tabular}{|c|c|c|c|c|c|c|c|c|c|c|c|c|}
\hline & 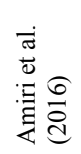 & 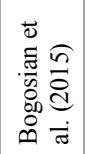 & 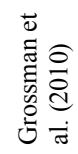 & 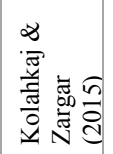 & 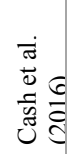 & 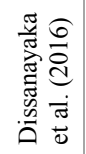 & 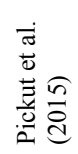 & 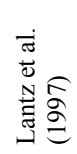 & 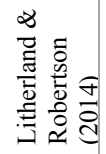 & 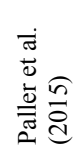 & 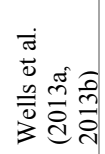 & 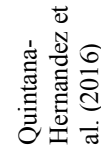 \\
\hline 2.6 Was contamination acceptably low? & ++ & ++ & ++ & ++ & NA & NA & ++ & + & NA & NA & ++ & ++ \\
\hline 2.7 Were other interventions similar in both groups? & + & + & ++ & + & NA & NA & + & NR & NA & NA & - & ++ \\
\hline $\begin{array}{l}2.8 \text { Were all participants accounted for at study } \\
\text { conclusion? }\end{array}$ & ++ & ++ & ++ & ++ & ++ & - & ++ & ++ & - & - & ++ & + \\
\hline 2.9 Did the setting reflect usual UK Practice? & - & ++ & + & - & + & + & + & - & ++ & + & + & + \\
\hline $\begin{array}{l}2.10 \text { Did the intervention or control comparison } \\
\text { reflect usual UK practice? }\end{array}$ & + & + & + & + & ++ & ++ & ++ & + & + & + & + & + \\
\hline \multicolumn{13}{|l|}{ 3. Outcomes } \\
\hline 31. Were outcome measures reliable? & + & + & + & + & + & + & + & + & + & + & ++ & + \\
\hline 3.2 Were all outcome measurements complete? & ++ & + & ++ & + & + & + & + & ++ & - & + & + & + \\
\hline 3.3 Were all-important outcomes assessed? & + & ++ & + & + & + & ++ & ++ & + & - & ++ & ++ & + \\
\hline 3.4 Were outcomes relevant? & ++ & + & ++ & ++ & ++ & ++ & ++ & ++ & + & ++ & ++ & + \\
\hline 3.5 Was Mindfulness measure included? & - & - & - & - & ++ & ++ & ++ & - & - & - & ++ & - \\
\hline 3.6 Was Home practice monitored? & - & + & ++ & - & ++ & ++ & + & - & - & - & + & + \\
\hline $\begin{array}{l}3.7 \text { Were there similar follow-up times in exposure } \\
\text { and comparison groups? }\end{array}$ & ++ & ++ & ++ & ++ & + & ++ & NA & NR & ++ & NA & NA & ++ \\
\hline 3.8 Was Follow-up time meaningful? & + & ++ & ++ & + & NA & NA & ++ & NA & ++ & NA & NA & ++ \\
\hline
\end{tabular}




\begin{tabular}{|c|c|c|c|c|c|c|c|c|c|c|c|c|}
\hline & 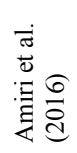 & 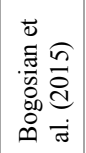 & 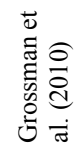 & 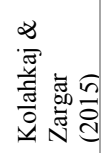 & 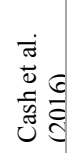 & 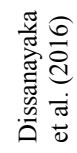 & 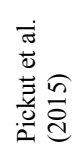 & 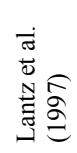 & 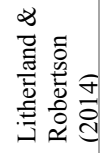 & 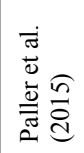 & 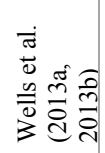 & 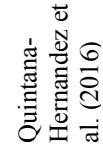 \\
\hline \multicolumn{13}{|l|}{ 4. Analyses } \\
\hline $\begin{array}{l}\text { 4.1 Were EXP CTL groups similar at baseline? If } \\
\text { not, were these adjusted? }\end{array}$ & ++ & ++ & ++ & ++ & NA & NA & ++ & NA & NA & NA & ++ & + \\
\hline 4.2 Was Intention to treat analysis conducted? & ++ & ++ & ++ & - & NA & NA & - & - & - & - & ++ & - \\
\hline 4.3 Was Power calculated? & + & + & ++ & ++ & - & - & - & - & - & - & - & + \\
\hline $\begin{array}{l}\text { 4.4 Were the estimates of Effect-size } \\
\text { given/calculable? }\end{array}$ & ++ & ++ & ++ & ++ & + & ++ & - & - & - & ++ & - & ++ \\
\hline 4.5 Were the analytical methods appropriate? & ++ & ++ & ++ & ++ & + & ++ & ++ & - & - & ++ & ++ & ++ \\
\hline $\begin{array}{l}\text { 4.6 Was the precision of intervention effects given or } \\
\text { calculable? Were they meaningful? }\end{array}$ & ++ & ++ & ++ & + & ++ & + & ++ & - & - & ++ & ++ & ++ \\
\hline \multicolumn{13}{|l|}{ 5. Summary } \\
\hline 5.1 Internal Validity Score & + & ++ & ++ & & & & + & & & & + & ++ \\
\hline 5.2 External Validity Score & & + & + & & & & & & & + & & + \\
\hline
\end{tabular}

Note. $++=$ Indicates that the study has been designed or conducted in such a way as to minimise the risk of bias; $+=$ Indicates that either the answer to the checklist question is not clear from the way the study is reported, or that the study may not have addressed all potential sources of bias for that particular aspect of study design; - = Indicates those aspects of the study design in which significant sources of bias may persist; $\mathrm{NR}=$ Indicates aspects in which the study under review fails to report how they have (or might have) been considered; NA = Indicates study design aspects that are not applicable given the study design under review (for example, allocation concealment would not be applicable for case control studies 


\section{Intervention characteristics}

Nine of the 12 studies used MBSR, two used MBCT and one study combined the aspects of both.

\section{MBSR studies}

MBSR was used by all of the PD and the dementia/MCI studies whereas only one of the MS studies used MBSR (Grossman et al., 2010). Typically, MBSR consists of eight-weekly 150 minutes sessions with daily 45-minute home practice, and a fullday retreat session between weeks 6 and 7 (Kabat-Zinn, 2013). All nine MBSR studies except one (Grossman et al., 2010) made some modifications to the typical MBSR protocol to accommodate the needs of the population. Main modifications included shortened length of sessions, smaller group size and slight changes in the content of the sessions. One of the MBSR studies reduced the number of sessions to six (Dissanayaka et al., 2016). Cash et al. (2016) and Paller et al. (2015) also included carers in their group along with people with a specific NDD and they modified their program to accommodate this. For example, Cash et al. (2016) also included a session on the stress and common challenges of caregiving.

Grossman et al. (2010) closely mapped their intervention to MBSR. Pickut et al. (2015) also closely followed the MBSR manual apart from taking out the retreat session. Quintana-Hernandez et al. (2016) used a less standardised version of MBSR, which included elements of Kirtan Kriya technique and multi-sensorial stimulation exercises based on sensorial integration theory. Furthermore, unusually, three weekly 90-minutes mindfulness sessions were delivered over a two-year period. Only three studies offered a retreat session as recommended in the MBSR program. Grossman et al. (2010) and Wells et al. (2013a \& 2013b) offered a full day (7-hour). Whereas Cash 
et al. (2016) included half a day (4-hour) retreat session but it was only attended by a third of the of participants.

Six studies shortened session length to minimise fatigue in participants. One study did not report the duration of their sessions (Dissanayaka et al., 2016). Lantz et al. (1997) had the shortest duration of only 60-minutes a session. Three studies shortened the length to 90 minutes (Cash et al., 2016; Paller et al., 2015 and QuintanaHernandez et al., 2016). Litherland \& Robertson (2014) and Wells et al. (2013a \& 2013b) reduced the length of sessions to 120 minutes.

A few of the studies tailored their programme to accommodate the needs of the participants affected by a specific NDD. For example, Dissanayaka et al. (2016) omitted the walking meditation due to postural and gait instability issues in PD. Similarly, Cash et al. (2016) incorporated chair yoga rather than floor-based exercises and offered psychoeducation about the emotional and cognitive symptoms of PD. Lantz et al. (1997) grouped participants according to the severity of dementia (mild deficits in one group, moderate to severe in another group). They also modified meditation scripts to incorporate multisensory aspects, i.e., auditory, olfactory, tactile and motor awareness and sessions 3-6 were repeated to help participants become familiar with the techniques. Nursing home staff was also encouraged to attend the treatment group as participants so that they could incorporate the techniques into residents' daily care.

All of the MBSR studies recommended home practice to the participants. Grossman et al., (2010) encouraged their participants to engage in 40 minutes/day of home practice. All of the PD studies recommended their participants to engage in 45 minutes of daily home practice. Of all the dementia/MCI studies, only one study did not report whether home practice was required (Lantz et al., 1997). Paller et al. (2015) 
recommended 30-60 minutes of home practice whereas Quintana-Hernandez et al. (2016) encouraged participants to practice the techniques for at least 10 minutes per day between sessions. Two studies encouraged home practice but did not report the recommended duration (Litherland \& Robertson, 2014; Wells et al., 2013a \& 2013b).

The facilitators for all three PD studies were trained and experienced in delivering MBSR. Dissanayaka et al. (2016) specifically trained their facilitators to teach MBSR to participants with PD. The MS study also had two certified MBSR teachers who facilitated all of the group sessions (Grossman et al., 2010). Two of the dementia/MCI studies did not report details of their facilitators (Paller et al., 2015 and Wells et al., 2013a \& 2013b) but the other three studies had trained facilitators (Lantz et al., 1997; Litherland \& Robertson, 2014 and Quintana-Hernandez et al., 2016).

\section{MBCT Studies}

MBCT typically follows similar structure as MBSR and is delivered over 8weekly sessions (Segal, Williams, \& Teasdale, 2002). The two MBCT studies were both in MS (Amiri et al., 2016 and Bogosian et al., 2015). Amiri et al. (2016) followed the typical program stipulated by Segal et al., (2002), but Bogosian et al. (2015) made substantial modifications to accommodate the cognitive and physical needs of participants. Their group size was restricted to five as the intervention was delivered via Skype. The session length was shortened from the original 120 minutes to 60 minutes and participants were given more time to reflect by shortening in-session meditation practices. The cognitive exercises were adapted to explore thoughts and feelings regarding being diagnosed with MS and to address issues common to progressive MS. Mindful movement exercises were adapted to accommodate the mobility difficulties of participants. 
Only Bogosian et al. (2015) recommended their participants engage in home practice between sessions but they shortened the daily home practice to $10-20$ minutes to account for concentration problems and fatigue in individuals with MS. Bogosian et al. (2015) reported that there was one trained mindfulness practitioner who facilitated all of the sessions. The sessions were recorded and checked for fidelity. Although Amiri et al. (2016) did not include any details of the MBCT facilitators; they reported recording sessions and checking treatment fidelity.

\section{Combined MBSR and MBCT}

Kolahkaj and Zargar (2015) investigated the effect of combined MBSR and MBCT on the mental health of women diagnosed with MS. There was no retreat session and the session length was shortened to 120 minutes. It was not clear whether participants were required to do home practice.

\section{Primary and secondary outcome measures}

Only two studies (both MS) clarified their primary focus. Grossman et al. (2010) targeted improving mood, fatigue and QoL while Bogosian et al. (2015) targeted reduction of distress. Three studies in individuals with dementia/MCI specifically evaluated one outcome only i.e. agitation, mental well-being and cognitive capacity ((Lantz et al., 1997; Litherland \& Robertson, 2014 and Quintana-Hernandez et al., 2016). Remaining studies did not elaborate on their primary focus.

As noted above, in addition to the physical symptoms of the illness, NDDs often affect emotional, behavioural and cognitive functioning, thus outcome measures reflected this and are shown in Tables 3-5. All studies used psychometrically valid measures to assess these variables. One study used the DASS-21, which is not validated for an MS population. The two studies originating from Iran reported using the Iranian version of questionnaires, validated for that population (Amiri et al., 2016 
and Kolahkaj \& Zargar, 2015). Two studies used age-specific measures, i.e. the Geriatric Anxiety inventory (GAI) and Geriatric Depression Scale (GDS).

\section{Mindfulness measure}

Only four of the studies measured mindfulness skills, one used the Mindful Attention Awareness Scale (MAAS) (Wells et al., 2013a, 2013b), which measures presence or absence of attention to the present moment (Brown \& Ryan, 2003). Three studies used the Five Facet Mindfulness Questionnaire (FFMQ) either 39 or 15 item (Cash et al., 2016; Dissanayaka et al., 2016 and Pickut et al., 2015). The FFMQ assesses five domains of mindfulness skills: observing, describing, acting with awareness, nonjudging of inner experience and nonreactivity to inner experience (Baer et al., 2008).

\section{Impact of MBIs on outcomes}

Given the aim of this review is to examine effectiveness of MBIs in NDDs generally and that by grouping NDDs together it provides more evidence from which to glean knowledge about its impact, this section has been structured according to the targeted outcome of the intervention, rather than type of NDD (Appendix 3 details individual outcomes for each study).

\section{Anxiety}

Of the seven studies that measured anxiety, five (including two MBCT studies) showed a significant improvement in symptoms of anxiety following intervention. These included four MS studies (Amiri et al., 2016; Bogosian et al., 2015; Grossman et al., 2010; Kolahkaj \& Zargar, 2015) and one PD study (Dissanayaka et al., 2016). Bogosian et al. (2015), however, only found the significant reduction in anxiety scores at three-month follow-up but not immediately post intervention. Three of the five that found an improvement carried out a follow-up, only two of which showed that gains 
were maintained (Grossman et al., 2010; Kolahkaj \& Zargar, 2015). Dissayanka et al. (2016) did not find any significant reduction in anxiety scores at follow-up compared to baseline. Two of the five studies were rated green, one was rated amber and two were rated red for overall internal validity (See Table 6). The overall external validity rating for two studies was amber and for the other three studies was red.

Two other MBSR studies (one PD and one dementia/MCI) that also measured anxiety included carers as well (Cash et al., 2016; Paller et al., 2015). Cash et al. (2016) did not report separate data for individuals with NDD. The other study found no statistically significant reduction in anxiety following the intervention (Paller et al., 2015). This study was rated red for overall internal validity and amber for external validity.

All of the studies showing significant improvement, apart from one, were with individuals with MS (the other was in people with PD). Thus, taking into account the quality of the studies (including two good quality RCTs both in MS), the evidence suggests that interventions based on either MBCT or MBSR are useful for reducing anxiety in MS. There is currently a lack of good quality studies assessing effectiveness of MBIs on anxiety in other NDDs.

\section{Depression}

Of the nine studies measuring depression, seven (four MS, two PD and one dementia/MCI) showed a significant reduction (Amiri et al., 2016; Bogosian et al., 2015; Cash et al., 2016; Dissanayaka et al., 2016; Grossman et al., 2010; Kolahkaj \& Zargar, 2015 and Paller et al., 2015). Four studies (all MS) carried out a follow-up (Bogosian et al., 2015; Dissanayaka et al., 2016; Grossman et al., 2010; Kolahkaj \& Zargar, 2015) and three found that the significant reduction in depression scores was maintained (Bogosian et al., 2015; Grossman et al., 2010; Kolahkaj \& Zargar, 2015). 
However, the follow-up period varied from $2-6$ months. Two of the seven studies that showed improvement were rated green, one was rated amber and four were rated red for overall internal validity (See Table 6). In terms of external validity, three were rated amber and four of these studies were rated red. Two other MBSR studies that measured depression showed no significant improvement in depressive symptoms (Pickut et al., 2015; Wells et al., 2013b). Both of these studies had a small sample size and were rated amber for overall internal validity and were rated red for external validity.

Therefore, there were two good quality studies (both MS) and one moderate (also MS) quality study showing a positive impact of MBIs on depression. Whereas, two studies with moderate quality showed no impact of MBI on depressive symptoms. Therefore, on balance the better quality studies suggest that MBCT or MBSR may be useful in reducing symptoms of depression only in MS. So far, there is no good quality research to clarify whether MBIs are effective in reducing depression in other NDDs.

\section{Stress}

Of the two studies (one MS and one dementia/MCI) that measured stress, one study (MS) showed a significant reduction (Kolahkaj \& Zargar, 2015) and was rated amber for overall internal validity and red for external validity. The dementia/MCI study did not show any significant change in stress scores (Wells et al., 2013b). This study was rated red for both internal and external validity. Based on the results of these two studies and taking into consideration of the quality as well, it is difficult to make firm conclusions about the evidence of effectiveness of MBI on reduction in stress in people with NDD. 


\section{Behavioural functioning}

Only one study measured the effect of MBSR on behavioural symptoms and this included people with dementia. This study found a significant reduction in agitation in the treatment group compared to the control group. However, this study did not describe the method of group allocation and it was also not clear whether statistical analyses were planned. It can be seen in Table 6 that this study was rated red for both internal as well as external validity. Therefore, taking into account the quality of the paper, as yet there is little evidence to suggest that MBSR is effective in reducing behavioural symptoms such as agitation in dementia or other NDDs.

\section{Cognition}

Three of the six MBSR studies (one dementia/MCI and two PD) showed a significant improvement in cognition. The dementia/MCI study (Quintana-Hernandez et al., 2016) showed an adapted MBSR intervention combined with donepezil, maintained cognitive capacities over a two-year period when compared to the control conditions (donepezil alone and progressive muscle relaxation group). This study was rated green for its overall internal validity and amber for overall external validity. The two PD studies showed significant improvement in various domains of cognition following the MBSR program. However, both of these studies received a rating of red for overall internal validity. These two studies had a small sample size and did not have a control group.

Three other studies (one MS and two dementia/MCI) did not show any significant improvement in cognitive functioning. Only one of these studies (MS) was rated amber for overall internal validity and the other two were rated red. Based on these results and taking into account the quality of the papers, it can be concluded that overall, aside from the study by Quintana-Hernandez et al., (2016), which combined 
mindfulness with a drug, there is evidence both for and against the positive impact of MBI in NDD but the quality of this evidence is weak on both sides. However, the evidence for benefits of mindfulness in maintaining cognitive capacity is stronger for an adapted MBSR program that combined donepezil over a longer period of time in individuals with a diagnosis of AD.

\section{Psychosocial outcomes}

Of the eight studies that explored the role of MBIs in improving psychosocial functioning, three (one in each NDD) showed significant improvement in QoL. Only the MS study was rated green (Grossman et al., 2010), whereas the other two studies were rated red (Dissanayaka et al., 2016; Paller et al., 2015) for overall internal validity. The external validity rating was amber for one study (MS) and red for the other two studies. Five (including one MBCT study in MS; two PD and two dementia/MCI) showed no significant improvement in QoL. One study (MS) was rated green, three studies (one dementia/MCI and two PD) were rated amber and one (dementia/MCI) was rated red for overall internal validity. In terms of external validity, only one study (MS) was rated amber and the remaining four studies (two PD and two dementia/MCI) were rated red.

Thus, there is only one good quality study (in MS) showing the positive impact of mindfulness on improving QoL but on the other hand there is a good quality study (again in MS) that shows no impact. Therefore, the evidence seems to be equally weighted on both sides for effectiveness of MBSR or MBCT in improving QoL in individuals with NDDs.

\section{Symptoms-specific outcomes}

Two of the MS studies (Bogosian et al., 2015; Grossman et al., 2010) measured fatigue in MS patients. Both of these were RCTs and of good quality (rated green for 
overall internal validity). Only one of these showed significant improvement in fatigue following MBI compared to the control group (Grossman et al., 2010). These gains were maintained at 6-months follow up. It is notable in the study by Bogosian et al. (2015) that the groups were uneven at baseline on fatigue scores (FSS-scores MBCTgroup: 39.9; control group: 48.2) and although this is not reported in the study, this was statistically significant (personal communication). This could be a reason for not reaching statistical significance after treatment. Only one study (Bogosian et al. (2015) - MBCT study) examined whether mindfulness reduced pain intensity in MS patients but did not find any difference between the MBCT and the control group.

Two of the PD studies examined the impact of mindfulness training on motor symptoms. Pickut et al. (2015) showed a significant improvement in MDS-UPDRS motor III scores in the intervention group compared to controls (rated amber for overall internal validity). In comparison, Dissanayaka et al. (2016) (rated red for overall internal validity) did not find a change in total motor disability, but there was significant improvement in specific areas, i.e. gait, posture, rigidity, postural instability and gait dysfunction (PIGD).

Paller et al. (2015) did not find any significant improvement in sleep quality after the intervention in people with dementia/MCI (rated red for overall internal validity). However, the authors report that participants did not have substantial sleep difficulties at baseline (mean PSQI score at baseline was 5.1, whereas score higher than 6 denotes substantial sleep problems), which could be a reason for lack of significant findings.

In summary, the evidence for MBIs in reducing fatigue in MS is weighted on both sides making it difficult to draw firm conclusions. In terms of pain and sleep, there is currently not sufficient research or evidence to suggest MBIs have a role to 
play in helping with pain or sleep in NDDs. Based on findings from two PD studies and also considering the quality of the studies, there is not sufficient evidence yet to suggest that MBIs are effective in improving motor disability in individuals with PD.

\section{Mindfulness measure and home practice monitoring}

Of the four studies that used a mindfulness measure, the study that used the MAAS did not find any significant improvement in mindfulness attention to the present moment (Wells et al., 2013a, 2013b). Similarly, two of the studies using FFMQ-39 did not find any significant changes in total FFMQ scores following the MBSR training (Cash et al., 2016 and Pickut et al., 2015). However, Pickut et al. (2015) did find that the intervention group significantly improved on the Observe subscale when compared to the control group. Dissanayaka et al. (2016) also noted a statistically significant increase in only the FFMQ-15 Observing subscale postintervention but not at six months follow-up.

Home practice has been recommended as essential for cultivating mindfulness in both MBSR and MBCT programmes (Kabat-Zinn, 2013; Segal et al., 2002). All except one study (Kolahkaj \& Zargar, 2015) recommended home practice to their participants but only seven studies monitored this. Furthermore, only three studies (Cash et al., 2016; Dissanayaka et al., 2016; Grossman et al., 2010) actually carried out a statistical analysis to investigate whether home practice compliance correlated with the change in outcome measures or with the mindfulness measure. Cash et al. (2016) showed that the amount of home practice correlated significantly with the change in mindfulness level as measured by FFMQ-39 and measures of anxiety and cognitive performance in individuals with PD. Grossman et al. (2010) also found that amount of home practice significantly correlated with measures of QoL, depression and fatigue in individuals with MS. In comparison, Dissanayaka et al. (2016) noted that only half of 
their participants completed the home practice logs and the data obtained from those who completed showed no significant correlation with a mindfulness measure.

\section{Discussion}

\section{Summary of main findings}

The aim of the present review was to systematically review the evidence for the effectiveness of MBIs on psychological, social, behavioural, symptoms-specific and cognitive functioning in individuals with a NDD. By taking an inclusive approach (i.e. including different conditions under an umbrella term of NDDs), it was hoped that this would provide sufficient evidence to help clarify the effectiveness of MBIs in this area. Thirteen papers describing 12 studies met the inclusion criteria for this review. Of these, 10 studies found some immediate positive effects whilst two studies showed no change in any of the outcomes post-intervention. The conclusions that can be drawn from these studies should be considered with caution due to poor quality of the studies such as lack of a control group and poor sample size for adequate statistical power. Moreover, it was difficult to make direct comparisons between studies due to significant differences with respect to the settings, intervention, the way MBI was delivered and the range of outcome measures used. The long-term impact of MBIs was also difficult to examine because six studies did not conduct a follow-up. Moreover, the studies carrying out a follow-up presented mixed findings and the length varied between $2-24$ months. Therefore, no firm conclusions could be drawn in terms of long-term effectiveness of MBIs in NDDs.

All of the studies investigated the effect of MBIs in improving the psychological, symptom-specific, psychosocial and cognitive functioning in people with NDDs. There is some evidence to suggest that MBIs based on MBSR or MBCT 
may be effective in reducing symptoms of anxiety and depression in NDDs. The strongest evidence comes from the studies carried out in people with MS. The studies in this area (one moderate and two good quality RCTs) showed a reduction in anxiety and depressive symptoms in the mindfulness group post intervention compared to the control group (usual care). The evidence for long-term effectiveness of MBIs is also stronger for anxiety and depression in MS. However, it is difficult to draw any conclusion about its effectiveness to reduce anxiety and depression in individuals with $\mathrm{PD}$ and dementia/MCI due to poor quality of studies in these areas.

Interestingly, only one study (Lantz et al., 1997) measured the effect of MBI on behavioural symptoms in people with Alzheimer's disease (AD), despite the high incidence reported in this population (Cummings \& Zhong, 2006). Lantz et al. (1997) reported a positive effect on agitated behaviour but the quality of this study was poor because of low statistical power and it was not clear how the participants were allocated to the experimental and control group. Therefore, it is difficult to draw conclusions about effectiveness of MBI in reducing behavioural symptoms.

No firm conclusions could be drawn about the effectiveness of MBIs to improve psychosocial functioning in individuals with NDDs. There was only one good quality RCT showing significant improvement in health-related QoL in individuals with MS (Grossman et al., 2010). But another RCT, which was equally good quality, found no significant improvement in the same NDD (Bogosian et al., 2015). It should be noted, however, that the direct comparison is difficult as the studies used different outcome measures for evaluating QoL. Furthermore, it could also be related to the type of measure used by these studies, i.e. Bogosian et al. (2015) used EQ-5D in which three of the five items focus on somatic symptoms that are unlikely to change in people with progressive MS (Bogosian et al., 2015). Furthermore, questions related to fatigue 
and cognition are also absent in EQ-5D scale which are often major issues in people with progressive MS. Whereas, Grossman et al. (2010) used HAQUAMS which is specifically designed to measure QoL in patients with MS and is a well-validated measure exhibiting low to moderate sensitivity to change (Gold et al., 2001).

Similarly, firm conclusions could not be made about the effect of mindfulness in improving cognitive functioning in individuals with MS and PD. However, there was one RCT providing strong evidence for its effectiveness in maintaining cognitive function in people with a diagnosis of $\mathrm{AD}$. The intervention was delivered three times weekly over a two-year period. Therefore, this study showed that MBI could be more effective if delivered over a longer period, particularly to individuals with dementia. Given the studies in the other two conditions were short-term interventions, results of this study are difficult to generalise to people with other types of dementia/MCI, MS and PD until similar protocols have been trialled in other conditions.

\section{Intervention content and delivery}

All of the studies used either MBSR or MBCT as an intervention. There was one study that used a combination of MBSR and MBCT. Most of the studies modified their intervention program to accommodate needs of their participants. Common modifications included: fewer and/or shorter sessions, slower pace, repetition of content and use of simplified language. A full-day (7 hours) silent retreat forms a part of the standard MBSR program (Kabat-Zinn, 2013). This day typically involves a series of guided meditations, offering an opportunity for seamless mindfulness practice and helps participants to consolidate their learning (Dobkin, Hickman, \& Monshat, 2014). However, only three out of nine studies using MBSR program included a retreat session. One study offered only half-a-day (4 hours) that was only attended by a third of the participants. Whereas, two RCTs offered a full day session but the authors have 
not mentioned in their papers how well this session was attended. Therefore, it is difficult to understand whether a retreat session is feasible for this population.

A few studies adapted or removed physical exercises such as walking meditation for safety purposes, particularly the studies with individuals who had PD. However, some of the studies making a lot of adaptations had higher attrition rates (e.g. Cash et al., 2016; Dissanayaka et al., 2016). Whereas the studies that made fewer modifications had a lower dropout rate (e.g. Amiri et al., 2016; Grossman et al., 2010). One could speculate that this could be related to the severity of symptoms experienced by participants, as those with more severe symptoms might require more adaptations, which might pose a hidden source of bias. Hence, dropout could actually be linked to symptom severity rather than the adaptations.

Home practice was recommended to participants in 11 out of 12 studies. However, only three studies explored whether compliance and amount of home practice correlated with improvement in mindfulness skills or psychological symptoms and presented mixed findings. It is worth noting though that the researchers relied on self-report homework logs to monitor the compliance and amount of practice, which presents the issue of social desirability potentially masking or producing spurious associations between variables.

The mode of delivery was mainly face to face except in one study. Bogosian et al. (2015) tried an innovative method of providing the intervention using video conferencing. Their study showed that it is feasible to deliver an MBI in this manner and the researchers were able to recruit nationally. The remote delivery of MBI can be accessible for individuals with severe disabilities who may find it difficult to go to a centre to attend sessions. However, the only drawback of using this technology would be that individuals without internet could be excluded. 


\section{Methodological issues}

There were a number of limitations in all of the reviewed studies. These included small sample sizes, lack of intent-to-treat analysis despite high attrition rates in several studies and either a short follow-up period or lack of a follow-up. The fidelity to the specified intervention was not monitored in most of the studies (except in studies by Amiri et al., 2016 and Bogosian et al., 2015). This makes it difficult to evaluate how closely the intervention protocol was adhered to; thus reducing confidence in the outcomes of the study. Another important factor in maintaining integrity of MBI is the facilitator's competence and teaching credentials particularly when working with a vulnerable population (Crane et al., 2012). Three studies did not include any details of the facilitators and whether they were trained.

Only eight studies were controlled trials. The lack of a control arm in the remaining four studies made it difficult to attribute the positive findings to the intervention. Of the studies that used a control group, only one used an active control group. The absence of an active control group makes it difficult to control for nonspecific therapy effects and other aspects such as general social support or motivational factors. There were other sources of bias in four of the controlled studies due to lack of adequate reporting in certain areas, such as allocation concealment and blinding of participants and investigators to group allocation. The overall external validity was generally poor across all of the studies because of convenience sampling used in many studies and lack of description regarding the source population and intervention setting.

Another limitation is the use of self-reported outcome measures in the majority of the studies. The self-reported measures are usually associated with various response biases, e.g. social desirability and memory effects. Only one study asked residential 
staff to rate the level of agitation in individuals with dementia. Only two studies used measures that were specifically designed and validated for the specific age group. These were the two PD studies, which used the Geriatric Anxiety Inventory (GAI). Also, only a few studies used a mindfulness measure. It is difficult to attribute significant changes in psychological health to the mindfulness intervention if a mindfulness measure has not been included.

\section{Limitations of the review}

There are a number of limitations of this review; therefore, the findings need to be considered with caution. This review included a range of conditions under the term NDD to help evaluate research in this area and this inclusive approach provided an opportunity to look at more evidence relating to the effectiveness of MBIs in this population. The psychological, cognitive and behavioural profile of individuals affected by different NDDs share common features, which was another reason for integrating different conditions under the umbrella term of NDD. But this inclusive approach resulted in challenges with synthesising the available evidence. It was not possible to avoid segmenting the various NDDs out when drawing overall conclusion as it soon became clear that the most robust evidence was in MS.

This review included only papers written in English language and published in peer-reviewed journals and these criteria meant that studies reported in other ways, e.g. theses or through conference abstracts may have been missed. Another limitation was that a second reviewer carried out the quality appraisal of only five papers in this review. Ideally, to ensure reliability of the process a second reviewer should independently rate all of the papers.

\section{Implications for clinical practice and future research}

There is some encouraging evidence that MBIs benefit individuals with a NDD, particularly people with MS in reducing symptoms of anxiety and depression. More 
high quality studies employing robust methodology such as RCTs with adequate statistical power are needed in PD and dementia/MCI. Future research in this area would also benefit from employing an active intervention in the control arm to control for non-specific therapy effects. Future research on MBIs should include a mindfulness measure to check if the effects of the intervention could be attributed to increase in mindfulness skills.

\section{Conclusion}

There is some evidence to suggest that MBIs have a role to play in reducing symptoms of anxiety and depression associated with a NDD, particularly those suffering from MS. However, the evidence is not strong enough to suggest the same for PD and dementia/MCI due to lack of good quality studies. Similarly, there is not strong evidence to draw firm conclusions about benefits of MBIs in improving behavioural, cognitive, psychosocial or symptom-specific functioning in NDDs. However, one good quality study provided some evidence for its effectiveness in maintaining cognitive function in people with a diagnosis of Alzheimer's disease. The inclusive approach used in this review to combine studies from different conditions under an umbrella of NDDs was perhaps not as fruitful as hoped due to the bias of evidence towards MS. More high quality studies utilising robust methodology such as RCTs with adequate statistical power are needed to explore outcomes in people with PD, dementia/MCI and other NDDs that have not yet been explored. 


\section{References}

Age UK (2017). Later Life in the United Kingdom: A factsheet. Retrieved from https://www.ageuk.org.uk/

Amiri, M., Rabiei, M., \& Donyavi, V. (2016). Effectiveness of Mindfulness Training in Enhancing Executive Function and Decreasing Symptoms of Depression and Anxiety in Patients with Multiple Sclerosis (MS). Journal of Behavioral and Brain Science, 6(8), 329.

Anonymous (2013). Joining forces to fight neurodegenrative diseases. The Lancet Neurology, 12(2), 119. http://dx.doi.org/10.1016/S1474-4422(13)70004-8

Baer, R. A. (2003). Mindfulness training as a clinical intervention: A conceptual and empirical review. Clinical Psychology: Science and Practice, 10(2), 125-143.

Baer, R. A., Smith, G. T., Lykins, E., Button, D., Krietemeyer, J., Sauer, S., ... Williams, J. M. G. (2008). Construct validity of the five facet mindfulness questionnaire in meditating and nonmeditating samples. Assessment, 15(3), $329-342$.

Baquero, M., \& Martín, N. (2015). Depressive symptoms in neurodegenerative diseases. World Journal of Clinical Cases: WJCC, 3(8), 682.

Batista, P., \& Pereira, A. (2016). Quality of Life in Patients with Neurodegenerative Diseases. Journal of Neurology and Neuroscience. 7, 1.

Bogosian, Chadwick P., Windgassen S., Norton S., McCrone P., Mosweu I., ... MossMorris R. (2015). Distress improves after mindfulness training for progressive MS: A pilot randomised trial. Multiple Sclerosis Journal, 21(9), 1184-1194. 
Bohlmeijer, E., Prenger, R., Taal, E., \& Cuijpers, P. (2010). The effects of mindfulness-based stress reduction therapy on mental health of adults with a chronic medical disease: a meta-analysis. Journal of Psychosomatic Research, $68(6), 539-544$.

Cash, T. V., Ekouevi, V. S., Kilbourn, C., \& Lageman, S. K. (2016). Pilot study of a mindfulness-based group intervention for individuals with Parkinson's disease and their caregivers. Mindfulness, 7(2), 361-371.

Chaudhuri, K. R., Healy, D. G., \& Schapira, A. H. (2006). Non-motor symptoms of Parkinson's disease: diagnosis and management. The Lancet Neurology, 5(3), $235-245$.

Chen, W., Zhang, X., \& Huang, W. (2016). Role of neuroinflammation in neurodegenerative diseases (Review). Molecular Medicine Reports, 13, 33913396.

Chiesa, A., \& Serretti, A. (2010). A systematic review of neurobiological and clinical features of mindfulness meditations. Psychological Medicine, 40(8), 12391252.

Crane, R. S., Kuyken, W., Williams, J. M. G., Hastings, R. P., Cooper, L., \& Fennell, M. J. (2012). Competence in teaching mindfulness-based courses: concepts, development and assessment. Mindfulness, 3(1), 76-84.

Cummings, J. L., \& Pillai, J. A. (Eds.). (2016). Neurodegenerative Diseases: Unifying Principles. Oxford University Press.

Cummings, J. L., \& Zhong, K. (2006). Treatments for behavioural disorders in neurodegenerative diseases: drug development strategies. Nature Reviews Drug Discovery, 5(1), 64-74. 
Davie, C. A. (2008). A review of Parkinson's disease. British Medical Bulletin, 86(1), $109-127$.

Di Maio, L., Squitieri, F., Napolitano, G., Campanella, G., Trofatter, J. A., \& Conneally, P. M. (1993). Suicide risk in Huntington's disease. Journal of Medical Genetics, 30(4), 293-295.

Dissanayaka N.N.W., Idu Jion F., Pachana N.A., O’Sullivan J.D., Marsh R., Byrne G.J., \& Harnett P. (2016). Mindfulness for motor and nonmotor dysfunctions in Parkinson's disease. Parkinson's Disease, 13. Retrieved from http://www.sagehindawi.com/journals/pd/

Dobkin, P. L., Hickman, S., \& Monshat, K. (2014). Holding the heart of mindfulnessbased stress reduction: balancing fidelity and imagination when adapting MBSR. Mindfulness, 5(6), 710-718.

Gard, T., Hölzel, B. K., \& Lazar, S. W. (2014). The potential effects of meditation on age-related cognitive decline: a systematic review. Annals of the New York Academy of Sciences, 1307(1), 89-103.

Gold, S., Heesen, C., Schulz, H., Guder, U., Mönch, A., Gbadamosi, J., ... Schulz, K. (2001). Disease specific quality of life instruments in multiple sclerosis: validation of the Hamburg Quality of Life Questionnaire in Multiple Sclerosis (HAQUAMS). Multiple Sclerosis Journal, 7(2), 119-130.

Goldstein, L. H., \& McNeil, J. E. (Eds.). (2012). Clinical neuropsychology: A practical guide to assessment and management for clinicians. John Wiley \& Sons.

Grossman, P., Kappos, L., Gensicke, H., D’Souza, M., Mohr, D., Penner, I., \& Steiner, C. (2010). MS quality of life, depression, and fatigue improve after mindfulness training: a randomized trial. Neurology, 75(13), 1141-9. 
Grossman, P., Niemann, L., Schmidt, S., \& Walach, H. (2004). Mindfulness-based stress reduction and health benefits: A meta-analysis. Journal of Psychosomatic Research, 57(1), 35-43.

Heesen, C., Schulz, K., Fiehler, J., Von der Mark, U., Otte, C., Jung, R., ... Gold, S. (2010). Correlates of cognitive dysfunction in multiple sclerosis. Brain, Behavior, and Immunity, 24(7), 1148-1155.

Henze, T., Rieckmann, P., \& Toyka, K. V. (2006). Symptomatic treatment of multiple sclerosis. European Neurology, 56(2), 78-105.

Hofmann, S. G., Sawyer, A. T., Witt, A. A., \& Oh, D. (2010). The effect of mindfulness-based therapy on anxiety and depression: A meta-analytic review. Journal of Consulting and Clinical Psychology, 78(2), 169.

Hölzel, B. K., Carmody, J., Vangel, M., Congleton, C., Yerramsetti, S. M., Gard, T., \& Lazar, S. W. (2011). Mindfulness practice leads to increases in regional brain gray matter density. Psychiatry Research: Neuroimaging, 191(1), 36-43.

Jackson, R., Ameratunga, S., Broad, J., Connor, J., Lethaby, A., Robb, G., ... Heneghan, C. (2006). The GATE frame: critical appraisal with pictures. Evidence Based Nursing, 9(3), 68-71.

Jauhar, S., \& Ritchie, S. (2010). Psychiatric and behavioural manifestations of Huntington's disease. Advances in Psychiatric Treatment, 16(3), 168-175.

Jha, A. P., Krompinger, J., \& Baime, M. J. (2007). Mindfulness training modifies subsystems of attention. Cognitive, Affective, \& Behavioral Neuroscience, 7(2), $109-119$.

Kabat-Zinn, J. (1982). An outpatient program in behavioral medicine for chronic pain patients based on the practice of mindfulness meditation: Theoretical 
considerations and preliminary results. General Hospital Psychiatry, 4(1), 3347.

Kabat-Zinn, J. (2009). Wherever you go, there you are: Mindfulness meditation in everyday life. Hachette UK.

Kabat-Zinn, J. (2013). Full catastrophe living, revised edition: how to cope with stress, pain and illness using mindfulness meditation. Hachette UK.

Keng, S.L., Smoski, M. J., \& Robins, C. J. (2011). Effects of mindfulness on psychological health: A review of empirical studies. Clinical Psychology Review, 31(6), 1041-1056.

Klevan, G., Jacobsen, C. O., Aarseth, J. H., Myhr, K.-M., Nyland, H., Glad, S., ... Farbu, E. (2014). Health related quality of life in patients recently diagnosed with multiple sclerosis. Acta Neurologica Scandinavica, 129(1), 21-26. https://doi.org/10.1111/ane.12142

Kolahkaj, B., \& Zargar, F. (2015). Effect of Mindfulness-Based Stress Reduction on Anxiety, Depression and Stress in Women With Multiple Sclerosis. Nursing and Midwifery Studies, 4(4), e29655. https://doi.org/10.17795/nmsjournal29655

Kozhevnikov, M., Louchakova, O., Josipovic, Z., \& Motes, M. A. (2009). The enhancement of visuospatial processing efficiency through Buddhist deity meditation. Psychological Science, 20(5), 645-653.

Langdon, D. W. (2011). Cognition in multiple sclerosis: Current Opinion in Neurology, 24(3), 244-249.

Lantz, M. S., Buchalter, E. N., \& McBee, L. (1997). The Wellness Group: a novel intervention for coping with disruptive behavior among [corrected] elderly nursing home residents. The Gerontologist, 37(4), 551-6. 
Lazar, S. W., Kerr, C. E., Wasserman, R. H., Gray, J. R., Greve, D. N., Treadway, M. T., ... Benson, H. (2005). Meditation experience is associated with increased cortical thickness. Neuroreport, 16(17), 1893.

Litherland, R., \& Robertson, G. (2014). Mindfulness meditation: can it make a difference? Journal of Dementia Care, 22, 31-33. Retrieved from https://dl.dropboxusercontent.com/u/65925762/Mindfulness\%20article.pdf

Medical Research Council (2017). Spotlight on: Neurodegenerative diseases: dementia. Retrieved from https://www.mrc.ac.uk/research/spotlights/neurodegenerative-diseasesdementia/

Marrie, R. A., Horwitz, R., Cutter, G., Tyry, T., Campagnolo, D., \& Vollmer, T. (2009). The burden of mental comorbidity in multiple sclerosis: frequent, underdiagnosed, and undertreated. Multiple Sclerosis, 15(3), 385-392.

NICE (2009). Depression: the treatment and management of depression in adults. Retrieved from http://www.nice.org.uk/guidance/cg90/resources/guidancedepression-in-adults-pdf

NICE (2012). Methods for the development of NICE public health guidance (third edition). Retreived from http://www.nice.org.uk/aboutnice/howwework/developingnicepublichealthguid ance/ publichealthguidanceprocessandmethodguides/ public_health_guidance_process_and_method_guides.jsp

Paller K.A., Creery J.D., Florczak S.M., Weintraub S., Mesulam M.-M., Reber P.J., ... Maslar M. (2015). Benefits of mindfulness training for patients with progressive cognitive decline and their caregivers. American Journal of Alzheimer's Disease \& Other Dementias, 30(3), 257-267. 
Patten, S. B., Beck, C. A., Williams, J. V. A., Barbui, C., \& Metz, L. M. (2003). Major depression in multiple sclerosis: A population-based perspective. Neurology, 61(11), 1524-1527. https://doi.org/10.1212/01.WNL.0000095964.34294.B4

Pickut, B., Vanneste, S., Hirsch, M., Van Hecke, W., Kerckhofs, E., Marien, P., ... Cras, P. (2015). Mindfulness Training among Individuals with Parkinson's Disease: Neurobehavioral Effects. Parkinson's Disease. Article ID 816404, http://dx.doi.org/10.1155/2015/816404

Przedborski, S., Vila, M., \& Jackson-Lewis, V. (2003). Series Introduction:

Neurodegeneration: What is it and where are we? The Journal of Clinical Investigation, 111(1), 3-10.

Quintana-Hernandez D.J., Miro-Barrachina M.T., Ibanez-Fernandez I.J., Santana-Del Pino A., Quintana-Montesdeoca M.P., Rodriguez-De Vera B., ... BravoCaraduje N. (2015). Mindfulness in the Maintenance of Cognitive Capacities in Alzheimer's Disease: A Randomized Clinical Trial. Journal of Alzheimer's Disease, 50(1), 217-232.

Richly, P., Manes, F., \& Bustin, J. (2012). Depression and Alzheimer's Disease. In Depression in Neurologic Disorders: Diagnosis and Management (pp. 177188). Wiley-Blackwell.

Schrag, A., Jahanshahi, M., \& Quinn, N. (2000). What contributes to quality of life in patients with Parkinson's disease? Journal of Neurology, Neurosurgery \& Psychiatry, 69(3), 308-312.

Segal, Z.V., Williams, J.M.G., \& Teasdale, J.D. (2002). Mindfulness-based cognitive therapy for depression: a new approach to preventing relapse. New York: Guilford Press. 
Simpson, R., Booth, J., Lawrence, M., Byrne, S., Mair, F., \& Mercer, S. (2014). Mindfulness based interventions in multiple sclerosis - A systematic review. BMC neurology, 14(1), 15.

Truong, D. D., Bhidayasiri, R., \& Wolters, E. (2008). Management of non-motor symptoms in advanced Parkinson disease. Journal of the Neurological Sciences, 266(1), 216-228.

University of York. (2009). Systematic reviews: Centre for Reviews and Dissemination's guidance for undertaking reviews in health care. CRD: University of York. Retrieved from: http://www.york.ac.uk/inst/crd/pdf/Systematic_Reviews.pdf

Wells R.E., Yeh G.Y., Kerr C.E., Wolkin J., Davis R.B., Tan Y., ... Kong J. (2013a). Meditation's impact on default mode network and hippocampus in mild cognitive impairment: Pilot study. Neuroscience letters, 556, 15-19.

Wells R.E., Kerr C.E., Wolkin J., Dossett M., Davis R.B., Walsh J., .. Yeh G. (2013b). Meditation for adults with mild cognitive impairment: A pilot randomized trial. Journal of the American Geriatrics Society, 61(4), 642-645. 


\section{Empirical Paper}

A qualitative study exploring the experiences of mindfulness training in people with acquired brain injury 


\begin{abstract}
Background: Very little qualitative research has been conducted so far examining experiences of individuals with acquired brain injury (ABI) receiving mindfulness intervention. Tinova (2015), in a mixed methods study, used a novel approach to collect 'in-vivo' data from individuals with ABI about their experiences of using mindfulness as they practiced it. However, this study included only four participants; thus replicating and extending this study may enhance our understanding of people's experiences further.
\end{abstract}

Aims: The present study aimed to examine how individuals with ABI make sense of their experiences of learning mindfulness skills and how it was viewed during their everyday practice.

Method: The present study extended Tinova's (2015) qualitative component in two ways, i.e. by collecting further in-vivo recordings and conducting focus group interviews. Fifteen participants were recruited to either or both of these methods. Focus group interviews were analysed using Interpretative Phenomenological Analysis (IPA) and in-vivo recordings were analysed using Template analysis (TA).

Results: Each type of data highlighted different aspects of participants' experiences. Four themes derived from focus groups revealed rich information regarding their experiences of mindfulness training and being in the group. Themes from in-vivo recordings illustrated participants' unique experiences of individual practice.

Conclusions: The findings suggested that most participants considered mindfulness beneficial in terms of helping them to cope with emotional and cognitive consequences of ABI. The very 'live' nature of in-vivo recordings revealed rich descriptions about their individual mindfulness practice. The limitations of this study, future research and clinical implications have been discussed. 


\section{Introduction}

The current study is a qualitative exploration of the experiences of mindfulness training in individuals with an acquired brain injury (ABI). This section provides background information about $\mathrm{ABI}$ and existing literature on the use of mindfulnessbased interventions (MBIs) in this population, and explains the rationale and aims of the current study.

$\mathrm{ABI}$ is an umbrella term to describe an injury to the brain that occurs after birth, which can be caused by a traumatic or non-traumatic event (Headway, 2017). Common traumatic causes include road traffic accidents, assaults and falls causing violent movement of the brain within the skull (Headway, 2017). Non-traumatic causes of brain injury include strokes or cerebral vascular accidents, infections (meningitis or encephalitis), brain tumours, aneurysm etc. (Headway, 2017). Such injuries have significant physical, cognitive, behavioural and emotional consequences. Initial and persistent cognitive impairment is a common complaint following an ABI, which interferes with work, leisure, relationships and activities of daily living (Mcallister, 2008; Rabinowitz \& Levin, 2014). In addition, a higher incidence of mood problems such as depression and panic disorder has also been observed in patients recovering from a ABI (Deb, Lyons, Koutzoukis, Ali, \& McCarthy, 1999; Seel et al., 2003).

The emphasis in the acute stages of brain injury rehabilitation can often be on the physical deficits. However, it is the cognitive, affective and behavioural deficits that significantly impairs an individual's capacity to re-integrate into society and return to work (Deb et al., 1999). These deficits can have a negative impact on quality of life and can lead to a change in one's view of oneself (Cicerone, 1989; Deb et al., 1999).

There is consensus that the ultimate aim of successful rehabilitation following ABIs is to enhance patient's participation in activities at home and in their social 
environment (Turner-Stokes, Williams, \& Abraham, 2001). Therefore, a rehabilitation programme encompassing psychological and emotional issues results in better outcomes (Cicerone, 2004; Morton \& Wehman, 1995). Although traditionally MBIs have not been a part of brain injury rehabilitation, more recently it has been growing popularity as a novel approach to improve cognitive and affective outcomes in individuals with ABI (Azulay, Smart, Mott, \& Cicerone, 2013; Bedard et al., 2003).

\section{What is Mindfulness?}

Mindfulness has been described as 'bringing one's attention to the present experience on a moment-to-moment basis' (Marlatt \& Kristeller, 1999). Kabat-Zinn initially explored the use of mindfulness in treating patients with long-term health conditions and developed the first clinical protocol, Mindfulness-based Stress Reduction (MBSR) programme (Kabat-Zinn, 1982). MBSR is a group-oriented program, in which participants are encouraged to develop mindfulness skills through formal techniques such as sitting meditation, body scan, walking meditation and dynamic yoga postures (Kabat-Zinn, 2013).

Since then, mindfulness training has been incorporated into different programmes such as Mindfulness-based Cognitive Therapy (MBCT; Segal, Williams, \& Teasdale, 2002), Dialectical Behavioural Therapy (DBT; Linehan, 1993) and Acceptance and Commitment Therapy (ACT; Hayes, Strosahl, \& Wilson, 1999). The evidence-base for mindfulness-based interventions (MBIs) in a number of clinical populations (cancer, chronic pain, substance misuse and various affective disorders) has grown over the last few decades (Kabat-Zinn, 2013; Kabat-Zinn et al., 1998; Keng, Smoski, \& Robins, 2011). MBIs have been shown to improve affect and cognitive functioning (Chiesa \& Serretti, 2010; Gard, Hölzel, \& Lazar, 2014; Schroevers \& Brandsma, 2010). 


\section{Impact of mindfulness in people with $\mathrm{ABI}$}

To date, only a few studies have investigated the use of MBIs on patients with ABI. A randomised controlled trial (RCT) explored the impact of brief MBI on attention problems in 130 participants with traumatic brain injury (TBI) of mixed severity (McMillan, Robertson, Brock, \& Chorlton, 2002). Participants were randomly assigned into two treatment groups (attention control training group and physical exercise group) and a control group. The participants in attention control training were taught a technique based on mindfulness over four-weekly sessions. The other treatment group received audiotape-based physical exercise training. The treatment groups received an equal amount of therapist contact, whereas the control group had no therapist contact. Their study failed to show significant effects on several aspects of attention and self-report measures of mood between treatment and control groups. One of the limitations could be the brief exposure to mindfulness meditation and the manner in which mindfulness training was delivered. Possibly, a more intensive training delivered by an expert may have led to an improvement in attention difficulties.

More positive findings have emerged from the work of Bédard and colleagues (Bedard et al., 2003). They conducted a pilot study using an uncontrolled pre vs. post design to evaluate the efficacy of MBIs to improve quality of life (QoL) in patients with TBI. Their results showed that 10 participants who completed the intervention had a significant improvement in their QoL and depressive symptoms when compared to three participants who dropped out and were used as controls. However, the small sample size significantly reduces the statistical power. Furthermore, the three participants who dropped out do not represent an adequate control group. Thus 
although the findings were promising, methodological limitations prevent the possibility of drawing any firm conclusions.

Most recently, Azulay, Smart, Mott, \& Cicerone (2013) in a pre vs. post study, reported significant improvements on measures of QoL, perceived self-efficacy and tests of sustained attention and working memory among patients with mild TBI. A convenience sample of 22 participants attended a 10-weeks group based on MBSR. Some of the limitations (lack of a comparison group; participants receiving concurrent rehabilitation making it difficult to isolate the effects of MBSR) of this study make it difficult to draw any firm conclusions about the effectiveness of MBI.

Johansson, Bjuhr, \& Rönnbäck (2012) conducted an RCT with a mixed population of people with TBI and stroke. The experimental group who attended an 8weekly MBSR group, showed a significant reduction in mental fatigue and information processing speed when compared to the control group (Johansson et al., 2012). Similarly, another RCT reported that depression scores in the experimental group significantly reduced following MBI when compared to a waitlist control group (Bédard et al., 2014). However, there were some limitations noted by the researchers in the latter study: a high attrition rate in the experimental group compared to the control group and five participants were assigned to the intervention without randomisation.

In summary, two pre vs. post and two RCTs suggest there may be some benefits of mindfulness in people with $\mathrm{ABI}$ and one RCT found no effect. Unfortunately, all five studies have limitations making it difficult to draw firm conclusions about the effectiveness of MBIs in people with $\mathrm{ABI}$ although evidence so far is promising. RCTs are often considered to be the gold standard of evaluating treatment effectiveness and efficacy of new interventions (e.g. Kazdin, 2008). However, qualitative studies, amongst other things, can offer another route to 
understand the acceptability of an intervention, particularly considering the high attrition rates found in many above-mentioned quantitative studies.

\section{Qualitative studies in mindfulness}

Very little qualitative research exists exploring experiences of individuals with $\mathrm{ABI}$ receiving a MBI. Qualitative studies have been used to explore the experience of participants with a number of physical health diagnoses such as cardiac (Griffiths, Camic, \& Hutton, 2009), cancer (Chadwick, Newell, \& Skinner, 2008; Mackenzie, Carlson, Munoz, \& Speca, 2007) and Parkinson's disease (Fitzpatrick, Simpson, \& Smith, 2010). Qualitative studies have also explored participants' experiences diagnosed with a number of mental health problems as well, e.g. psychosis (Dennick, Fox, \& Walter-Brice, 2013), depression and anxiety (Finucane \& Mercer, 2006; Mason \& Hargreaves, 2001; Williams, McManus, Muse, \& Williams, 2011). Some of the common themes emerging from these qualitative studies included:

- Participants undergoing a phase of learning new skills that requires openness, patience and persistence.

- Common challenges experienced by participants in mindfulness course included: length and use of language, increased vulnerability, high expectations and frustration at not achieving desired goals.

- Experiencing benefits in terms of changing relationship to the illness experience, e.g. increased acceptance, sense of command over the body and illness

- The group as a source of support to participants in the face of struggle with the illness

All of these studies explored participants' experiences retrospectively, i.e. after completing the MBI. The exploration of participants' experiences while they are 
undergoing MBI (which is one of the techniques used in this study) may bring a new perspective on how they use skills during their everyday lives.

A recent study with individuals with $\mathrm{ABI}$ utilised a novel approach to collect "in-vivo" data by asking participants attending a mindfulness group to record their experiences on a digital recorder at home during the period of participation in the group (Tinova, 2015). An IPA revealed four main themes: pain; understanding/experience of mindfulness; mindfulness as a state with distinct sensory quality; and mindfulness as a source of calmness/relaxation. The methodology used in this study provided rich information about participants' experiences of using mindfulness as they practiced it (including how and when they used mindfulness). However, this study was part of a mixed methods approach, and included only four participants and so replicating and extending this study may enrich our understanding of people's experiences further.

\section{Present study}

The present study is therefore a qualitative endeavour to examine how individuals with $\mathrm{ABI}$ make sense of their experiences of learning and using mindfulness skills. A clinical psychologist who is one of the collaborators in this study has been conducting mindfulness groups for individuals with ABIs at a regional outpatient brain injury rehabilitation centre (the rehabilitation unit from now on) and the current study is set in this context.

The present study extends the qualitative component of the previous study (Tinova, 2015) in two ways i.e. by collecting further in-vivo recordings and also carrying out a series of focus groups. By combining in-vivo recordings with retrospective data from focus group interviews, may help to answer broader research questions regarding participants' experiences of mindfulness training and it's 
acceptability in addition to the daily application of mindfulness in this population. The rationale of using focus groups was to explore the experiences of multiple participants in one sitting closely following completion of mindfulness group while the experience was still fresh. Thus, allowing more participants to provide a range of views in the time available. Moreover, in some situations, a group discussion has more likelihood of generating conversations to elicit more experiential reflections than a one-to-one interview (Palmer, Larkin, de Visser, \& Fadden, 2010). Furthermore, participants reported preferring a focus group to individual interviews during a service user consultation prior to commencing the project. Participants were an established group who, having undergone mindfulness together, were already accustomed to disclosure as a group.

\section{Aims}

The main aim of this study is to explore how individuals with ABI make sense of their experiences of learning and practicing mindfulness skills and how it is viewed during their everyday practice. The in-vivo recordings will hopefully tell us more about the experience of everyday practice and the focus groups will provide information about participants' experiences of attending the mindfulness group.

\section{Methods}

This section explains the rationale for the chosen methodology, describes the recruitment procedure, data collection and analysis method.

\section{Interpretative Phenomenological Analysis}

Interpretative Phenomenological Analysis (IPA) was chosen as the approach for focus group interviews in this study because the phenomenological approach inherent in IPA (Smith, Flowers, \& Larkin, 2009) is consistent with the 
stated aim of exploring participants' lived experiences of mindfulness training from their own perspective. IPA is idiographic in nature involving intensive analysis of a particular experience of each individual, which is again in keeping with aims of this study (Smith et al., 2009). Typically, IPA is applied to semistructured one-to-one interviews (Smith et al., 2009). However, recently IPA has been utilised successfully to analyse data from focus groups (Flowers, Duncan, \& Frankis, 2000; Flowers, Knussen, \& Duncan, 2001; Palmer et al., 2010).

\section{Template Analysis}

As the current study also aimed to extend the qualitative part of Tinova's (2015) study, it was decided to utilise the themes originating from this study as a template. A methodology based on Template Analysis (TA) was chosen for this part (Brooks, McCluskey, Turley, \& King, 2015). TA has been described as a flexible technique (Brooks et al., 2015), which has been used in previous studies with a phenomenological focus, thus fitting well with the epistemological position of the researcher used for the other part (King, Carroll, Newton, \& Dornan, 2002).

\section{Design}

This study employs focus groups as well as 'in-vivo' recordings. Participants were able to choose either or both of these. Each type of data from was audio-recorded and transcribed verbatim.

\section{Procedure}

\section{Ethical Approval}

Since this study was a follow-on study, a substantial amendment was submitted to the Local Research Ethics Committee. The approved documentation can be found in Appendix 1. 


\section{Mindfulness based intervention}

The mindfulness group for patients at the rehabilitation unit has been running for the past four years. The group runs for 8-weekly sessions, each lasting one hour. The mindfulness protocol for the group has been adapted from Dunkley and Stanton (2014) (Appendix 2 provides a summary of the intervention). The groups were kept deliberately small, usually up to 4-5 patients and a new group began every two months. Some patients attend more than one group stating that they found the sessions beneficial.

\section{Recruitment}

Participants were recruited using a purposive sampling procedure from the mindfulness group over a period of 15 months. The inclusion criteria were similar to those for the mindfulness group, summarised in Table 1. The participant information sheet (PIS) was used as a basis for invitations to take part in the study (Appendix 3). The group facilitator was asked to provide the PIS to all the participants at the beginning of the group, thus allowing at least two weeks to consider participation in the study. Once a participant agreed to take part, the researcher gained informed consent (Appendix 4-6).

Table 1: Inclusion criteria for the present study

- Acquired Brain Injury (including traumatic brain injury, stroke, brain infections, brain tumour)

○ At least 6 months post-ABI

- Sufficient command of English to understand mindfulness instructions

- Ability to recall how to practice mindfulness between sessions (using appropriate memory strategies if necessary) 


\section{The sample}

Fifteen participants ${ }^{1}$ took part in this study (Table 2). There were eight women and seven men. Their ages ranged from 31 to 73 years. The sample varied in their ethnic origin. One participant took part in only in-vivo recordings, whereas eight took part only in the focus group. Five participants took part in both aspects of data collection.

Table 2: Participant demographics

\begin{tabular}{|c|c|c|c|c|c|c|}
\hline Code & Alias & $\begin{array}{l}\text { Age/ } \\
\text { Gender }\end{array}$ & Ethnic origin & Diagnosis & $\begin{array}{l}\text { Focus } \\
\text { Group }\end{array}$ & $\begin{array}{l}\text { In-vivo } \\
\text { recordings }\end{array}$ \\
\hline P1 & Linda & 52/Female & $\begin{array}{l}\text { Mixed (White } \\
\& \text { African- } \\
\text { Caribbean) }\end{array}$ & Stroke & $\checkmark$ & $x$ \\
\hline $\mathrm{P} 2$ & Tracey & 55/Female & $\begin{array}{l}\text { African- } \\
\text { Caribbean }\end{array}$ & Encephalopathy & $\gamma$ & $x$ \\
\hline P3 & Ian & 56/Male & White British & Stroke & $\checkmark$ & 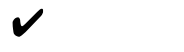 \\
\hline P4 & Miriam & 31/Female & British Asian & $\begin{array}{l}\text { Subarachnoid } \\
\text { Haemorrhage }\end{array}$ & $\checkmark$ & $x$ \\
\hline P5 & Mark & 71/Male & White British & Stroke & $\checkmark$ & $x$ \\
\hline P6 & Yusuf & 57/Male & British Asian & Stroke & $\checkmark$ & $x$ \\
\hline P7 & Joanne & 55/Female & White British & Stroke & $\checkmark$ & $\checkmark$ \\
\hline P8 & Anna & 31/Female & $\begin{array}{l}\text { African- } \\
\text { Caribbean }\end{array}$ & Stroke & $\mathcal{V}$ & $x$ \\
\hline P9 & Chris & 57/Male & White British & TBI & $\checkmark$ & $\checkmark$ \\
\hline P10 & Tanya & 50/Female & White British & TBI & $\nu$ & $\checkmark$ \\
\hline P11 & Raj & 59/Male & British Asian & $\begin{array}{l}\text { Hypoxic brain } \\
\text { injury }\end{array}$ & $\checkmark$ & $x$ \\
\hline P12 & Paul & 73/Male & White British & Stroke & $\checkmark$ & $x$ \\
\hline $\mathrm{P} 13$ & Sam & 42/Female & $\begin{array}{l}\text { Eastern } \\
\text { European }\end{array}$ & TBI & $\checkmark$ & $x$ \\
\hline P14 & Simon & 57/Male & White British & $\begin{array}{l}\text { Anoxic brain } \\
\text { injury }\end{array}$ & $\checkmark$ & $x$ \\
\hline P15 & Rina & 47/Female & British Asian & $\begin{array}{l}\text { Subdural } \\
\text { haematoma }\end{array}$ & $x$ & $\checkmark$ \\
\hline
\end{tabular}

\footnotetext{
${ }^{1}$ Alias names were given to all participants in order to ensure anonymity
} 


\section{Ethical considerations and information storage}

The participants were informed that they could withdraw from the study at any point without needing to give a reason and doing so would not affect the care they received from the rehabilitation unit. The limits of confidentiality were agreed with participants, i.e. that the researcher would have to share information with appropriate services if the researcher thought that someone was at risk of harm. Participants were informed that although their quotes would be used in the write-up for the research paper and journal article, these would not be identifiable. It was made clear to them that the researcher's academic supervisor would also look at the anonymised transcripts.

All of the audio files were immediately transferred to a password-protected USB and were labelled with a participant code to protect confidentiality. The audio files were then erased from the dictaphone. All confidential information pertaining to the research was kept in a locked cabinet or stored electronically on a passwordprotected device.

\section{Data collection}

\section{Focus group}

The researcher conducted six focus groups. A semi-structured interview schedule (Appendix 7) was developed to allow participants to speak freely and reflectively (Smith et al., 2009). The interview schedule was used as a guide to cover a range of topics around their experience of mindfulness. All groups took place at the rehabilitation unit on the last day of the intervention. The average length of focus groups was 45 minutes and four participants attended more than one group (Appendix 8 summarises length of focus groups and participants attending each group). 


\section{In-vivo recordings}

Tinova (2015) used a method inspired by the Descriptive Experience Sampling (DES: Hurlburt \& Akhter, 2006) to gain participants' in-vivo accounts of their experience and to compensate for memory problems often presented by participants with ABI. The present study retained this aspect of data collection. Participants were provided with a dictaphone from the fourth session of mindfulness group to record their immediate experiences whenever they noticed themselves using mindfulness between the sessions. They were given a prompt sheet containing a set of open questions for the recordings (Appendix 9). Participants were invited to attend up to two sessions of instructions with the researcher on how to use the recorder. In order to compensate for often-present memory difficulties in this population, the researcher prompted participants by sending two text messages to make the recordings during the week at a time agreed.

In accordance with the DES recommendations (Hurlburt \& Akhter, 2006), the researcher arranged a session with participants after the first week of recordings. This session provided another opportunity to clarify any aspects of the study procedure and to understand the optimal level of details required in their answers.

\section{Data Analysis}

\section{Focus groups}

The focus group transcripts were analysed using a systematic approach described by Smith et al. (2009) and Palmer et al. (2010). Table 3 illustrates the key stages that were followed during analysis. The researcher kept a reflective diary log of experiences throughout enabling her to reflect on any preconceptions during the analytic stages (Smith et al., 2009). Peer consultation was sought to examine researcher's interpretations and themes development. The academic supervisor 
independently analysed one of the transcripts to further verify the reliability of the analyses. To enhance transparency, an audit trail of the analytic process has been provided in Appendix 12 and 13. Furthermore, the participants' verbatim quotations in the results section will help the reader to view the source of interpretation.

\section{Reflexivity}

Qualitative researchers are encouraged to reflect on and 'bracket-off' their own assumptions to avoid overtly influencing the interpretative process (Elliot, 1999; Smith et al., 2009; Yardley, 2000). Therefore, it is important to note the researcher's position. The researcher is a 39-years old British Indian woman, who completed this research during her Clinical Psychology doctoral program. The researcher has been practicing yoga and meditation regularly for the past four years. She has a particular interest in understanding how individuals cope with a long-term health condition. She has not worked with people with ABI prior to engaging with this study.

From an epistemological standpoint, the researcher believes that there is no one objective reality that exists and experiences are constructed in a social context and subjectively experienced. Thus, the researcher's epistemological position can be described somewhere between contextual constructionist and critical realist positions fitting well with IPA as well as TA analytic approaches.

\section{In-vivo recordings}

In keeping with the TA method (Brooks et al., 2015), each of the five participant's in-vivo transcript was examined and any data that fitted the existing template was added to it, thus assessing applicability of the themes in the initial template. When data from current participants did not 'fit' the existing template, new themes and subthemes were inserted into the template. Any themes that were not reflected in the current data were deleted. 
Table 3: Key stages followed during IPA

1. Reading and re-reading: Each focus group recording was listened to at least once and each transcript was read several times to become familiar with the data.

2. Initial coding: Right hand margin was used to note items of significance/interest at a descriptive level. Phenomenological coding involved going through transcripts line-by-line, noting the content, the language use and initial interpretive comments. As recommended by Palmer et al. (2010), another column on the right hand margin was created to note any group dynamics or a significant change in participants' narrative in relation to other participants in the focus group (See Appendix 10).

3. Development of emerging themes on the individual focus group level: Left hand margin was used to note inferences from interpreting the meaning of participants' claims and these were recorded as emergent themes (See Appendix 10).

4. Connections across emergent themes: Emergent themes for each focus group transcript were organised into a table (See Appendix 11).

5. Moving to the next focus group transcript: First four stages were repeated for each focus group transcript individually.

6. Identifying common patterns across transcripts: The tables containing emergent themes from each coded transcript were printed and cut according to the themes. An exploration of a spatial-representation of how emergent themes related to one another was carried out (Smith et al., 2009, p.96) Common themes were clustered together to create superordinate themes.

7. Developing Superordinate and sub-themes: The emergent themes were organised into 'superordinate' and 'sub-themes' by following a process described by Smith et al. (2009). For example, by putting like with like and developing a new name for the cluster (Abstraction); where an emergent theme itself became a super-ordinate theme as it drew other related themes towards it (Subsumption); transcripts were examined for oppositional relationships (Polarization) and the frequency with which a theme was supported (Numeration). Research supervision was also used to discuss and identify the overarching superordinate themes. 


\section{Results}

This section reports the superordinate themes derived from the IPA of focus group transcripts and the TA of in-vivo recordings.

\section{Focus Groups}

Four superordinate themes, each with a number of subthemes emerged

(summarised in Table 4). Figure 1 displays a diagrammatical representation and interconnection of these themes. Participants' quotes (italicised in the results section) are used to illustrate these themes. Minor changes have been introduced to the verbatim extracts to improve readability (see Table 5).

Table 4: Master Table of Themes for the Focus Groups

\begin{tabular}{|c|c|}
\hline Superordinate theme & Sub-theme \\
\hline $\begin{array}{ll}\text { 1. } & \text { DEVELOPMENTAL } \\
\text { LEARNING PROCESS }\end{array}$ & $\begin{array}{l}\text { 1.1 Overcoming initial scepticism: "it's more } \\
\text { than relaxation" } \\
1.2 \text { "Mindfulness is a bit of a technique to get } \\
\text { used to" } \\
1.3 \text { "It's become part of me" }\end{array}$ \\
\hline $\begin{array}{l}\text { 2. } \text { GROUP AS A } \\
\text { SUPPORTIVE } \\
\text { ENVIRONMENT FOR } \\
\text { LEARNING }\end{array}$ & $\begin{array}{l}\text { 2.1 Sense of belonging - "I am not the only } \\
\text { one" } \\
2.2 \text { Learning from each other }\end{array}$ \\
\hline $\begin{array}{l}\text { 3. INCREASED } \\
\text { AWARENESS }\end{array}$ & $\begin{array}{l}\text { 3.1 Taking everything in } \\
\text { 3.2 Taking a step back }\end{array}$ \\
\hline & $\begin{array}{l}3.3 \text { "Stopping my thoughts to go and run } \\
\text { everywhere" } \\
\text { 3.4 Increasing awareness of self-to-self } \\
\text { relationship and increasing self-compassion }\end{array}$ \\
\hline $\begin{array}{l}\text { 4. } \text { BENEFITS OF } \\
\text { MINDFULNESS }\end{array}$ & $\begin{array}{l}\text { 4.1 Mindfulness bringing improvement to sleep } \\
\text { and pain } \\
4.2 \text { Mindfulness bringing improvement in } \\
\text { memory and concentration } \\
4.3 \text { Mindfulness bringing improvement in } \\
\text { emotional well-being }\end{array}$ \\
\hline
\end{tabular}




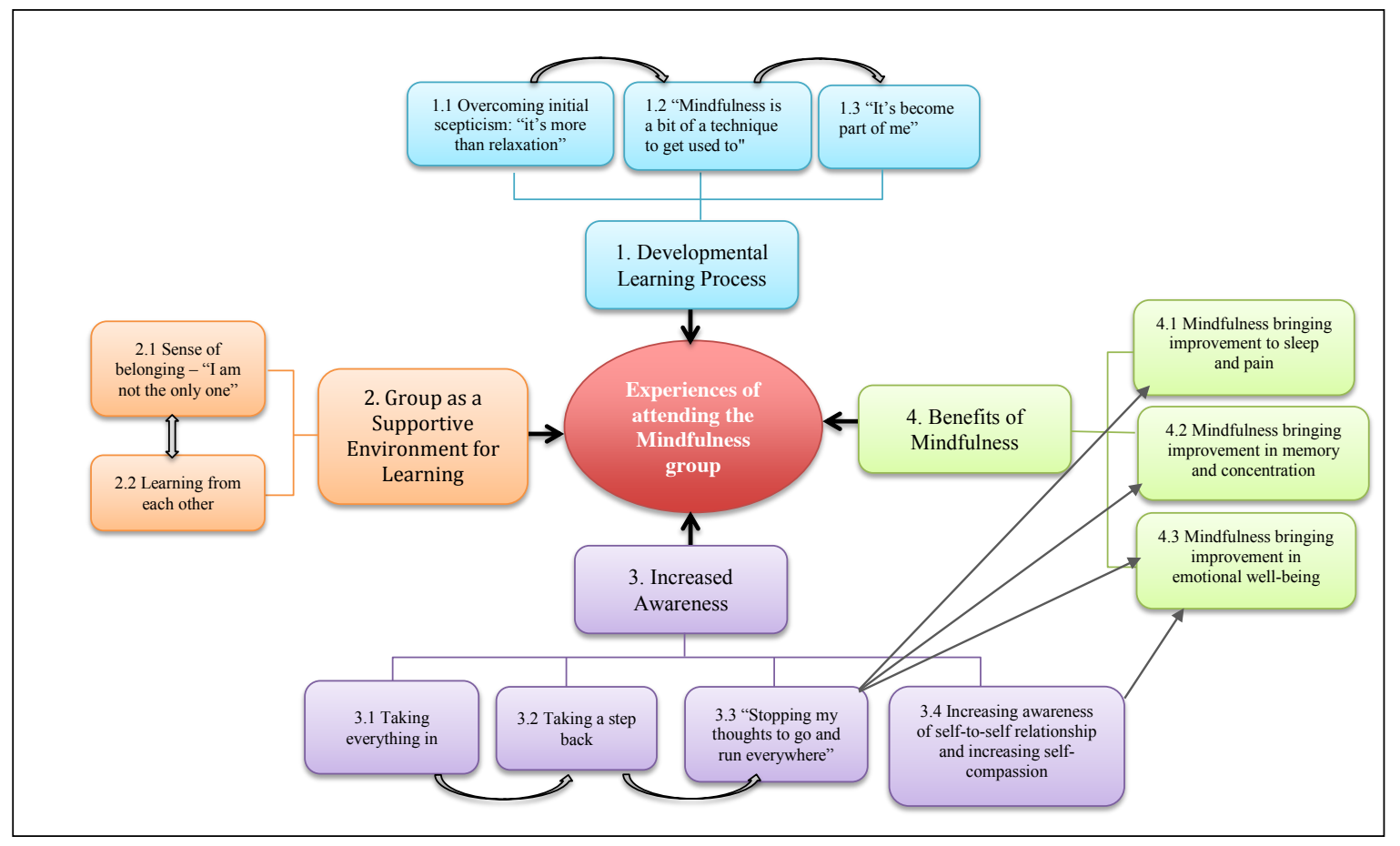

Figure 1: Diagrammatical representation of superordinate and subthemes from the focus group transcripts 
Table 5: Annotation of changes introduced to verbatim extracts

$\circ(\ldots)=$ Indicates the pauses in speech

$\circ[\ldots]=$ Indicates missing texts and where extracts have been condensed

$\circ \quad[\mathrm{xxxx}]=$ Indicates explanatory text by researcher

$\circ \quad[$ Laughter $]=$ non-verbal behaviour is presented in square brackets

○ $\mathrm{R}=$ indicates the researcher

○ Utterance such as 'erm', 'uhh' have been removed

\section{Theme 1. Developmental Learning Process}

This theme and its three sub-themes captured participants' journeys relating to engaging with mindfulness practice. Initially, participants described overcoming their initial scepticism about mindfulness before engaging with learning the skill and finally integrating the practice into their everyday lives.

\subsection{Overcoming initial scepticism: "it's more than relaxation"}

The theme of participants being initially sceptical about mindfulness as an intervention emerged in four out of six focus group interviews, with only a few participants starting the group with an open-minded attitude. For example, Paul mentioned, "I come in with an open mind and what lay ahead". Most of the other participants described some initial scepticism. The reasons for this are outlined below as well as how their views changed over the course of a few sessions.

For Mark, his initial scepticism seemed to relate to his lack of knowledge about the concept: "I was very sceptical to start with. The main reason was because I didn't understand what mindfulness meant [...]'. Whereas, most other participants assumed that mindfulness would be another "relaxation group" like a group that they had just completed at the rehabilitation unit, e.g. Linda said that "because... to me it 
was just relaxation ...it was like... I was bored". Linda was left pondering "do I want to stay or not?" Similarly, Miriam reported:

“Well...I was kind of reluctant to do it. Because, initially I did a relaxation group ...I didn't like that relaxation group at all; I couldn't relax. And I thought mindfulness would be very similar to it." (Miriam, FG-1 ${ }^{2}$ : 15)

Miriam's use of 'initially' suggested that her view quickly changed. In fact, this reflected change of attitude in other participants too when they started to learn more from the group facilitator about the concept and experienced first-hand what it involved. For example, Joanne said:

“It wasn't until FACILITATOR sat us down, explained it and took us through the breathing techniques and stuff like that... and then...I look forward to it now. " (Joanne, FG-4: 109)

It appeared that experiential learning, i.e., learning by doing was more powerful for Joanne after engaging with breathing and other mindfulness exercises. What also seemed to help participants overcome their initial scepticism was understanding the difference between mindfulness and relaxation:

"It's more about training your mind to become more focused and to deal with things in a good way." (Ian, FG-2: 47)

"It's more than relaxation. [...] In relaxation, you just let your mind drift off but in mindfulness you let you mind focus on something and not drift off." (Miriam, FG-2: 166)

There was a moment of realisation when Ian recognised that mindfulness was quite different from what he had done before. Miriam's quote “it's more than relaxation" above summed up her understanding of the difference between relaxation and mindfulness. Both, Ian and Miriam alluded to the training or skill aspect of

\footnotetext{
${ }^{2}$ FG-X refers to the focus group number
} 
mindfulness and described its goal was to increase one's concentration. This understanding appeared to be a crucial turning point for changing participants' attitudes and helping them to engage with learning the skill.

\section{2 "Mindfulness is a little bit of a technique that you have to get used to"}

This subtheme related to participants' accounts of learning the skill once they overcame their initial scepticism. Participants described mindfulness as a technique to bring their focus on the present moment and one of the things that they found helpful was to use an object:

"[...] Like I said before you are given a task to focus on like a leaf or a raisin but in relaxation you're just left with nothing but soothing music [...] Because my mind is full of things it is not easy to shut down but if I focus on something then it works." (Miriam, FG-2: 231, 238)

Thus an object seemed to act like an anchor to help sustain their attention. Above, Miriam highlighted the 'busy’ nature of her mind and her helplessness in being able to 'shut it down'; however, learning to focus attention on an object appeared to be helpful. Echoing Miriam's words, Tanya also described:

"Sometimes I think it's little bit of a technique that you have to get used to do it [...] about wandering off. When you are trying to be mindful but you keep wandering off. But you just have to, and it takes time to learn how to you know switch-off... "(Tanya, FG-5: 300, 529)

Tanya seemed to experience her mind as 'wandering-off' implying it had an almost itinerant nature and she felt that persisting with the technique would bring it under control. There was also an acceptance that it would take time to learn the technique. 


\section{3 "It's implemented now in our day-to-day life"}

This subtheme captured the final step on participants' developmental learning journey. A consistent theme that emerged was that participants had integrated mindfulness into their daily routine over the course of the group. Most participants were quite certain about their commitment to continue the practice when researcher asked them about their plans:

"Sam: I think in a way, it's implemented now in our day-to-day life... that this is one of the strategies we put in place to be able to cope and to continue with our lives." (Sam, FG-6: 546)

"Yeah...it's part of the day-to-day thing that you do. [...] I think that it will be with me now forever really." (Tanya, FG-5: 432, 443)

From Sam's extract, it seemed that she embodied mindfulness in her daily routine. The use of 'we' and 'our' and the certainty in Sam's commitment suggested that the group members might have discussed this topic before the focus group discussion and were of similar mind. She described that mindfulness had become one of the essential strategies for coping. Tanya strikingly echoed Sam's sentiments of mindfulness as becoming part of daily routine and a sense of mindfulness becoming a part of her.

Although a few participants were less certain when they talked about their commitment, they expressed a wish to be able to continue the practice: e.g. Tracey said "it's just lovely to take it with you". Here, Tracey talked about mindfulness as if it was something one could own and carry with them. Anna seemed to have realised that mindfulness is not like other interventions that she learnt in the rehabilitation unit but "it is for life". She talked about this in the second focus group that she attended, which perhaps, showed the leap that she made over the course of time: 
Anna: Mindfulness is for life, definitely. Doing the sessions here... I hope... I hope that I can continue after [Crosstalk 0:38:31].

Tanya: And you probably will because again, it's/

Chris: How can you not? (Anna, Tanya \& Chris; FG-6: 504)

It can be seen that a discussion amongst group members was generated in response to Anna. Tanya and Chris were trying to reassure Anna that she would be able to continue the practice. For some participants (e.g. Ian), it was about continuing and "carry on practicing it...until it becomes a habit".

When asked by the researcher, participants reflected on some of the barriers that could get in the way of continuing practice. Some of the common things mentioned included memory impairment, pain, and a crisis of some sort or 'just busyness of life'. There was a consistent theme of seeing the benefits of mindfulness being a powerful reinforcer for continuing practice, e.g. Ian in his group discussion stated, "I think once you have done it a few times and you have seen the benefits of it... that encourages you to carry on."

\section{Theme 2. Group as a supportive environment for learning}

The second superordinate theme captured participants' recurrent comments about the ethos of the mindfulness group. Two subthemes emerged highlighting the importance of the group, which created a safe and supportive environment for learning mindfulness skills.

\section{1 "We are not the only one"}

There was a consistent theme of the benefits of being with other people who had a common experience of ABI. There was a clear sense from participants' narrative that they could relate to each other, for example Simon described, "We've all been through it". Below, Linda explained the sense of belonging they felt within the group: 
"It's like... we all have the same thing and we all have a brain injury...I know every person is different but when we are in this room, we are just like one person. It just feels like that." (Linda, FG-1: 188)

Linda's phrase "just like one person" was quite poignant, conveying a sense of being fused with each other and encapsulating how connected she felt within the group. This common experience of ABI helped participants to feel reassured, for example, Sam described:

"...Realising that we are not the only one getting through difficult times in our life. This is helping and encouraging us." (Sam, FG-6: 223)

Sam used 'we' and 'our', also illustrating her connectedness with other group members. The realisation that she was not the only one going through difficult times seemed to be very helpful. She further described how the group had "created a bond between them", which interestingly echoed Linda's sentiments of feeling 'just like one person' in the group.

Many participants highlighted how participants helped each other in times of difficulty, e.g. Sam stated, "we will be supportive to each other and when somebody's coming up with a problem, we will try to bring up our ideas". Yusuf appreciated Mark being there with him in the group:

"Sometimes, he [Mark] has got more experience because he would say I have been through this so ... don't worry. And that's what we need to help each other." (Yusuf, FG-3: 123)

In fact, the researcher witnessed first-hand in the interviews how individuals had developed a supportive stance when one member was struggling with word finding due to her communication problems:

$R$ : Can you tell me more about what was going through your mind before you came to attend the group? 
Tracey: I am only started to think about things in [long pause] ah what... just started to think... ahh [annoyed]

Linda: Mindfulness

Tracey: Yeah... I have just started to think about... [Inaudible]

Linda: Take your time, Tracey.

Tracey: oh... [...] Ahh... glorious writing [inaudible] ... oh... gosh...

Linda: Think what you want to say and then say it. (Tracey \& Linda, FG-1: 21)

Here, Linda was able to see that Tracey was struggling to express herself and she tried to help by reassuring her and reminding her of a helpful strategy. There were many such examples during other focus group interviews.

Participants also described how that mindfulness group reduced their sense of isolation. Below, Miriam and Ian illustrated this:

Miriam: You kind of feel...when I come here; I feel that I've got some real friends here. When I'm out there, I feel like there's nobody.

Ian: Because I don't...this is my social life coming here...so...

Miriam: Yeah

Ian: So, I feel part of something here but when I'm outside its different kettle of fish. [...] Yeah, you feel like you belong in here [...] you've got support and it's safe, which is nice. (Miriam \& Ian, FG-2: 144)

The above extract conveyed a clear sense of sadness. Both of them felt that the group became a place that provided them with a 'sense of belonging'. There was also a sense of apprehensiveness for some of participants who were finishing their rehabilitation journey, e.g. Linda, Tracey and Tanya shared feeling anxious and fearful of losing the friendships they had developed.

\subsection{Learning from each other}

Most participants described how they not only shared their difficulties but also shared coping strategies and experiences of mindfulness with each other. They highlighted the value of learning from each other: 
"[...] Especially when you are in a group you learn from others and get the experience of others. [...] We all have our own experiences and we share it to others and others share it with us and then you know more about it, you know."

(Yusuf, FG-3: 103)

Whilst, Yusuf illustrated how sharing experiences was helpful, Tracey had a divergent view. She described a negative aspect of sharing experiences and how it would disrupt the sense of calmness that had been achieved with the mindfulness practice.

"[...] When we talk at the end, it's like nice but not nice, if you know what I mean. It's nice listening to the others but it would be nice if we can listen to the others as well as go... calm, you know what I mean." (Tracey, FG-1: 249)

However, other people described the value of gaining another perspective when learning a new skill, e.g. Mark explained, “because you get the other person's point of view... and you can relate to what you are thinking and doing yourself". Ian also highlighted that sharing experiences helped to validate his feelings and improve his self-esteem, "it affirms that you are doing something right if somebody else is doing that as well and that makes you good about yourself."

It appeared that a safe environment within the group created a space for participants to learn from each other, e.g. Ian commented, "it is done in such a nice and gentle way that it's not stressed at all. So, sharing is quite easy [...] '. His description of the group conveyed a clear sense of warmth and trust within the group that facilitated disclosure. Exploring further what made the group a safe environment, Tanya and Chris highlighted the fact that group members understood each other:

Tanya: [...] You are talking to a group that understands. Where outside of here you could be talking somewhere else where people actually don't understand...

Chris: They might not understand why we stop talking or we have forgotten what we have said... 
Tanya: Yeah.

Chris: Or in my case I sometimes have trouble getting the words out. It's like there is a logjam or something. And they know it in this group or other groups that I have. They will hang on for a little bit because I will get there in the end.

(Tanya \& Chris, FG-5: 184)

Interestingly, this extract evoked connotations of one of the central features of mindfulness, i.e. the idea of non-judgementalness. Chris and Tanya's conversation alluded to a sense of vulnerability whilst sharing but having a non-judgemental ethos within the group enabled this. They both noted that the group members developed a good understanding of each other's difficulties over the course of the group because they had been through similar experiences again echoing the theme of belonging.

\section{Theme 3. Increased awareness}

This theme captured participants' experiences of noticing an increased level of awareness in their everyday lives as they regularly began to practice mindfulness. Four subthemes were identified summarising how mindfulness facilitated an increased awareness at different levels.

\subsection{Taking everything in}

Most participants reflected on an increase in awareness of their surroundings and external environment, which they reported never focusing on before. For example, Linda described:

"Whereas I would just walk normally through a park but now I'm looking at the leaves, the flowers, the trees, the plants. And I'm thinking, "this is new me" because I wouldn't think of doing that. [...] And that's part of me that I will always enjoy." (Linda, FG-1: 354)

Here, Linda contrasted how awareness of her external environment changed after attending the group. She initially spoke in the past tense, stating that she "would just walk normally' through a park. But now she was noticing the nature around her 
while walking. She sounded astounded at this new aspect of self. Below, Tanya also described:

"When I go walking...I just take in all what's around me. [...] Yeah...I'm more aware of what's around me and taking in all the lovely things...the beauty of the nature that's around me. Whereas before I never used to really..." (Tanya, FG5: 486)

Interestingly, Tanya echoed Linda's comments, with respect to becoming more aware of the surrounding environment and described its 'therapeutic' effect. She also compared her 'new' self with the 'old' self, noting that she had become more aware of the 'beauty of the nature' around her. Below, Sam also described a similar level of increased awareness as Linda and Tanya. She seemed to be paying momentto-moment sensory attention to her surroundings:

"One of my colleagues asked me, "Why are you so lazy? Why are you walking that slowly?" [Laughter] [...] And I ask him, "Do you know what colour are the leaves of that tree? Do you know how the sunshine was today? Umm, do you know the song of the birds?" [...] That's mindfulness, I think, to realise what's going around you.” (Sam, FG-6: 398)

While most participants noticed an increase in awareness of their external environment, Simon described mindfulness promoting greater awareness of his internal experience: “It makes you more aware, doesn't it? Of what's going on with your body, what's going on with your mind? It makes you think more”. Simon alluded to an increased awareness of interaction between body and mind. It is not a surprising finding, as mindfulness exercises such as body scan emphasise teaching individuals to become more aware of their internal experiences and encourages an attitude of openness and curiosity towards these experiences (Kabat-Zinn, 2013). 


\section{2 "Stopping my thoughts to run and go everywhere"}

This subtheme captured participants' experiences of an increased awareness of their thought patterns. They reflected on the role of mindfulness in helping them to develop this awareness, which seemed to help them break these patterns. Mark summarised the process of mindfulness as, "just breaking the habit of the mind of... wearing-off in all directions and churning over different things". Below, Yusuf also described:

"So, in that way you are wasting a lot of your mind... giving your mind, I think a lot of pressure you know. When you are going in the past or thinking of future you are using your mind harder. [...] So, yeah when you are there, just think of the present moment that's what you should do and enjoy it think. I think it is helpful." (Yusuf, FG-3: 64)

Yusuf's expression of 'wasting mind' evoked connotations of mind only consisting of a certain amount of energy and how engaging in worrying/rumination could waste a lot of this precious resource. It seemed that he had been trying to develop an ability to recognise when he was engaging in this ruminative process and to bring self to the present moment.

Participants also showed psychological mindedness in their accounts, in that they were able to reflect on how their own thought patterns could impact on their emotional wellbeing. Below, Chris spoke about the upsetting nature of thoughts going out of control:

"I get these cascading thoughts, your brain sort of starts [...] I was having a particularly upsetting bout of it one weekend. So I thought I'd try it to see if the mindfulness would work on that. And it certainly took the edge off it. It certainly did that. As you say, it centred me more. And it took my mind off it." (Chris, FG6: 74-78) 
The 'cascading' thought pattern described here seems akin to a characteristic process described by Teasdale et al., (2002), which can trigger a depressive relapse. It seemed that an increased awareness of thought patterns through mindfulness and then using the mindfulness skills not only gave Chris some control back but also provided a grounding effect. Below, Sam illustrated engaging in a similar process of managing these uncontrolled thoughts:

"Learning and developing new skills to control our feelings, like now, I can give a very good example. Tomorrow is, I have twin boys. They will be 11 in a few days' time. Then they will move to secondary school in September and I'm worried to death as tomorrow is the day when ... I will find out what secondary school they will go. Then I'm trying to keep myself here into the present, this moment of time, rather than to, to leave my thoughts to run and to go everywhere and to make plans and to..." (Sam, FG-6: 161)

Here, Sam provided a live example during the focus group interview. She used the expression 'worried to death' to emphasise the negative impact of worrying on her wellbeing. Sam described that she was no longer engaging passively in a process of chasing her thoughts. Instead, she seemed to be adopting an active stance of keeping herself in the present moment. This account illustrated her increased capacity to observe and being able to relate to her thoughts in a different way, thus showing an increase in metacognitive awareness.

\subsection{Taking a step back}

Many participants reflected on the emotional difficulties that they experienced as a result of an $\mathrm{ABI}$ and how mindfulness helped them to create some distance from the situation. Ian described how he used mindfulness when feeling overwhelmed by the consequences of brain injury:

"I've been using it as well [...] to focus on what's the important thing rather than letting everything crush over me...drive me crazy...” (Ian, FG-2: 88) 
Ian described that mindfulness helped him to discriminate what was important to focus. The expressions 'letting everything crush over' and 'drive me crazy' evoked a sense of passivity, as if at times, he felt out of control with the things going on in his life. In this sense, mindfulness seemed to be giving him some control over the situation and an ability to be able to step out of the situation. Paul also noted that mindfulness took him out of the situation so that he could think of other options, "It's nice to be able to try new things out. And take you out of the situation that you're in... look for better options, really”.

Below, Tanya described that this increased ability to step out of an overwhelming situation helped her to manage difficult emotions:

"I think as well just say you...there are things going in your life and you are anxious and everything...I know now to say to myself in my own head, "stop you need to be more mindful about this" (Tanya, FG-5: 258)

Tanya's use of 'you' in this extract seemed quite interesting; perhaps speaking in this way created some distance for her from her overwhelming emotions. Similar to Tanya, Joanne in her account below also illustrated how she was learning to 'take a step back' from situations, which facilitated regulation of her emotions. And similar to Ian and Paul, Joanne also felt that mindfulness provided her with some control over a situation where she was able to think more clearly about how to react:

"Instead of going on 100 miles an hour, you know what I mean, like I would normally do like a bull in the china shop [long pause] ... to take a step back and breath [...] all of a sudden grrrrrrrr!!! I am angry. What I am trying to learn to do now is to think, breath, try and relax...so I am a bit more cal-calmer. That's what I am trying to get at ... calmer. I...instead of blowing straight away." (Joanne, FG-4: 234)

Joanne's expression 'bull in the china shop', brought to mind a powerful image of an uncontrolled rage that might annihilate the order at any instant. The long 
pause in the second sentence seemed significant, perhaps representing a sense of disbelief regarding a dramatic change in her reaction to such a situation. Joanne's account speaks to the core feature of mindfulness that promotes standing back and just witnessing emotional states. By developing a capacity to 'stand back', Joanne could break her automatic behavioural pattern and seemed no longer controlled by her emotional state.

\subsection{Increasing awareness of self-to-self relationship and increasing self- compassion}

In this subtheme, participants described becoming more aware of how they related to themselves, noting an increased level of self-compassion as they began to practice mindfulness. There was also a consistent theme of mindfulness bringing a change in their values. Most participants noted that they have slowed down. For example, Yusuf talked about how he was able to take a more laid back approach in everyday life:

"I used to be same you know rushing or wanting to do that and that ... you know. But since after we are having this mindfulness class I am taking it all easy."

(Yusuf, FG-3: 298)

Similarly, Paul also noted how mindfulness made a difference in his life:

"[...] Instead of tearing away at this, that and the other... just take time out and be mindful of the situation. Can it wait for tomorrow? [...] It's wise being slow, isn't it? Wise being slow." (Paul, FG-6: 447)

Paul's account above conveyed a sense that he was passively consumed by doing things but was now taking an active stance giving himself more space to explore a situation.

Many participants commented on mindfulness sessions providing opportunities for reflecting on certain aspects of their ABI and its consequences. For 
example, Tracey described how an exercise used in the group focussing on a sprig from a tree which had an old dying leaf and a new growth had particular meaning for her and became a metaphor for her own life:

"It was like the end of a life... yeah... oh gosh! I am going to cry... [Tearful] [Long pause] It was the end of my life and this new life at the bottom of it... it was beautiful; it was wonderful. It was like... that was a leaf ... representing a new life for me. I mean...that was just a leaf and that this beautiful and rest of it... but this was a new life with new something about it and aww that really spoke to me." (Tracey, FG-1: 311)

The new growth on the sprig represented a new life and new opportunities after her ABI. Linda echoed this when she also reflected on these aspects of her life.

"Yeah... because it's like... you have your old life before the brain injury but now you have a new life. And it's like... I have got lot of disabilities and I think “well it's my life now”. But now...this is a new beginning." (Linda, FG-1: 339)

She seemed to be viewing her disabilities with less aversion now. There was a sense that she had started to accept her new life. Acceptance is a central feature of mindfulness practice, therefore it is perhaps not surprising that participants felt encouraged to reflect on what has happened to them and start the process of accepting their losses. Exploring how mindfulness practice might help with acceptance, Tanya reflected on the fact that it's the time that they take out to reflect.

"It helps you to be more mindful about accepting what's happened to you since your brain injury. [...] It's when you take time out for you, as we were calling it earlier... the time for you. And again, it may, it might seem selfish to other people, but when you sit and just think about yourself, just for those few minutes or however long it takes, that's, that's where it helps you to accept it [...]",

(Tanya, FG-6: 452)

Tanya conveyed enormous pain and difficulty of the acceptance process that participants have to go through after experiencing such a major change in their lives. 
The fact that Tanya only talked about this process in the second focus group after completing a second mindfulness group, suggested that she made a 'leap' in this process after she continued mindfulness practice.

Participants also described noticing a specific form of awareness in the way their self-to-self relationship changed. The participants talked about how mindfulness helped them to become more compassionate towards themselves. Tanya commented that following ABI, she had become quite self-critical but there was a shift in this attitude, which she attributed to engaging with mindfulness practice.

"I know from my own personal experiences, since what happened to me, I can be quite hard on myself [...] but doing mindfulness I think helps you to be... give more self love to yourself. [...] Before any of this, I would never have kind of used mindfulness as such. Like Simon said, I'm busy doing this, that and the other. You know, but I, I never kind of thought, "Well I need to, you know..." But obviously I do now. And, but it does help. You know, at the end of the day, you've gotta feel better about yourself inside." (Tanya, FG-6: 187)

Above, Tanya seemed to be reflecting on her life prior to ABI where she was constantly busy. In this sense, she was perhaps alien to the ethos of non-striving that mindfulness represents. Tanya described developing a more kindly and nonjudgemental attitude towards herself now. Below, Chris echoed Tanya's sentiments:

"I will sort of sometimes...you know...I used to shout at myself mentally you know "stupid Chris why are you doing that?" But now I don't do that so much because I have got this instead. So, I can ...I can think to myself "alright this is bad at the moment but in five minutes time I am going to do some mindfulness and that's going to help me more than beating myself up" (Chris, FG-5: 269)

Initially, Chris spoke of himself in the past tense, noting that his internal voice used to have a critical and almost 'bullish' tone. He appeared to adopt an attitude of non-judgementalness towards the self and his internal voice also had a positive tone now. He also viewed mindfulness as an antidote that he knew would work. 


\section{Theme 4. Benefits of mindfulness}

The final overarching theme aimed to capture the benefits that all participants noted of integrating mindfulness into their lives. One of the common themes was the 'calming' effect of mindfulness that they believed could be leading to an improvement in different areas of their lives. Three subthemes were identified.

\subsection{Mindfulness bringing improvement to sleep and pain}

Paul described how mindfulness could have a beneficial physiological effect, which he attributed to the calmness of his mind. He also realised that he had been doing this in the past without realising:

"Just the calmness of the mind. [...] You know, I've done that for years, when I'm in the dentist chair or going to sleep. And uh, and it's helped me a lot, that does. Without realising it was part of the, the mindfulness [...] it's brought down [clears throat] blood pressure, you know, and heart rate as well. Just a simple act." (Paul, FG-6: 285)

Below, Anna also talked about improvement in her sleep pattern:

"So it's...the worry stops me from sleeping properly. So I've learnt now how to just trying to take my...learn to take my mind-off by listening to sounds like rain and thunder [Laughs] ...which completely takes my mind-off from whatever I am worrying about." (Anna, FG-4: 260)

Here, Anna highlighted the mind-body interaction, noting that it was the worry stopping her to get to sleep. She described that by learning to sustain her attention on the sound, she could switch-off from worrying, eventually helping her to sleep better.

Below, Chris noted that mindfulness helped him with pain in his hand that was exacerbated by gardening one day:

"[...] And my this hand [POINTING TO RIGHT HAND] was aching because this was damaged in the accident. And it... when I was going through the you know "think about your feet, think about your knees and hands and all that" it 
took ...it took the worry about the pain... well not the pain but the sensation that I was getting...it took that away. It took that worry away.” (Chris, FG-5: 383)

Chris described how focusing on internal sensations helped with managing the worry related to pain, which is in contrast to Anna who focussed on her external surroundings to manage her worrying thoughts.

\subsection{Mindfulness bringing improvement in memory and concentration}

Participants also described how mindfulness could impact on cognitive functioning:

"Depending on which part of brain it affects...it can...you can lose your memory and certain other things but...mindfulness helps you to concentrate more and ...re-associate things with what it should be." (Mark, FG-3: 333)

"Say I have got an appointment on Thursday... with my GP. Now if I on Thursday... I get up and start wandering around with other things then obviously I will not be thinking about what I'm going to do on Thursday. But if I stay in the present [...] I am going to get up and do that" (Yusuf, FG-3: 315)

Mark's account suggested that if he concentrated more he could build associations helping him to remember things whereas Yusuf explained how mindfulness stopped his wandering thoughts distracting him from what he should be doing that day and so staying in the present helped. Miriam described a direct impact of the improved concentration that she felt came with mindfulness:

"Before I used to think of other things while I was drawing... and at the end of it there was some bits of the drawing I didn't like and I had to edit them again because, I wasn't concentrating on it. It is bit less now. I just think about what I'm doing and nothing else. [...]." (Miriam, FG-2: 291)

Ian also described a shift in his ability to concentrate, and he further explained how he was achieving this: 
"It becomes useful because you learn to control the distractions, internal as well as external and put them in a place where they are supposed to be." (Ian, FG-2: 250)

In his account, Ian alluded to a core feature of mindfulness promoting to become an observer of one's internal and external experiences without any evaluation. Chris also explained the role of mindfulness in managing the external experiences:

"It's almost...I sometimes see it as an insulation...you know instead of having a live wire there you've got a plastic sheeting around it...so...in a way the outside world can't really touch it." (Chris, FG-5: 255)

His expression of 'live wire' was quite powerful, evoking a sense of his internal world being something quite dangerous, with mindfulness protecting it from being sparked-off by the outside world.

\subsection{Mindfulness bringing improvement in emotional well-being}

Most participants described the role of mindfulness in improving their emotional wellbeing. Below, Tanya and Simon described how mindfulness could help to manage their mood:

Tanya: When you're, when you're just in your daily life and you're suffering with, you know, bad times or whatever.

Simon: Depression and things like that.

Tanya: Or just things aren't going as planned, things, you, you do become more mindful to take notice of yourself and, you know...

Simon: How to get out of that mood, you know...yeah.

Tanya: To...to try and calm yourself down on your emotions, things like that.

(Tanya \& Simon, FG-6: 119)

Tanya illustrated becoming more aware of her emotional states, which eventually prompted her to take a responsive action rather than being passive. Similarly, Mark reflected on how mindfulness helped him to manage his anxiety 
about going out into the community following his stroke: "things like getting on a bus...now if I can just relax my mind before I have to do any of these tasks it helps me enormously."

One of the reasons Joanne thought that mindfulness helped to reduce stress was via a reduction in tension in her body: "If I get agitated then I can try and get myself more relaxed and a bit less tense because I am always tense." Other participants were able to use mindfulness in stressful life situations too, in her second focus group Anna recalled that mindfulness gave her a method of managing her anxiety during a stressful hospital procedure:

"I was scared. I was shaking. My whole body went into like... It was shaking really bad. The nurses and the doctor were trying to calm me down. Soon as she mentioned the... Yeah, soon as she mentioned the, concentrate on your breathing, brought me back to the mindfulness stuff, [...] I started to calm myself down then." (Anna, FG-6: 102)

Anna's account highlighted that she had embodied mindfulness and the words 'concentrate on breathing' helped her to connect to her learning.

Overall, most of the participants noticed a number of benefits after they started to engage with mindfulness practice. However, one participant (Raj) diverged from this position although it was clear that he did not make an effort to engage with mindfulness or understand what it was:

"So about like mindfulness has no meaning to me because I don't pay no attention to it about. [...] Because... see ... as far as myself is concerned ....I'm not worried about my brain, because I remember present and the past. All I am worried about... is my speech and my legs [POINTS TO HIS WHEELCHAIR]. If I could get my speech proper and I could walk properly. [...] I am happy." (Raj, FG-5: 92)

Thus, from Raj's point of view mindfulness had no role to play in helping him meet his goals. 


\section{Individual In-vivo Recordings}

This section describes the themes derived from in-vivo recordings. The length and number of recordings from each participant are summarised in Table 6.

Table 6: Total number and length of recordings for each participant

\begin{tabular}{cc}
\hline Participant & $\begin{array}{c}\text { Number of recordings (total length } \\
\text { in minutes and seconds) }\end{array}$ \\
\hline 1. Ian & $3\left(2^{\prime} 66^{\prime \prime}\right)$ \\
2. Joanne & $8\left(21^{\prime} 58^{\prime \prime}\right)$ \\
3. Chris & $9\left(17^{\prime} 62^{\prime \prime}\right)$ \\
4. Tanya & $3\left(6^{\prime} 37^{\prime \prime}\right)$ \\
5. Rina & $1\left(3^{\prime} 41^{\prime \prime}\right)$ \\
\hline
\end{tabular}

The table of themes originating from Tinova (2015) study was used as a template in the present study. A revised template (summarised in Table 7) emerged when the original template was applied to the in-vivo transcripts in the current study. As shown in Table 7, three of the major themes were retained (in black font), one main theme and four subthemes were deleted (in red font) from the original template.. One new theme with two subthemes (in blue font) emerged exclusively from the new data.

\section{Contextual information}

All except Joanne's recordings, which were made at the rehabilitation unit, were made at home. The transcripts from short recordings contained rich information about participants' individual practice as they engaged with mindfulness. In accordance with the prompt sheet (Appendix 9), most participants described why they chose to do mindfulness and which mindfulness exercise they used (summarised in Table 8). 
Table 7: Revised template of Themes from interpreting the in-vivo recordings of current participants

\begin{tabular}{|c|c|c|}
\hline Theme & Subtheme & $\begin{array}{l}\text { Participants } \\
\text { contributing to } \\
\text { the themes from } \\
\text { the current study }\end{array}$ \\
\hline \multirow[t]{2}{*}{$\circ \quad$ Pain } & $\begin{array}{l}\text { - Acting as a body } \\
\text { force, which can be } \\
\text { dynamic }\end{array}$ & \\
\hline & $\begin{array}{l}\text { - Ways of dealing } \\
\text { with pain }\end{array}$ & Tanya, Rina \\
\hline \multirow[t]{3}{*}{$\begin{array}{l}\circ \text { Understanding/experiencing } \\
\text { Mindfulness }\end{array}$} & $\begin{array}{l}\text { - As a treatment } \\
\text { (similar to a pill) }\end{array}$ & Ian, Chris, Tanya \\
\hline & $\begin{array}{l}\text { - As a physical space, } \\
\text { a spiritual space or } \\
\text { "zone" }\end{array}$ & Joanne, Chris \\
\hline & $\begin{array}{l}\text { - A relaxation } \\
\text { technique }\end{array}$ & Joanne \\
\hline $\begin{array}{l}\circ \text { Mindfulness as a state which } \\
\text { has a distinct sensory quality }\end{array}$ & $\begin{array}{l}\text { - Sensations related to } \\
\text { pain } \\
-\quad \text { Sensations related to } \\
\text { mindfulness }\end{array}$ & \\
\hline \multirow[t]{3}{*}{$\begin{array}{l}\circ \text { Mindfulness as a source of } \\
\text { calmness and relaxation }\end{array}$} & $\begin{array}{l}\text { - Feeling calm and } \\
\text { relaxation }\end{array}$ & $\begin{array}{l}\text { Ian, Joanne, } \\
\text { Chris, Tanya, } \\
\text { Rina }\end{array}$ \\
\hline & $\begin{array}{l}\text { - Recharging of } \\
\text { batteries }\end{array}$ & Joanne \\
\hline & $\begin{array}{l}\text { - Relaxation as the } \\
\text { main ingredient of } \\
\text { mindfulness }\end{array}$ & \\
\hline \multirow[t]{2}{*}{$\begin{array}{l}\text { ○ Mindfulness as a source of } \\
\text { emotional regulation }\end{array}$} & - Taking a step back & $\begin{array}{l}\text { Joanne, Chris, } \\
\text { Tanya }\end{array}$ \\
\hline & $\begin{array}{l}\text { - Improving } \\
\text { mood/anxiety }\end{array}$ & Chris, Tanya \\
\hline
\end{tabular}

Note: Black font $=$ indicates themes/subthemes that have been retained in the current study from Tinova (2015) study; Red font = indicates deleted themes/subthemes from Tinova (2015) study; Blue font = indicates themes/subthemes emerging exclusively from the current participants' data. 
Table 8: Reasons given by participants for practicing mindfulness

\begin{tabular}{lll}
\hline \multicolumn{1}{c}{ Reasons } & \multicolumn{1}{c}{ Mindfulness exercise } \\
\hline$\circ$ To Relax or calm down & Visualisation exercise (Ian); focus \\
& on breathing (Joanne, Chris \& \\
& Tanya); focus on sound \& smell \\
& (Chris); eating meditation (Chris) \\
& Focus on breathing (Joanne, Chris \& \\
& Help with managing mood/anxiety & Tanya); Body scan (Chris) \\
& Focus on sound (Joanne); leaf \\
& To manage thoughts & exercise (Chris); focus on breathing \\
& (Tanya); Body Scan (Chris) \\
\hline To improve concentration & Focus on breathing (Ian) \\
\hline To keep self in the present & Focus on sound and leaf exercise \\
& (Joanne); focus on an object (Chris) \\
& Body scan and distraction techniques \\
\hline No help with sleep & (Tanya) \\
\hline
\end{tabular}

\section{Themes from in-vivo recordings}

Themes and subthemes derived from current participants based on the revised template are outlined below.

\section{Pain}

\section{- Ways of dealing with pain}

Two participants contributed to the overarching theme of pain. Tanya explained "I have just learnt that my body has these pains all the time, which also can bring on overwhelming emotions..." However, she went on to describe how mindfulness helped her cope with this:

"But, learning to do mindfulness is really helpful... Sometimes it's good if you just do things like, look out of the window, (pause)... just be aware of what's 
happening in your body...not the pain areas but may be other areas of your body just to be present, aware. And you can think of visually think that you are somewhere that's really nice and it all just helps. It helps you to understand and experience the condition and just got to tune into yourself and be in the present moment." (Tanya, AR- $4^{3}: 43$ )

On one level, Tanya seemed to be using mindfulness practice to be present in the moment by tuning into her internal experience of other areas of her body but she also appeared to be using mindfulness as a distraction technique.

\section{Understanding/experiencing Mindfulness}

\section{- As a treatment (similar to a pill)}

Similar to the previous study by Tinova (2015), Rina equated using mindfulness with taking medication to help her sleep:

"I'm trying to do it [mindfulness] before I go to bed at night-time... because it is helping me to sleep... and I don't need to take any painkillers at night time because this mindfulness is like taking all...like giving me energy" (Rina, AR-5: 22)

This was echoed by Chris who tried mindfulness like a medication when he was in a 'filthy mood': "I thought I'd see how it [mindfulness] works as a remedy. I have done mindfulness a few times now ... So, this was going to be the acid test of it."

\section{- As a physical space or "zone"}

This theme was also present in the current study. Joanne repeatedly described how she 'went straight back to it', 'coming back into the room' or 'coming back round'. In one of her recordings after practicing, Joanne reported: "So you're not dreaming but you're not fully awake, so that's why I say you go off with the fairies".

Here, the immediacy of these recordings allowed us to see how Joanne felt that she was not in 'the real world' anymore but in a different space. Similarly Chris

\footnotetext{
${ }^{3}$ AR-X refers to the focus group number
} 
said, "The next thing I know I was well into mindfulness". He also described how even time had a different quality:

"I thought it, you know would be 10-15 minutes or something. And the next thing I know [...] I didn't look at my clock or anything... my phone... and the next thing I know about 40 minutes had gone past." (Chris, AR-3: 137)

\section{- As another relaxation exercise}

One participant clearly thought of mindfulness as akin to a relaxation exercise (interestingly this also featured in the focus group interviews in the present study as part of participant's early understanding of mindfulness), e.g. Joanne: “just sat there breathing properly... listen to the birds on the tape and just relaxed". However, in her later recordings we could notice a shift in her view describing mindfulness not just a relaxation exercise but as learning to focus on the present moment: "I'm attending mindfulness to help me keep calm, keep in the moment...try to sort things out in my head".

\section{Mindfulness as a source of calmness and relaxation}

This theme related to how participants experienced mindfulness. All of the participants described experiencing calmness and relaxation after practicing mindfulness.

\section{- Feeling calm and relaxation}

Several participants described how their aim was to "achieve a sense of relaxation" from doing their practice and how this feeling can continue beyond that moment:

"And when I finish the mindfulness session after that I feel very lighter, relaxed...normally that day when I go home I have a good sleep, good nap good sleep that night after I do the mindfulness session." (Rina, AR-5: 15)

One participant seemed disappointed when he didn't achieve this: 
“Afterwards...I didn't achieve the sense of relaxation. My mind was ...too busy." (Ian, AR-1: 5)

\section{- Recharging of batteries}

Although only Joanne was the only person in the present study who contributed to this theme, she repeatedly mentioned stretching and feeling refreshed after her practice: “you just feel as though you've just woke up first thing in the morning when you have a nice long stretch [...]”.

\section{Mindfulness as a source of emotional regulation}

This emerged as a new theme with two subthemes.

\section{- Being able to take a step back}

Again echoing the focus groups, participants described noticing an increased ability to take an observer position rather than getting 'hooked' into unhelpful thoughts.

"[...] most days I get a negative thought but you have to think of it as a thought or a feeling and you've just got to think about it and move on. It is hard to do but it's something that I am learning to do. "(Tanya, AR-4: 20)

Above, Tanya seemed to allude to a 'de-centring' process, which is a core feature of MBCT emphasising to observe thoughts as simply thoughts (Segal et al., 2002).

\section{- Improvement in mood/anxiety}

In their individual recordings, participants described experiencing an improvement in emotional wellbeing there and then. Below, Chris portrayed this in one of his recordings:

"I was in a bit of a filthy mood. I have had a series of things going wrong in the evening. And I was stomping around the house calling myself every name under the sun. [...]". (Chris, AR-3: 152) 
Above, his intense frustration was quite palpable, and he later went on to report how mindfulness helped:

"And as soon as I started going into the routine of concentrating on my breathing...working my way through my body from my feet, my fingers [...]I felt the tension draining away from me... and eventually after about 20-25 minutes, [...] you know a good 60-70\% of that mood had gone away. And I felt much better and I had a good night sleep afterwards as well. [...] And my body just recognised what I was doing...body and mind ... all that sort of a thing. " (Chris, AR-3: 161)

Interestingly, his expression above 'my body just recognised' alluded to the embodiment of mindfulness practice, which has been noted in the literature when practice is consolidated (Kabat-Zinn, 2003).

\section{Discussion}

\section{Main findings}

The present study explored the experiences of people with ABI receiving mindfulness intervention. Focus group interviews and in-vivo recordings were utilised, each highlighting different aspects of participants' experiences. The focus group interviews provided rich information regarding their experiences of mindfulness training and being in the group whereas in-vivo recordings highlighted participants' unique experiences of individual practice.

Four superordinate themes emerged from an IPA of the focus group interviews with 14 participants. The first theme "Developmental learning process" captured the journey of participants from being initially sceptical to implementing mindfulness in their everyday lives. "Group as a supportive environment for learning” addressed participants' experiences of being in the group, noting a sense of belonging and a safe environment where they could learn mindfulness skills from each other. The third 
theme "Increased awareness" related to participants' experiences of noticing an increased awareness of their internal and external experiences. This theme also captured their changing relationship to themselves as expressed in terms of an increased level of self-compassion. The final theme "Benefits of mindfulness" illustrated the benefits of attending the group in terms of physical, emotional and cognitive domains.

The TA of in-vivo recordings retained three of the main themes from the template from Tinova’s (2015) study, "Pain”, “Understanding/Experiencing mindfulness" and "Mindfulness as a source of calmness and relaxation". A new theme of "Mindfulness as a source of emotional regulation" emerged from the current participants' recordings.

In the following section key findings derived from each type of data are discussed. The implications of combining these two types of data, methodological issues and implications for practice are then explored.

\section{Findings from focus groups}

Although most participants were initially sceptical about learning mindfulness, the subthemes "Mindfulness is a bit of a technique to get used to" and "It's become part of me" suggested that they eventually found it acceptable as a rehabilitation intervention. The scepticism found here, has similarities to the theme, "My desire to experience change in the face of initial uncertainties" identified in an IPA study by Williams et al., (2011). The latter also noted that their participants, who had severe health anxiety, felt sceptical initially which was related to their high expectations from the treatment (Williams et al., 2011). However, in the current study, the scepticism was either due to lack of knowledge about the intervention or comparing it with the relaxation group. Interestingly, participants even referred to 'testing it out' as 
if trying to prove it for themselves. It may be that future participants need more information about mindfulness and how it differs from relaxation before starting the group. Despite these initial difficulties, most participants developed a good understanding about mindfulness and were keen to learn and integrate the skill.

Participants' accounts of being in the group conveyed a sense of safeness, displaying the characteristics of mindfulness such as non-judgementalness and accepting attitudes. The group therefore became a facilitating environment where they could explore new ways of being. Participants highlighted the role of the group in reducing their isolation and helping them realise that they were 'not the only one'. This echoed findings of Smith et al. (2007), in which participants described meeting others "in the same boat" which helped them to normalise and validate their own experiences, a theme also identified in Mason \& Hargreaves, (2001) and Griffiths et al., (2009).

Although this study did not set out to explore the underlying mechanism of mindfulness, the theme of "Increased awareness" has been able to shed some light on this. Four subthemes revealed how an increased awareness of internal and external experiences facilitated the ability to recognise and break a pattern of unhelpful thoughts and/or emotions. The subtheme "Taking a step back" illustrated that mindfulness helped participants with managing impulsivity, which is a common consequence of ABI (Kocka \& Gagnon, 2014). It has been suggested that the cultivation of present-moment awareness and non-judgmental acceptance in mindfulness training promotes executive control because it facilitates increased sensitivity to internal affective cues (Teper, Segal, \& Inzlicht, 2013). These mechanisms have similarities with those proposed by Hölzel, et al. (2011), who suggested four interrelated components: attention regulation, body awareness, 
emotional regulation and change in perspective on the self. The subtheme "Increasing awareness of self-to-self relationship and increasing self-compassion" in the current study described an increased awareness of change in their relationship to themselves resonating with the 'change in perspective on the self' described by Hölzel et al. (2011). This shift in perspective has been termed as 'reperceiving' by Shapiro, Carlson, Astin and Freedman (2006). Reperceiving has been considered as a metamechanism of action that comes out of a natural developmental process facilitating transformation and positive outcomes in psychological symptoms (Shapiro et al., 2006).

Most participants in this study reported several benefits of practicing mindfulness exercises. Benefits such as improvement in sleep, pain, and a reduction in emotional distress have been noted in previous qualitative studies of MBIs in other clinical populations (Chadwick et al., 2008; Finucane \& Mercer, 2006; Mackenzie et al., 2007). However, unique to this study, participants themselves reported benefits in the cognitive domain, which is an important new finding. The improvement in various cognitive domains (e.g. attention, working memory and information processing speed) following MBI in people with ABI has also been noted by two of the quantitative studies reported above (Azulay et al., 2013; Johansson, Bjuhr, \& Rönnbäck, 2012). The emergence of this subtheme could be related to the importance that people with ABI place on improving cognitive impairment, which often impacts on return to work and social participation (Fish, et al., 2008). Some participants described possible underlying mechanisms for the improvement in cognitive functioning, i.e. learning to sustain attention and a reduction in 'mind wandering'. This resonates with the first component of Hölzel, et al. (2011) model, who considered successful attention regulation, in particular conflict monitoring 
(disregarding distractions), as a building block for participants to also benefit from the other mechanisms of mindfulness practice (Hölzel, et al., 2011).

The loss of 'sense of self' and grief in the context of ABI has been well documented in the literature (Carroll \& Coetzer, 2011; Nochi, 1998). In the present study, participants highlighted that some mindfulness exercises provided opportunities for taking time out to reflect on these aspects of their lives helping them to 'come to terms' with their losses. Interestingly, participants also reported an increased level of self-compassion even though the protocol did not specifically include any self-compassion exercises. It has been acknowledged that the enhancement of self-compassion partially mediates the relationship between mindfulness and well-being (Hollis-Walker \& Colosimo, 2011; Kuyken, et al., 2010). Perhaps, further cultivation of self-compassion by including specific exercises for this population might be helpful.

\section{Findings from in-vivo recordings}

The in-vivo recordings highlighted participants' experiences of using mindfulness in the context of their everyday life. Most of the expectations noted at the beginning of the recordings in this study were similar to those noted by Tinova (2015) although one participant specifically practiced mindfulness in order to improve his focus, which was not present in the previous study. This could be related to the participant's specific goal to get back to work.

In the previous study by Tinova (2015), several of the participants were suffering from chronic pain. As a result, the main themes of "Pain" and "Mindfulness as a state which has a distinct sensory quality" (which was often related to the change in pain sensations) emerged. One participant in the current study was experiencing 
pain and contributed to this theme, the latter theme however may not have emerged because of the absence of pain symptoms in most of the current sample.

A new theme of "Mindfulness as a source of emotional regulation" emerged in this study. One possible reason that it did not emerge in the previous study could be that current participants were more advanced in their practice as some had attended more than one mindfulness group. Hence, they were more able to take the observer's position emphasised in mindfulness training. Although the mindfulness group protocol did not include such aspects of $\mathrm{MBCT}$, the de-centring process evident in some participants' narratives may have arisen from the nonjudgmental observation that pain and anxiety-related thoughts may lead to the understanding that they are “just thoughts," rather than reflections of truth or reality (Baer, 2003).

\section{Significance of combining findings from focus groups and in-vivo recordings}

There were several areas of overlap between the themes derived from each type of data, thus confirming participants' experiences. For example, Joanne's understanding of mindfulness as 'relaxation exercise' in her early in-vivo recordings is similar to the comments made in focus groups by many participants under the subtheme of "overcoming initial scepticism" (also in part related to it being potentially just another relaxation technique). Thus the in-vivo recordings allowed us to see how the change of attitude came about as it was happening. Similarly, the subtheme of "Taking a step back" in focus groups is similar to "Being able to take a step back" in in-vivo recordings, both relating to taking an observer's position.

There are some aspects of immediate experience that were possibly only likely to emerge from the on-line approach that the in-vivo recordings offered. For example, we get a clearer picture of how participants view using mindfulness there 
and then, e.g. like taking a pill. Some very rich descriptions emerged through the very 'live' nature of recordings including their sense of it being 'a distinct physical space' and the resulting feeling of 'recharging'. Such experiences are less likely to emerge during retrospective accounts such as focus groups because they are not situated so definitely in the moment. It is also important to note that many people with ABI suffer from memory impairment (Mcallister, 2008), so the in-vivo recordings not only compensated for this but also captured their experiences in a very 'live' context.

\section{Strengths and limitations}

A unique aspect and one of the strengths of this study was to obtain a new perspective on participants' experiences of mindfulness by combining experiences gained retrospectively via the focus groups with the 'in-vivo' data. Most of the previous qualitative studies have focused only on experiences of being in a group, which potentially confounds practice, and the benefit of group processes. The in-vivo recordings allowed us to see how participants described what they were experiencing during mindfulness practice.

Another strength of this study was that the study recruited participants from several different mindfulness groups. Previous similar qualitative studies (Fitzpatrick et al., 2010; Griffiths et al., 2009; Mackenzie et al., 2007) interviewed participants drawn from only one mindfulness group and the experience of that particular group could therefore have been unique.

There were some limitations that should be kept in mind when considering the findings of this study. Firstly, four participants in this study took part in more than one focus group, thus these participants might have greater voice/contribution than others in the study. However, this is balanced by a major advantage i.e. it enabled us 
to see how attending another mindfulness group resulted in a change in attitude and skills development over time. This interesting and longitudinal perspective of their development would have otherwise been missed had these participants not been allowed to attend a second focus group discussion. Secondly, the views of participants who dropped-out of the mindfulness groups could be different, so we should be cautious about making assumptions about feasibility from the current study. Finally, although in-vivo recordings provided rich information about participants' experiences at the time some of these recordings were quite brief and one participant (Rina) only made one recording because she was admitted to hospital and had to drop out of the group.

\section{Future research}

The qualitative research in this area is sparse therefore more qualitative studies should be carried out perhaps also including the perspective of those who dropout of the mindfulness group. This will not only capture their unique experiences but may help to improve clinical practice by modifying the mindfulness protocol to suit their needs. In this study, most participants highlighted the benefits of mindfulness but it is difficult to establish which components of the training are effective i.e. is it related to practice or non-specific factors such as being in a group setting. Future studies with a quantitative methodology could be designed to determine whether group variables mediate outcome.

\section{Implications for clinical practice}

Overall, the findings of this study indicated that most participants found the mindfulness training acceptable and beneficial. Recommendations to improve future clinical practice are listed below.

○ Providing information leaflets about the mindfulness group, what it would involve and how it differs to relaxation. 
- Promoting the potential cognitive benefits of mindfulness for people with ABI could be an incentive to join the group.

○ Participants who lack insight into their condition may not be ready for an intervention that promotes acceptance. Therefore, the inclusion criteria for the group should be considered carefully.

- Based on the reasons cited above for using mindfulness, therapists in the rehabilitation service could prompt the use of mindfulness skills when they notice patients getting into difficulties e.g. when getting frustrated with themselves during difficult tasks or starting to worry/ruminate.

- Given participants reported a willingness to maintain their mindfulness practice, even after completing the group. The group facilitator could offer a top-up session after discharge and/or participants could be signposted to another local service that can help them to maintain their practice after they complete their rehabilitation journey.

○ There were a few participants who clearly benefited from attending a second mindfulness group suggesting perhaps that an eight-week program might be too short for people with ABI to consolidate learning due to cognitive and communication impairment; hence extending the mindfulness group might be more beneficial.

- The mindfulness group protocol could be modified to include concepts from MBCT (Segal et al., 2001), as most participants in this study seemed to struggle with negative thought patterns.

- Another modification to the protocol could be the inclusion of specific exercises promoting compassion as participants had clearly begun to do this naturally when they struggled with loss and grief following ABI. 


\section{Conclusion}

The present study explored how people with ABIs made sense of their experiences of attending the mindfulness group by using a combination of retrospective data collected through focus group interviews and 'in-vivo' data from short recordings. The themes resulting from focus groups fitted well with existing qualitative studies of MBIs in other clinical populations although the impact on cognition has not been documented previously in qualitative accounts. The findings suggested that majority of the participants in this study considered mindfulness beneficial in terms of helping them to cope with emotional and cognitive consequences of $\mathrm{ABI}$. The in-vivo recordings revealed rich descriptions that emerged through the very 'live' nature of recordings made by participants as soon as they finished the mindfulness practice and these both complemented and confirmed the focus group data. Although the intention of the study was to explore experience and not to clarify mechanisms by which mindfulness worked, this study did reveal some possible mechanisms for its benefit. This study has therefore contributed something novel to the existing evidence-base. 


\section{References}

Azulay, J., Smart, C. M., Mott, T., \& Cicerone, K. D. (2013). A pilot study examining the effect of mindfulness-based stress reduction on symptoms of chronic mild traumatic brain injury/postconcussive syndrome. The Journal of Head Trauma Rehabilitation, 28(4), 323-331.

Baer, R. A. (2003). Mindfulness training as a clinical intervention: A conceptual and empirical review. Clinical Psychology: Science and Practice, 10(2), 125-143.

Bédard, M., Felteau, M., Marshall, S., Cullen, N., Gibbons, C., Dubois, S., ... Rees, L. (2014). Mindfulness-based cognitive therapy reduces symptoms of depression in people with a traumatic brain injury: results from a randomized controlled trial. The Journal of Head Trauma Rehabilitation, 29(4), 13-22.

Bédard, M., Felteau, M., Mazmanian, D., Fedyk, K., Klein, R., Richardson, J., ... Minthorn-Biggs, M.B. (2003). Pilot evaluation of a mindfulness-based intervention to improve quality of life among individuals who sustained traumatic brain injuries. Disability and Rehabilitation, 25(13), 722-731.

Brooks, J., McCluskey, S., Turley, E., \& King, N. (2015). The Utility of Template Analysis in Qualitative Psychology Research. Qualitative Research in Psychology, 12(2), 202-222.

Carroll, E., \& Coetzer, R. (2011). Identity, grief and self-awareness after traumatic brain injury. Neuropsychological Rehabilitation, 21(3), 289-305.

Chadwick, P., Newell, T., \& Skinner, C. (2008). Mindfulness groups in palliative care: a pilot qualitative study. Spirituality and Health International, 9(3), 135144. 
Chiesa, A., \& Serretti, A. (2010). A systematic review of neurobiological and clinical features of mindfulness meditations. Psychological Medicine, 40(8), 12391252.

Cicerone, K. D. (1989). Psychotherapeutic interventions with traumatically braininjured patients. Rehabilitation Psychology, 34(2), 105-114.

Cicerone, K. D. (2004). Participation as an outcome of traumatic brain injury rehabilitation. The Journal of Head Trauma Rehabilitation, 19(6), 494-501.

Deb, S., Lyons, I., Koutzoukis, C., Ali, I., \& McCarthy, G. (1999). Rate of Psychiatric Illness 1 Year After Traumatic Brain Injury. American Journal of Psychiatry, 156(3), 374-378.

Dennick, L., Fox, A. P., \& Walter-Brice, A. (2013). Mindfulness groups for people experiencing distressing psychosis: An interpretative phenomenological analysis. Mental Health Review Journal, 18(1), 32-43.

Dunkley, C., \& Stanton, M. (2014). Teaching Clients to Use Mindfulness Skills: a Practical Guide. London, England and New York, NY: Routledge.

Elliott, R., Fischer, C. T. \& Rennie, D. L. (1999). Evolving guidelines for publication of qualitative research studies in psychology and related fields. British Journal of Clinical Psychology, 38, 215-229.

Finucane, A., \& Mercer, S. W. (2006). An exploratory mixed methods study of the acceptability and effectiveness of mindfulness-based cognitive therapy for patients with active depression and anxiety in primary care. BMC Psychiatry, $6(1), 14$.

Fish, J., Manly, T., Emslie, H., Evans, J. J., \& Wilson, B. A. (2008). Compensatory strategies for acquired disorders of memory and planning: differential effects of a paging system for patients with brain injury of traumatic versus 
cerebrovascular aetiology. Journal of Neurology, Neurosurgery \& Psychiatry, 79(8), 930-935.

Fitzpatrick, L., Simpson, J., \& Smith, A. (2010). A qualitative analysis of mindfulness-based cognitive therapy (MBCT) in Parkinson's disease. Psychology and Psychotherapy: Theory, Research and Practice, 83(2), 179192.

Flowers, P., Duncan, B., \& Frankis, J. (2000). Community, responsibility and culpability: HIV risk-management amongst Scottish gay men. Journal of Community \& Applied Social Psychology, 10(4), 285-300.

Flowers, P., Knussen, C., \& Duncan, B. (2001). Re-appraising HIV testing among Scottish gay men: The impact of new HIV treatments. Journal of Health Psychology, 6(6), 665-678.

Gard, T., Hölzel, B. K., \& Lazar, S. W. (2014). The potential effects of meditation on age-related cognitive decline: a systematic review. Annals of the New York Academy of Sciences, 1307(1), 89-103.

Griffiths, K., Camic, P. M., \& Hutton, J. (2009). Participant experiences of a mindfulness-based cognitive therapy group for cardiac rehabilitation. Journal of Health Psychology, 14(5), 675-681.

Hayes, S.C., Strosahl, K., \& Wilson, K. (1999). Acceptance and Commitment Therapy: An experiential approach to behaviour change. New York, NY: Guilford Press.

Headway. (2017). Key Facts and Statistics. Retrieved March 9, 2017, from https://www.headway.org.uk/About-Brain-Injury.aspx 
Hollis-Walker, L., \& Colosimo, K. (2011). Mindfulness, self-compassion, and happiness in non-meditators: A theoretical and empirical examination. Personality and Individual Differences, 50, 222-227

Hölzel, B. K., Lazar, S. W., Gard, T., Schuman-Olivier, Z., Vago, D. R., \& Ott, U. (2011). How Does Mindfulness Meditation Work? Proposing Mechanisms of Action From a Conceptual and Neural Perspective. Perspectives on Psychological Science, 6(6), 537-559.

Hurlburt, R. T., \& Akhter, S. A. (2006). The descriptive experience sampling method. Phenomenology and the Cognitive Sciences, 5(3-4), 271-301.

Johansson, B., Bjuhr, H., \& Rönnbäck, L. (2012). Mindfulness-based stress reduction (MBSR) improves long-term mental fatigue after stroke or traumatic brain injury. Brain Injury, 26(13-14), 1621-1628.

Kabat-Zinn, J. (1982). An outpatient program in behavioral medicine for chronic pain patients based on the practice of mindfulness meditation: Theoretical considerations and preliminary results. General hospital psychiatry, 4(1), 3347.

Kabat-Zinn, J. (2003). Mindfulness-based interventions in context: past, present, and future. Clinical Psychology: Science and Practice, 10(2), 144-156.

Kabat-Zinn, J. (2013). Full catastrophe living, revised edition: how to cope with stress, pain and illness using mindfulness meditation. Hachette UK.

Kabat-Zinn, J., Wheeler, E., Light, T., Skillings, A., Scharf, M. J., Cropley, T. G., ... Bernhard, J. D. (1998). Influence of a mindfulness meditation-based stress reduction intervention on rates of skin clearing in patients with moderate to 
severe psoriasis undergoing photo therapy (UVB) and photochemotherapy (PUVA). Psychosomatic Medicine, 60(5), 625-632.

Kazdin, A. E. (2008). Evidence-based treatment and practice: new opportunities to bridge clinical research and practice, enhance the knowledge base, and improve patient care. American psychologist, 63(3), 146.

Keng, S.L., Smoski, M. J., \& Robins, C. J. (2011). Effects of mindfulness on psychological health: A review of empirical studies. Clinical Psychology Review, 31(6), 1041-1056.

King, N., Carroll, C., Newton, P., \& Dornan, T. (2002). "You can’t Cure it so you have to Endure it": The Experience of Adaptation to Diabetic Renal Disease. Qualitative Health Research, 12(3), 329-346.

Kocka, A., \& Gagnon, J. (2014). Definition of Impulsivity and Related Terms Following Traumatic Brain Injury: A Review of the Different Concepts and Measures Used to Assess Impulsivity, Disinhibition and other Related Concepts. Behavioral Sciences, 4(4), 352-370.

Kuyken, W., Watkins, E., Holden, E., White, K., Taylor, R. S., Byford, S., . . . Dalgleish, T. (2010). How does mindfulness-based cognitive therapy work? Behaviour Research and Therapy, 48, 1105-1112.

Linehan, M. (1993). Cognitive Behavioral Treatment of Borderline Personality Disorder (1st ed.). New York: Guilford Press.

Mackenzie, M. J., Carlson, L. E., Munoz, M., \& Speca, M. (2007). A qualitative study of self-perceived effects of mindfulness-based stress reduction (MBSR) in a psychosocial oncology setting. Stress and Health, 23(1), 59-69. 
Marlatt, G. A., \& Kristeller, J. L. (1999). Mindfulness and meditation. In W. R. Miller (Ed.), Integrating spirituality into treatment (pp. 67-84). Washington, DC: American Psychological Association.

Mason, O., \& Hargreaves, I. (2001). A qualitative study of mindfulness-based cognitive therapy for depression. British Journal of Medical Psychology, 74(2), 197-212.

Mcallister, T. W. (2008). Neurobehavioral sequelae of traumatic brain injury: evaluation and management. World Psychiatry, 7(1), 3-10. Retrieved from

McMillan, T., Robertson, I. H., Brock, D., \& Chorlton, L. (2002). Brief mindfulness training for attentional problems after traumatic brain injury: A randomised control treatment trial. Neuropsychological Rehabilitation, 12(2), 117-125.

Morton, M., \& Wehman, P. (1995). Psychosocial and emotional sequelae of individuals with traumatic brain injury: a literature review and recommendations. Brain Injury, 9(1), 81-92.

Nochi, M. (1998). "Loss of self” in the narratives of people with traumatic brain injuries: A qualitative analysis. Social Science \& Medicine, 46(7), 869-878.

Palmer, M., Larkin, M., de Visser, R., \& Fadden, G. (2010). Developing an interpretative phenomenological approach to focus group data. Qualitative Research in Psychology, 7(2), 99-121.

Rabinowitz, A. R., \& Levin, H. S. (2014). Cognitive Sequelae of Traumatic Brain Injury. The Psychiatric Clinics of North America, 37(1), 1.

Schroevers, M. J., \& Brandsma, R. (2010). Is learning mindfulness associated with improved affect after mindfulness-based cognitive therapy? British Journal of Psychology, 101(1), 95-107. 
Seel, R. T., Kreutzer, J. S., Rosenthal, M., Hammond, F. M., Corrigan, J. D., \& Black, K. (2003). Depression after traumatic brain injury: a National Institute on Disability and Rehabilitation Research Model Systems multicenter investigation. Archives of Physical Medicine and Rehabilitation, 84(2), 177184.

Segal, Z.V., Williams, J.M.G., \& Teasdale, J.D. (2002). Mindfulness-based cognitive therapy for depression: a new approach to preventing relapse. New York: Guilford Press.

Shapiro, S. L., Carlson, L. E., Astin, J. A., \& Freedman, B. (2006). Mechanisms of mindfulness. Journal of clinical psychology, 62(3), 373-386.

Smith, A., Grahman, L., \& Senthinathan, S. (2007). Mindfulness- based cognitive therapy for recurring depression in older people: a qualitative study. Aging and Mental Health, 11(3), 346-357.

Smith, J., Flowers, P., \& Larkin, M. (2009). Interpretative Phenomenological Analysis: Theory, Method and Research. London: Sage.

Teasdale J. D., Moore R. G., Hayhurst H., Pope M., Williams S., Segal Z. V. (2002). Metacognitive awareness and prevention of relapse in depression: empirical evidence. Journal of Consulting and Clinical Psychology, 70(2), 275-287.

Teper, R., Segal, Z. V., \& Inzlicht, M. (2013). Inside the Mindful Mind. Current Directions in Psychological Science, 22(6), 449-454.

Tinova, M. (2015). Mindfulness, neurobehavioural functioning and sleep. Unpublished Doctorate of Clinical Psychology thesis. University of Birmingham. 
Turner-Stokes, L., Williams, H., \& Abraham, R. (2001). Clinical standards for specialist community rehabilitation services in the UK. Clinical Rehabilitation, 15(6), 611-623.

Williams, M. J., McManus, F., Muse, K., \& Williams, J. M. G. (2011). Mindfulnessbased cognitive therapy for severe health anxiety (hypochondriasis): An interpretative phenomenological analysis of patients' experiences. British Journal of Clinical Psychology, 50(4), 379-397.

Yardley, L. (2000). Dilemmas in qualitative health research. Psychology and Health, $15,215-228$. 


\title{
Public Domain Briefing Paper
}

\section{A qualitative study exploring the experiences of mindfulness training in people with acquired brain injury}

\author{
Shruti Niraj
}

\section{Overview}

This research was carried out by Shruti Niraj as Partial Fulfilment of the Regulations for the degree of Doctor of Clinical Psychology at the University of Birmingham.

\section{Background}

Mindfulness has been described as paying non-judgmental attention to the present moment, which can be developed through meditation (Baer, 2003). Although the concept of mindfulness has its origin in ancient Buddhist traditions, Jon KabatZinn started to explore it's use in treating patients with long-term health conditions (Kabat-Zinn, 1982). Since then, a number of studies have shown that mindfulnessbased interventions (MBIs) can be effective in improving mood ( Hofmann, Sawyer, Witt, \& Oh, 2010) and coping with long-term health problems (Bohlmeijer, Prenger, Taal, \& Cuijpers, 2010). Research has also shown that MBIs can improve cognitive performance in both healthy individuals and those with age-related cognitive problems (Chiesa \& Serretti, 2010; Gard, Hölzel, \& Lazar, 2014).

Recently, there has been an increased interest in using MBIs in brain injury rehabilitation. So far, only a few studies have evaluated the role of MBIs in patients with acquired brain injury (ABI) (Azulay, Smart, Mott, \& Cicerone, 2013; Bedard et al., 2003; Bédard et al., 2014; Johansson, Bjuhr, \& Rönnbäck, 2012; McMillan, Robertson, Brock, \& Chorlton, 2002). Though the results are promising but due to various limitations of these studies, it is difficult to draw firm conclusions about the 
effectiveness of MBIs in this area. These studies have focused only on quantitative outcomes (e.g. improvement in scores on a mood questionnaire), leaving the personal experiences of people with $\mathrm{ABI}$ receiving mindfulness training unexplored.

Personal experiences of individuals can be explored using a qualitative research design. So far, only one study has explored experiences of individuals with $\mathrm{ABI}$ receiving $\mathrm{MBI}$. By using an innovative method (asking people to audio record their experiences of using mindfulness as soon as they practiced it), this study captured rich 'live' experiences of how and when people were using mindfulness (Tinova, 2015). However, this study was part of a mixed-methods approach and included only four participants. Therefore, extending this study may enhance our understanding of people's experiences further.

\section{Details of the study}

\section{Aims}

The current study extended the qualitative part study by Tinova (2015) in two ways, i.e. by asking more people to audio record their experiences of using mindfulness and also interviewing people in a focus group about their experiences of mindfulness group. The main aim of this study was to understand how people with $\mathrm{ABI}$ made sense of their experiences of learning and practicing mindfulness skills and how they described their experience when they carried out mindfulness in their dayto-day lives.

\section{Method}

Participants were recruited from a mindfulness group at a local brain injury rehabilitation unit where a clinical psychologist (who is one of the collaborators in this study) ran a mindfulness group for people with ABI. The researcher approached 
potential participants once they showed an interest in taking part and took their written consent. Consequently, 15 participants with $\mathrm{ABI}$ took part in this study.

\section{Summary of findings}

Focus groups

Qualitative analysis of focus group interviews identified four main themes.

The first theme, "Developmental learning process" described participants' journey of learning and applying mindfulness in everyday lives. The second theme, "Group as a supportive environment for learning" explained how participants felt a sense of belonging in the group where they could learn mindfulness skills from each other. Participants noticed that they had become more aware of their surroundings and bodily sensations in the third theme "Increased awareness", which might have helped them to recognise and break a cycle of unhelpful thoughts. Participants also described developing a more kindly attitude towards themselves. In the final theme "Benefits of mindfulness" participants reported several benefits after attending the group, such as improvement in their sleep, concentration and mood.

\section{Audio recordings}

The qualitative analysis of audio recordings also identified four themes: "Pain", "Understanding/Experiencing mindfulness", "Mindfulness as a source of calmness and relaxation" and "Mindfulness as a source of emotional regulation".

\section{Evaluation and recommendations}

The results of this study suggested that majority of the participants found mindfulness beneficial in terms of helping them to cope with the emotional and cognitive effects of ABI. A unique feature of this study was to combine the two types of data, each bringing a new perspective on participants' experiences of mindfulness. The audio recordings allowed us to see how participants described what they were 
experiencing during the mindfulness practice as they experienced it at the time. The focus groups revealed how participants felt about the mindfulness training and being in the group.

The study has a few limitations that should be kept in mind while considering the results. For example, a few audio recordings were brief and the perspective of participants who dropped-out of the mindfulness groups were not taken into account.

Recommendations that may improve future clinical practice include:

1. Providing information leaflets on mindfulness and how it differs from relaxation sessions.

2. Facilitating participants to think about how they can maintain mindfulness practice in their daily lives.

3. Including specific exercises promoting self-compassion to help participants cope with the loss and grief following ABI. 


\section{References}

Azulay, J., Smart, C. M., Mott, T., \& Cicerone, K. D. (2013). A pilot study examining the effect of mindfulness-based stress reduction on symptoms of chronic mild traumatic brain injury/postconcussive syndrome. The Journal of Head Trauma Rehabilitation, 28(4), 323-331.

Baer, R. A. (2003). Mindfulness training as a clinical intervention: A conceptual and empirical review. Clinical Psychology: Science and Practice, 10(2), 125-143.

Bédard, M., Felteau, M., Marshall, S., Cullen, N., Gibbons, C., Dubois, S., ... Rees, L. (2014). Mindfulness-based cognitive therapy reduces symptoms of depression in people with a traumatic brain injury: results from a randomized controlled trial. The Journal of Head Trauma Rehabilitation, 29(4), E13-E22.

Bedard, M., Felteau, M., Mazmanian, D., Fedyk, K., Klein, R., Richardson, J., ... Minthorn-Biggs, M.B. (2003). Pilot evaluation of a mindfulness-based intervention to improve quality of life among individuals who sustained traumatic brain injuries. Disability and Rehabilitation, 25(13), 722-731.

Bohlmeijer, E., Prenger, R., Taal, E., \& Cuijpers, P. (2010). The effects of mindfulness-based stress reduction therapy on mental health of adults with a chronic medical disease: a meta-analysis. Journal of Psychosomatic Research, $68(6), 539-544$.

Chiesa, A., \& Serretti, A. (2010). A systematic review of neurobiological and clinical features of mindfulness meditations. Psychological Medicine, 40(8), 1239 1252.

Gard, T., Hölzel, B. K., \& Lazar, S. W. (2014). The potential effects of meditation on age-related cognitive decline: a systematic review. Annals of the New York Academy of Sciences, 1307(1), 89-103. 
Hofmann, S. G., Sawyer, A. T., Witt, A. A., \& Oh, D. (2010). The effect of mindfulness-based therapy on anxiety and depression: A meta-analytic review. Journal of Consulting and Clinical Psychology, 78(2), 169.

Johansson, B., Bjuhr, H., \& Rönnbäck, L. (2012). Mindfulness-based stress reduction (MBSR) improves long-term mental fatigue after stroke or traumatic brain injury. Brain Injury, 26(13-14), 1621-1628.

Kabat-Zinn, J. (1982). An outpatient program in behavioral medicine for chronic pain patients based on the practice of mindfulness meditation: Theoretical considerations and preliminary results. General Hospital Psychiatry, 4(1), 3347.

McMillan, T., Robertson, I. H., Brock, D., \& Chorlton, L. (2002). Brief mindfulness training for attentional problems after traumatic brain injury: A randomised control treatment trial. Neuropsychological Rehabilitation, 12(2), 117-125.

Tinova, M. (2015). Mindfulness, neurobehavioural functioning and sleep. Unpublished Doctorate of Clinical Psychology thesis. University of Birmingham. 
Appendices - Literature review 


\section{Appendix 1. Search Strategy}

1. mindful*.mp. [mp=title, abstract, heading word, drug trade name, original title, device manufacturer, drug manufacturer, device trade name, keyword]

2. meditation\$.mp. [mp=title, abstract, heading word, drug trade name, original title, device manufacturer, drug manufacturer, device trade name, keyword]

3. "mindfulness based interventions".mp. [mp=title, abstract, heading word, drug trade name, original title, device manufacturer, drug manufacturer, device trade name, keyword]

4. "mindfulness based stress reduction\$".mp. [mp=title, abstract, heading word, drug trade name, original title, device manufacturer, drug manufacturer, device trade name, keyword]

5. "mindfulness based cognitive therap*".mp. [mp=title, abstract, heading word, drug trade name, original title, device manufacturer, drug manufacturer, device trade name, keyword]

6. "mindfulness based therap*".mp. [mp=title, abstract, heading word, drug trade name, original title, device manufacturer, drug manufacturer, device trade name, keyword]

7. "mindful* train*".mp. [mp=title, abstract, heading word, drug trade name, original title, device manufacturer, drug manufacturer, device trade name, keyword]

8. \$meditation.mp. [mp=title, abstract, heading word, drug trade name, original title, device manufacturer, drug manufacturer, device trade name, keyword]

9. ("breathing exercise\$" or "breathing technique\$" or mindful\$ or meditat\$ or relaxation or vipassana or yog\$).mp. [mp=title, abstract, heading word, drug trade name, original title, device manufacturer, drug manufacturer, device trade name, keyword]

10. 1 or 2 or 3 or 4 or 5 or 6 or 7 or 8 or 9

11. neurodegenerative dis $\$ . \mathrm{mp}$. [mp=title, abstract, heading word, drug trade name, original title, device manufacturer, drug manufacturer, device trade name, keyword]

12. ("neurodegeneration" or "neurodegenerative disease" or "neurodegenerative disorders" or "progressive neurodegenerative dis\$").mp. [mp=title, abstract, heading word, drug trade name, original title, device manufacturer, drug manufacturer, device trade name, keyword]

13. exp multiple sclerosis/ or exp multiple sclerosis, chronic progressive/ or exp multiple sclerosis, relapsin-remitting/ or exp neuromyelitis optica/

14. ("disseminated sclerosis" or "demyelinating disease" or devic or "acute disseminated encephalomyelitis" or "multiple sclerosis" or "neuromyelitis optica" or "optic neuritis" or "transverse myelitis").mp.

15. Huntington* disease.mp. [mp=title, abstract, heading word, drug trade name, original title, device manufacturer, drug manufacturer, device trade name, keyword]

16. huntington's disease.mp. [mp=title, abstract, heading word, drug trade name, 
original title, device manufacturer, drug manufacturer, device trade name, keyword]

17. ("Huntington's disease" or "Huntington chorea" or "huntington disease").mp.

18. exp alzheimer's disease/ or exp dementia, senile dementia/ or exp alzheimers disease/

19. ("alzheimer's disease" or "alzheimers disease" or "\$dementia" or "dementia\$" or "mild cognitive impairment" or "MCI" or "cognitive decline").mp. $[\mathrm{mp}=$ title, abstract, heading word, drug trade name, original title, device manufacturer, drug manufacturer, device trade name, keyword]

20. exp motor neurone disease/ or exp MND/ or motor neuron dieasese.mp. $[\mathrm{mp}=$ title, abstract, heading word, drug trade name, original title, device manufacturer, drug manufacturer, device trade name, keyword]

21. (Amyotrophic Lateral Sclerosis or ALS).mp. [mp=title, abstract, heading word, drug trade name, original title, device manufacturer, drug manufacturer, device trade name, keyword]

22. exp amyotrophic Lateral Sclerosis/ or exp ALS/

23. exp parkinson's disease/ or exp parkinsons disease/ or exp parkinsonims/

24. ("parkinson's disease" or "parkinsons disease" or "parkinsonism").mp. [mp=title, abstract, heading word, drug trade name, original title, device manufacturer, drug manufacturer, device trade name, keyword]

25.11 or 12 or 13 or 14 or 15 or 16 or 17 or 18 or 19 or 20 or 21 or 22 or 23 or 24

26. 10 and 24

27. limit 25 to (human and english language)

28. limit 26 to (adult $<18$ to 64 years $>$ or aged $<65+$ years $>$ ) 


\section{Appendix 2. NICE quality framework (Revised version)}

\section{Section 1: Population}

1.1 Is the source population/area well described?

1.2 Is the eligible population representative of the source population?

1.3 Do the selected participants represent the eligible population?

\section{Section 2: Method of allocation to intervention (or comparison)}

2.1 Allocation to intervention (comparison)/How was Selection bias minimised?

2.2 Were Intervention/Comparison well-described and appropriate?

2.3 Was the allocation concealed?

2.4 Were participants or investigators blind to exposure and comparison?

2.5 Was the exposure to the intervention and comparison adequate?

2.6 Was contamination acceptably low?

2.7 Were other interventions similar in both groups?

2.8 Were all participants accounted for at study conclusion?

2.9 Did the setting reflect usual UK Practice?

2.10 Did the intervention or control comparison reflect usual UK practice?

\section{Section 3: Outcomes}

3.1 Were outcome measures reliable?

3.2 Were all outcome measurements complete?

3.3 Were all-important outcomes assessed?

3.4 Were outcomes relevant?

3.5 Was Mindfulness measure included?

3.6 Was Home practice monitored?

3.7 Were there similar follow-up times in exposure and comparison groups?

3.8 Was Follow-up time meaningful?

\section{Section 4: Analyses}

4.1 Were EXP CTL groups similar at baseline? If not, were these adjusted?

4.2 Was Intention to treat analysis conducted?

4.3 Was Power calculated?

4.4 Were the estimates of Effect-size given/calculable?

4.5 Were the analytical methods appropriate?

4.6 Was the precision of intervention effects given or calculable? Were they meaningful?

\section{Section 5: Summary}

\subsection{Are the study results internally valid (i.e. unbiased)?}

How well did the study minimise sources of bias (i.e. adjusting for potential confounders)?

Were there significant flaws in the study design?

\subsection{Are the findings generalisable to the source population (i.e. externally} valid)?

Are there sufficient details given about the study to determine if the findings are generalisable to the source population? Consider: participants, interventions and comparisons, outcomes, resource and policy implications. 
Checklist items are worded so that 1 of 5 responses is possible:

\begin{tabular}{|l|l|}
\hline++ & $\begin{array}{l}\text { Indicates that for that particular aspect of study design, the study has } \\
\text { been designed or conducted in such a way as to minimise the risk of } \\
\text { bias. }\end{array}$ \\
\hline+ & $\begin{array}{l}\text { Indicates that either the answer to the checklist question is not clear } \\
\text { from the way the study is reported, or that the study may not have } \\
\text { addressed all potential sources of bias for that particular aspect of } \\
\text { study design. }\end{array}$ \\
\hline- & $\begin{array}{l}\text { Should be reserved for those aspects of the study design in which } \\
\text { significant sources of bias may persist. }\end{array}$ \\
\hline $\begin{array}{l}\text { Not } \\
\text { reported } \\
\text { (NR) }\end{array}$ & $\begin{array}{l}\text { Should be reserved for those aspects in which the study under review } \\
\text { fails to report how they have (or might have) been considered. }\end{array}$ \\
\hline $\begin{array}{l}\text { Not } \\
\text { applicable } \\
\text { (NA) }\end{array}$ & $\begin{array}{l}\text { Should be reserved for those study design aspects that are not } \\
\text { applicable given the study design under review (for example, } \\
\text { allocation concealment would not be applicable for case control } \\
\text { studies). }\end{array}$ \\
\hline
\end{tabular}

Note. (Adapted from NICE GATE framework; retrieved from https://www.nice.org.uk/process/pmg4/chapter/appendix-f-quality-appraisalchecklist-quantitative-intervention-studies) 
Appendix 3. Results of the outcome measures used in the studies

\begin{tabular}{|c|c|c|c|c|c|c|c|c|c|c|c|c|c|c|}
\hline Study author & $\begin{array}{l}\text { Type of } \\
\text { NDD }\end{array}$ & $\begin{array}{l}\text { Quality } \\
\text { rating }\end{array}$ & Anxiety & Depression & Stress & Behavioural & Cognition & $\begin{array}{l}\text { Quality } \\
\text { of life }\end{array}$ & $\begin{array}{l}\text { Psychological } \\
\text { well-being }\end{array}$ & Sleep & Fatigue & Pain & $\begin{array}{l}\text { Disease- } \\
\text { specific } \\
\text { physical } \\
\text { health }\end{array}$ & $\begin{array}{l}\text { Mindfulness } \\
\text { measure }\end{array}$ \\
\hline \multirow{2}{*}{$\begin{array}{l}\text { Amiri et al. } \\
(2016)\end{array}$} & \multirow[t]{2}{*}{ MS } & $\mathrm{IV}=\mathrm{A}$ & \multirow[b]{2}{*}{$\downarrow$} & \multirow[b]{2}{*}{$\downarrow$} & \multirow[b]{2}{*}{ - } & \multirow[b]{2}{*}{ - } & \multirow[b]{2}{*}{$\mathrm{x}$} & \multirow[b]{2}{*}{ - } & \multirow[b]{2}{*}{ - } & \multirow[b]{2}{*}{ - } & \multirow[b]{2}{*}{ - } & \multirow[b]{2}{*}{ - } & \multirow[b]{2}{*}{ - } & \multirow[b]{2}{*}{ - } \\
\hline & & $E V=R$ & & & & & & & & & & & & \\
\hline \multirow{2}{*}{$\begin{array}{l}\text { Bogosian et } \\
\text { al. (2015) }\end{array}$} & \multirow[t]{2}{*}{ MS } & $I V=G$ & \multirow[b]{2}{*}{$\downarrow$} & \multirow[b]{2}{*}{$\downarrow$} & \multirow[b]{2}{*}{ - } & \multirow[b]{2}{*}{ - } & \multirow[b]{2}{*}{ - } & \multirow[b]{2}{*}{$\mathrm{x}$} & \multirow[b]{2}{*}{ - } & \multirow[b]{2}{*}{ - } & \multirow[b]{2}{*}{ - } & \multirow[b]{2}{*}{$\mathrm{x}$} & \multirow[b]{2}{*}{$\mathrm{x}$} & \multirow[b]{2}{*}{ - } \\
\hline & & $E V=A$ & & & & & & & & & & & & \\
\hline \multirow{2}{*}{$\begin{array}{l}\text { Grossman et } \\
\text { al. }(2010)\end{array}$} & \multirow[t]{2}{*}{ MS } & $\mathrm{IV}=\mathrm{G}$ & & & & & & & & & & & & \\
\hline & & $E V=A$ & $\downarrow$ & $\downarrow$ & - & - & - & $\uparrow$ & - & - & $\downarrow$ & - & - & - \\
\hline Kolahkaj \& & MS & $\mathrm{IV}=\mathrm{A}$ & & & & & & & & & & & & \\
\hline $\begin{array}{l}\text { Zargar } \\
(2015)\end{array}$ & & $\mathrm{EV}=\mathrm{R}$ & $\downarrow$ & $\downarrow$ & $\downarrow$ & - & - & - & - & - & - & - & - & - \\
\hline Cash et al. & PD & $\mathrm{IV}=\mathrm{A}$ & & & & & & & & & & & & \\
\hline (2016) & & $E V=R$ & No data & $\downarrow$ & - & - & $\uparrow$ & $\mathrm{x}$ & - & - & - & - & $\mathrm{x}$ & - \\
\hline Dissanayaka & PD & $\mathrm{IV}=\mathrm{R}$ & & & & & & & & & & & & \\
\hline et al. (2016) & & $E V=R$ & $\downarrow$ & $\downarrow$ & - & - & $\uparrow$ & $\uparrow$ & $\mathrm{x}$ & & & & $\mathrm{x}$ & \\
\hline Pickut et al. & PD & $\mathrm{IV}=\mathrm{A}$ & & & & & & & & & & & & \\
\hline & & $E V=R$ & - & $\mathrm{x}$ & - & - & - & $\mathrm{x}$ & - & - & - & - & $\uparrow$ & $\uparrow$ \\
\hline $\begin{array}{l}\text { Lantz et al. } \\
\text { (1997) }\end{array}$ & $\begin{array}{l}\text { Dementia } \\
\text { /MCI }\end{array}$ & $\begin{array}{l}I V=R \\
E V=R\end{array}$ & - & - & - & $\downarrow$ & - & - & - & - & - & - & - & - \\
\hline Litherland \& & Dementia & $\mathrm{IV}=\mathrm{R}$ & & & & & & & & & & & & \\
\hline $\begin{array}{l}\text { Robertson } \\
\text { (2014) }\end{array}$ & /MCI & $E V=R$ & - & - & - & - & - & - & $\mathrm{x}$ & - & - & - & - & - \\
\hline $\begin{array}{l}\text { Paller et al. } \\
(2015)\end{array}$ & $\begin{array}{l}\text { Dementia } \\
\text { /MCI }\end{array}$ & $\begin{array}{l}\mathrm{IV}=\mathrm{R} \\
\mathrm{EV}=\mathrm{A}\end{array}$ & $\mathrm{x}$ & $\downarrow$ & - & - & $\mathrm{x}$ & $\uparrow$ & - & $\mathrm{x}$ & - & - & - & - \\
\hline Wells et al. & Dementia & $\mathrm{IV}=\mathrm{A}$ & & & & & & & & & & & & \\
\hline $\begin{array}{l}\text { (2013a; } \\
\text { 2013b) }\end{array}$ & $/ \mathrm{MCI}$ & $E V=R$ & - & $\mathrm{x}$ & $\mathrm{x}$ & - & $\mathrm{x}$ & $\mathrm{x}$ & - & - & - & - & - & $\mathrm{x}$ \\
\hline Quintana- & Dementia & $\mathrm{IV}=\mathrm{G}$ & & & & & & & & & & & & \\
\hline $\begin{array}{l}\text { Hernandez et } \\
\text { al. (2016) }\end{array}$ & /MCI & $E V=A$ & - & - & - & - & $\uparrow$ & - & - & - & - & - & - & - \\
\hline
\end{tabular}

Note. $\boldsymbol{\uparrow}=$ Significant improvement; $\boldsymbol{\Downarrow}=$ Significant reduction; $\mathbf{X}=$ No change; $-=$ Not available; IV=Internal Validity;

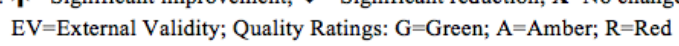


Appendices - Empirical Paper 
Appendix 1. Local Research Ethics Committee Approval Letter

[The ethical approval letter is redacted to protect confidentiality.] 


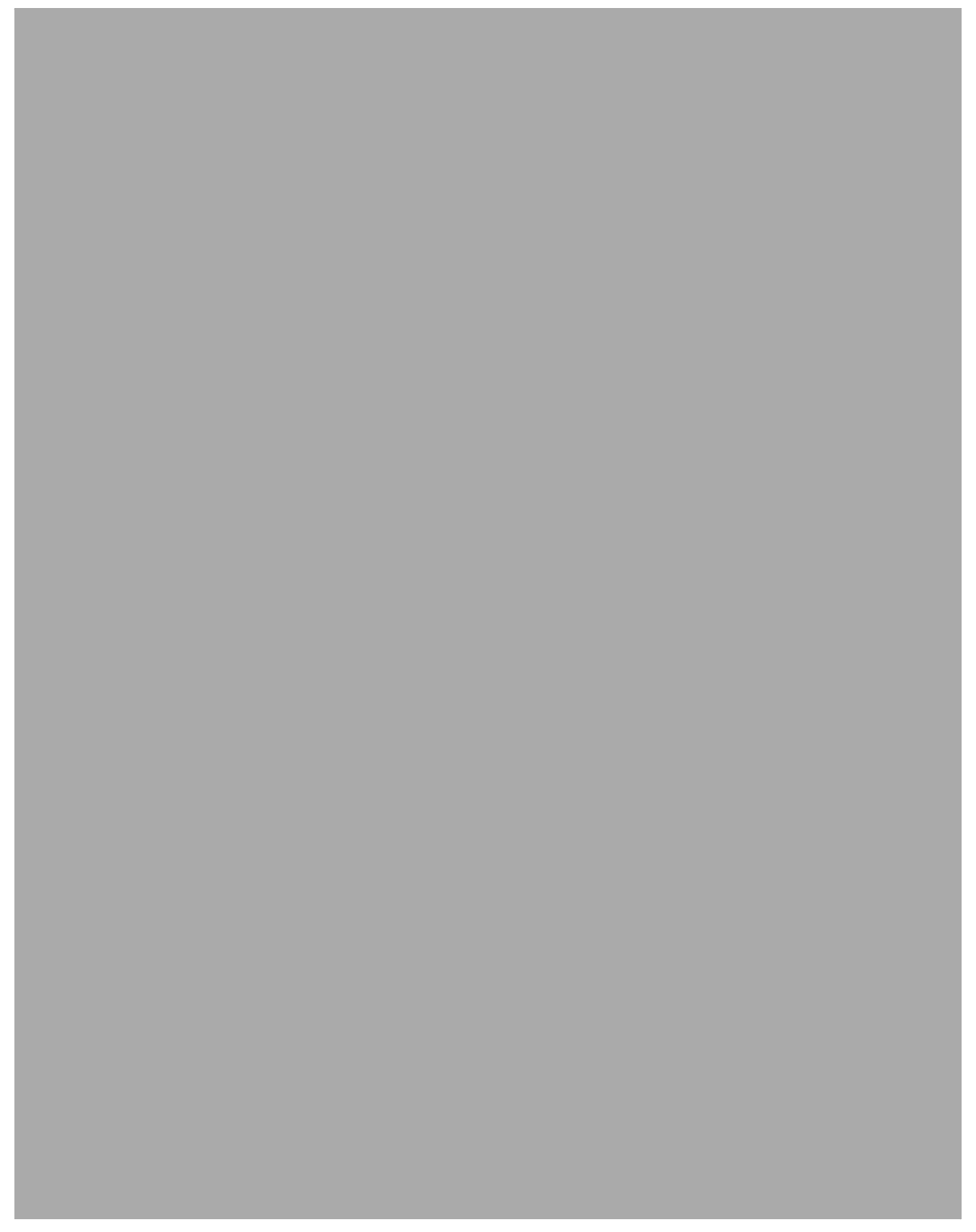




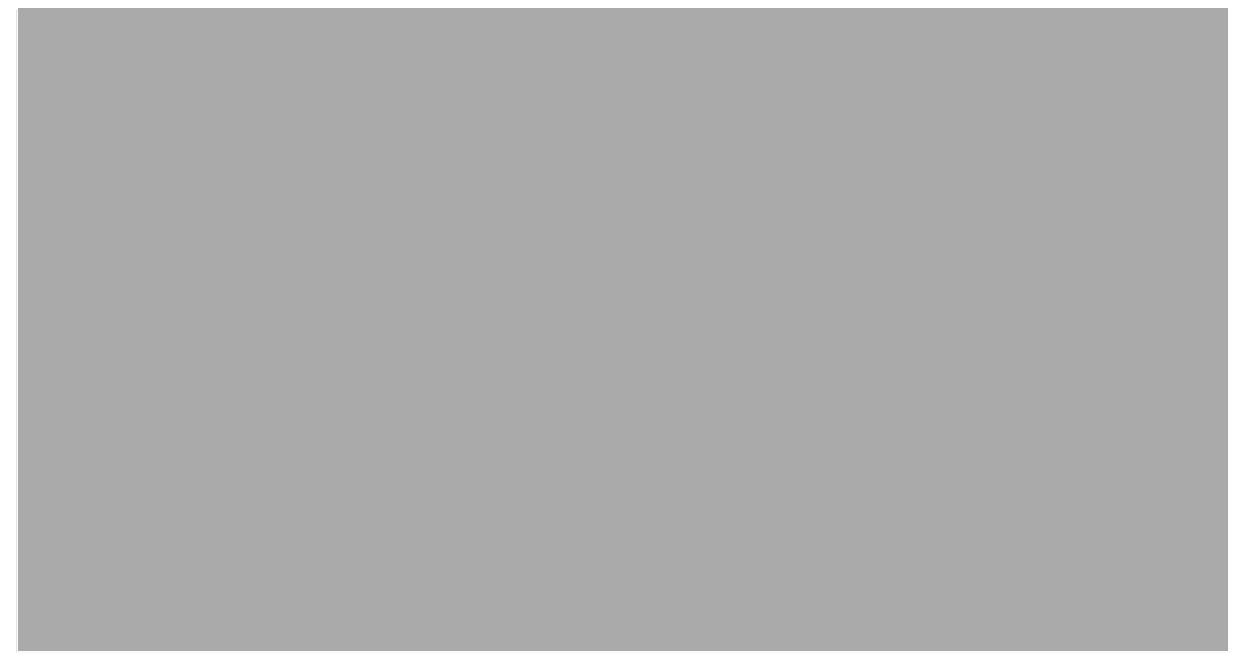




\section{Appendix 2. Brief programme of the 8 weeks mindfulness group}

Mindfulness training consists of: orienting the client to the mindfulness skill; obtaining and using client feedback effectively; introducing simple mindfulness practises; teaching clients to utilise mindfulness in everyday life and case scenarios practically demonstrating the skills (Dunkley \& Stanton, 2014).

- Week 1: ground rules, what is mindfulness, basic body scan and mindfulness of breathing, how to practice at home

- Week 2: reminder what is mindfulness, use of metaphor (clouds, leaf), practice body scan and mindfulness of breathing

○ Week 3: adapting mindfulness in everyday life e.g. leaf task; practice body scan and mindfulness of breathing

○ Week 4: adaptations to mindfulness of breathing e.g. counting the breath, practice body scan and mindfulness of breathing

○ Week 5: adaptations to mindfulness e.g. adding background music to help tinnitus, practice body scan and mindfulness of breathing

○ Week 6: further discussion of adapting mindfulness and practicing mindfulness in daily life situations, practice body scan and mindfulness of breathing

○ Week 7: adapting mindfulness in everyday life e.g. raisin task; practice body scan/mindfulness of breathing

○ Week 8: recap of 8 weeks, practice body scan and mindfulness of breathing, how to continue own practice, group evaluation

If clients attend the group for more than one timetable then more activities related to practicing and applying mindfulness during everyday life are added.

Body Scan meditation (Kabat-Zinn, 2013)

Clients practice meditation in sitting position when they attend the mindfulness group, but at home it can be practised by lying on the back and moving one's mind systematically through the different regions of the body.

The exercise starts with the left foot and the attention is slowly moved to the different regions of the foot and the left leg. During the exercise the participants are 
instructed to fill each region of their body with their full awareness, noticing all sensations they might encounter. This way the exercise moves the attention through to the hip, then back to the toes of the right foot up, through the torso, low back, abdomen, the upper back and chest, through the shoulder blades to the left arm and right arm.

Mindful breathing mediation (Kabat-Zinn, 2013)

Clients are encouraged to focus their attention on their breathing and focus their attention on the sensations associated with breathing. They are invited not to modify their breathing, just to pay attention, without trying to control it or think about it. If their mind starts to wonder, they are instructed just to notice it and bring the attention gently back to their breathing.

\section{References}

Dunkley, C., \& Stanton, M. (2014). Teaching Clients to Use Mindfulness Skills: a Practical Guide. London, England and New York, NY: Routledge. Kabat-Zinn, J. (2013). Full catastrophe living, revised edition: how to cope with stress, pain and illness using mindfulness meditation: Hachette UK. 
(Version 1.1/19.12.2015)

Title of Project: Does improving mindfulness impact on neurobehavioural

functioning?

Researchers: Shruti Niraj (Principal)

You are being invited to take part in a clinical psychology doctoral student research study. Before you decide it is important for you to understand why the research is being done and what it will involve. Please take time to read the following information carefully. Talk to others about the study if you wish. Ask us if there is anything that is not clear or if you would like more information. Take time to decide whether or not you wish to take part. You do not have to participate and choosing not to participate will not affect the standard care of rehabilitation you are receiving. If you agree to participate we believe that this won't cause any form of distress but if it did you would be able to talk to and gain help from your key worker and psychologist who are aware of the study.

\section{- What is the purpose of this research?}

This research study is designed to collect data that can help us to learn more about whether mindfulness is helpful to people with acquired brain injury. We hope to learn about how people with acquired brain injury use mindfulness and understand how their views about mindfulness change over the course of attending a mindfulness group.

\section{- Why have I been invited to take part?}

All patients who have been accepted for the mindfulness group between January 2016 and March 2017 are invited to take part in the study.

\section{- What will happen to me if I agree to take part?}

You will be invited to meet the researcher, who can answer any questions you have and you will have two weeks to sign a consent form. You will have a choice to do the voice recordings or a focus group or both of these.

\section{Voice recordings}

For the duration of the study, you will be given a personal voice recorder. A member of the psychology rehabilitation team or the researcher will be available to provide up 
to two sessions of instructions on how to use the recorder. Following the fourth session of the Mindfulness Group, you will be given a set of five open questions and you will be invited to use the recorder and record your answers to the questions at home every time you use mindfulness skills. You will be reminded to use your recorder by a text message twice a week. After the first week you will be invited to meet the researcher and you will listen together to your answers. The researcher will give you feedback on how detailed the information is expected to be. The interview will be conducted at your pace and you will be able to take a break at any point. You will keep recording your mindfulness experiences until the Mindfulness Group is finished. You will then return the recorder with the recordings to the researcher.

\section{Focus group}

The researcher will arrange a focus group at the end of your mindfulness group. The focus group will take place at Moor Green and will last for 45 - 60 minutes. You will attend this group with other members who have attended the same mindfulness group. The researcher will ask questions about your views and experiences of attending the mindfulness group. The interview will be conducted at your pace and you will be able to take a break at any point. Your discussion will be taped using digital voice recorder.

\section{- What will happen if I do not want to carry on with the study?}

You can withdraw from the study at any point. Withdrawing from the study at any point will not affect the standard care of rehabilitation you receive. If you do decide to withdraw you can then decide whether any data collected up to that point can still be included in the study or whether you wish your data to be removed.

\section{- Expenses and payments}

The study will be conducted in the outpatient unit and the meetings and interviews will be held either prior to or after the Mindfulness group, so that you do not need to make any additional journeys to the clinic.

\section{- What will happen with my questionnaires and recordings?}

Once your data have been collected, they will be anonymised and included into a common database. Your recordings will be transcribed anonymised and analysed by the researcher. Original recordings will be deleted.

- What will happen to the results of the research study? 
The results of the study will be published in a peer-reviewed journal and a brief summary of the results will be made available to you after the study is completed.

\section{- What happens if I have any further concerns?}

If you would like to discuss any aspect of this research please contact my academic supervisor: Dr. Theresa Powell or you can email on: . You could also talk to the Patient Advice and Liaison Service (PALS) on 0800917 2855 if you've more generic questions or concerns related to the research. 


\section{Appendix 4. Consent Form - For clients participating in Voice recordings and Focus group of the study}

(Version 2.1/19.12.2015)

Participant Identification Number:

Title of Project: Does improving mindfulness impact on neurobehavioural

functioning?

Researcher: Shruti Niraj

For clients participating in Part B - Voice recordings and Focus group of the study

Please initial box

○ I confirm that I have understood the information sheet dated 19.12.2015 (Version1.1) for the above study. I have had the opportunity to consider the information, ask questions and have had these answered satisfactorily.

- I understand that my participation is voluntary and that I am free to withdraw at any time during the research study, without giving any reason, without my medical/social care or legal rights being affected.

- I understand and give my consent that my audio recordings will be used as part of this study.

- I understand and agree, to be reminded twice weekly between the mindfulness sessions via text messages from a researcher to record my experiences.

- I understand and agree that the data collected during this study will be looked at by the researcher and relevant others at the University of
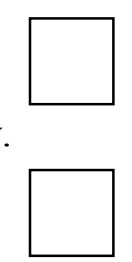
Birmingham to ensure that the analysis is a fair and reasonable representation of the data. Parts of the data may also be made available to the NHS team responsible for me.

- I understand and agree that direct quotes from my recordings may be published in any write-up of the data, but that my name will not be attributed to any such quotes and that I will not be identifiable by my comments.

- I understand and agree that the data and case notes collected by my local clinical rehabilitation team prior to the study may be accessed by the researcher and may be used in an anonymised form in the final data analysis.

- I give permission to inform my GP about my participation in the research study

Name of participant

Name of researcher
Date

Date
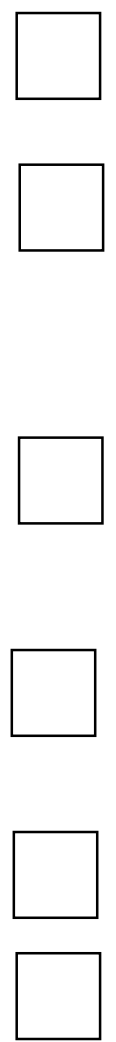


\section{Appendix 5. Consent Form - For clients participating in Focus Group of the study}

(Version 2.1/19.12.2015)

Participant Identification Number:

Title of Project: Does improving mindfulness impact on neurobehavioural functioning?

Researcher: Shruti Niraj

\section{For clients participating only in Part B - Focus Group of the study}

Please initial box

o I confirm that I have understood the information sheet dated 19.12.2015 (Version1.1) for the above study. I have had the opportunity to consider the information, ask questions and have had these answered satisfactorily.

- I understand that my participation is voluntary and that I am free to withdraw at any time during the research study, without giving any

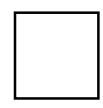
reason, without my medical/social care or legal rights being affected.

- I understand and give my consent that my focus group recordings will be used in part of the study.

- I understand and agree that the data collected during this study will be looked at by the researcher and relevant others at the University of Birmingham to ensure that the analysis is a fair and reasonable

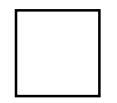
representation of the data. Parts of the data may also be made available to the NHS team responsible for me.

- I understand and agree that direct quotes from my focus group recordings may be published in any write-up of the data, but that my name will not be attributed to any such quotes and that I will not be identifiable by my comments.

- I understand and agree that the data and case notes collected by my local clinical rehabilitation team prior to the study may be accessed by the

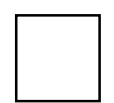
researcher and may be used in an anonymised form in the final data analysis.

- I give permission to inform my GP about my participation in the research study.

- I agree to take part in the above study.

- I confirm that I have understood the information sheet dated 19.12.2015 (Version1.1) for the above study. I have had the opportunity to consider the information, ask questions and have had these answered satisfactorily.

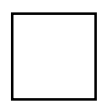




\section{Appendix 6. Consent Form - - Voice recordings of the study}

(Version 2.1/19.12.2015)

Participant Identification Number:

Title of Project: Does improving mindfulness impact on neurobehavioural functioning?

Researcher: Shruti Niraj

\section{For clients participating only in Part B - Voice recordings of the study}

Please initial box

- I confirm that I have understood the information sheet dated 19.12.2015 (Version1.1) for the above study. I have had the opportunity to consider the information, ask questions and have had these answered satisfactorily.

- I understand that my participation is voluntary and that I am free to withdraw at any time during the research study, without giving any reason, without my medical/social care or legal rights being affected.

- I understand that and give my consent that my audio recordings will be used as part of this study.

- I understand and agree, to be reminded twice weekly between the mindfulness sessions via text messages from a researcher to record my experiences.

- I understand and agree that the data collected during this study will be looked at by the researcher and relevant others at the University of Birmingham to ensure that the analysis is a fair and reasonable representation of the data. Parts of the data may also be made available to the NHS team responsible for me.

- I understand and agree that direct quotes from my audio recordings may be published in any write-up of the data, but that my name will not be attributed to any such quotes and that I will not be identifiable by my comments.

- I understand and agree that the data and case notes collected by my local clinical rehabilitation team prior to the study may be accessed by the researcher and may be used in an anonymised form in the final data analysis.

- I give permission to inform my GP about my participation in the research study.

- I agree to take part in the above study.
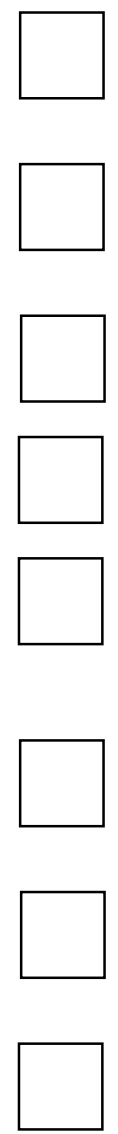

Name of participant

Name of researcher
Date

Date
Signature

Signature 


\section{Appendix 7. Focus group interview schedule}

(Version 1/19.12. 2015)

Interview Schedule:

1. What were your expectations before you attended the group?

2. What are your experiences of being in the group?

3. What do you think about mindfulness approach? What have you learnt after coming to the mindfulness group?

4. What impact has mindfulness group made on your day-to-day lives?

5. What does future hold for you in terms of mindfulness? Would you continue practicing mindfulness now that you have finished the group?

6. What things might help you to use mindfulness practice in future?

7. What kind of things might stop you from practising mindfulness in future? 


\section{Appendix 8. Total length of each focus group and participants attending each group}

\begin{tabular}{|c|c|c|}
\hline Focus group & Participants attended & $\begin{array}{l}\text { Total length in minutes and } \\
\text { seconds }\end{array}$ \\
\hline Focus group 1 & $\begin{array}{l}\text { Linda (P1) } \\
\text { Tracey (P2) }\end{array}$ & $48{ }^{\prime} 19{ }^{\prime \prime}$ \\
\hline Focus group 2 & $\begin{array}{l}\text { Ian (P3) } \\
\text { Miriam (P4) }\end{array}$ & 38'09”' \\
\hline Focus group 3 & $\begin{array}{l}\text { Miriam (P4) } \\
\text { Mark (P5) } \\
\text { Yusuf (P6) }\end{array}$ & $51 ' 11 ”$ \\
\hline Focus group 4 & $\begin{array}{l}\text { Joanne (P7) } \\
\text { Anna (P8) }\end{array}$ & $35^{\prime} 51^{\prime \prime}$ \\
\hline Focus group 5 & $\begin{array}{l}\text { Chris (P9) } \\
\text { Tanya (P10) } \\
\text { Raj (P11) }\end{array}$ & $44^{\prime}$ \\
\hline Focus group 6 & $\begin{array}{l}\text { Anna (P8) } \\
\text { Chris (P9) } \\
\text { Tanya (P10) } \\
\text { Paul (P12) } \\
\text { Sam (P13) } \\
\text { Simon (P14) }\end{array}$ & 50 \\
\hline
\end{tabular}




\section{Appendix 9. Instructions for the Participants}

For clients participating in Individual audio recordings

Researcher: Shruti Niraj

Thank you very much for agreeing to participate in our study. During the last two weeks you were given a personal recorder and a member of our team showed you how to use it in order to make short recordings. We would like to ask you to use it during the week, between the sessions of your Mindfulness Group, whenever you notice that you have used any of the mindfulness skills you learned. When you are recording the experience, please try to answer the following five questions:

- Why did you choose this moment to use mindfulness?

- What did you hope to achieve?

- How (in what way) did you practice mindfulness just now?

- What were you noticing while you did it?

- What were you noticing afterwards?

Please remember, that there are no right and wrong answers, we are interested in your authentic experience. It may help us better understand how mindfulness affects your everyday life. You can make as many recordings as you want, and we will send you a text message twice a week to remind you to use your recorder.

Following the first week of recordings, you will have an opportunity to meet with Shruti to discuss your recordings and ask any questions. We will ask you to return the recorder together with all recordings when your Mindfulness Group sessions finish. The data will be anonymised, transcribed and original recordings will be deleted. 


\section{Appendix 10. An Example of a Worked-out Transcript from Focus Group - 2}

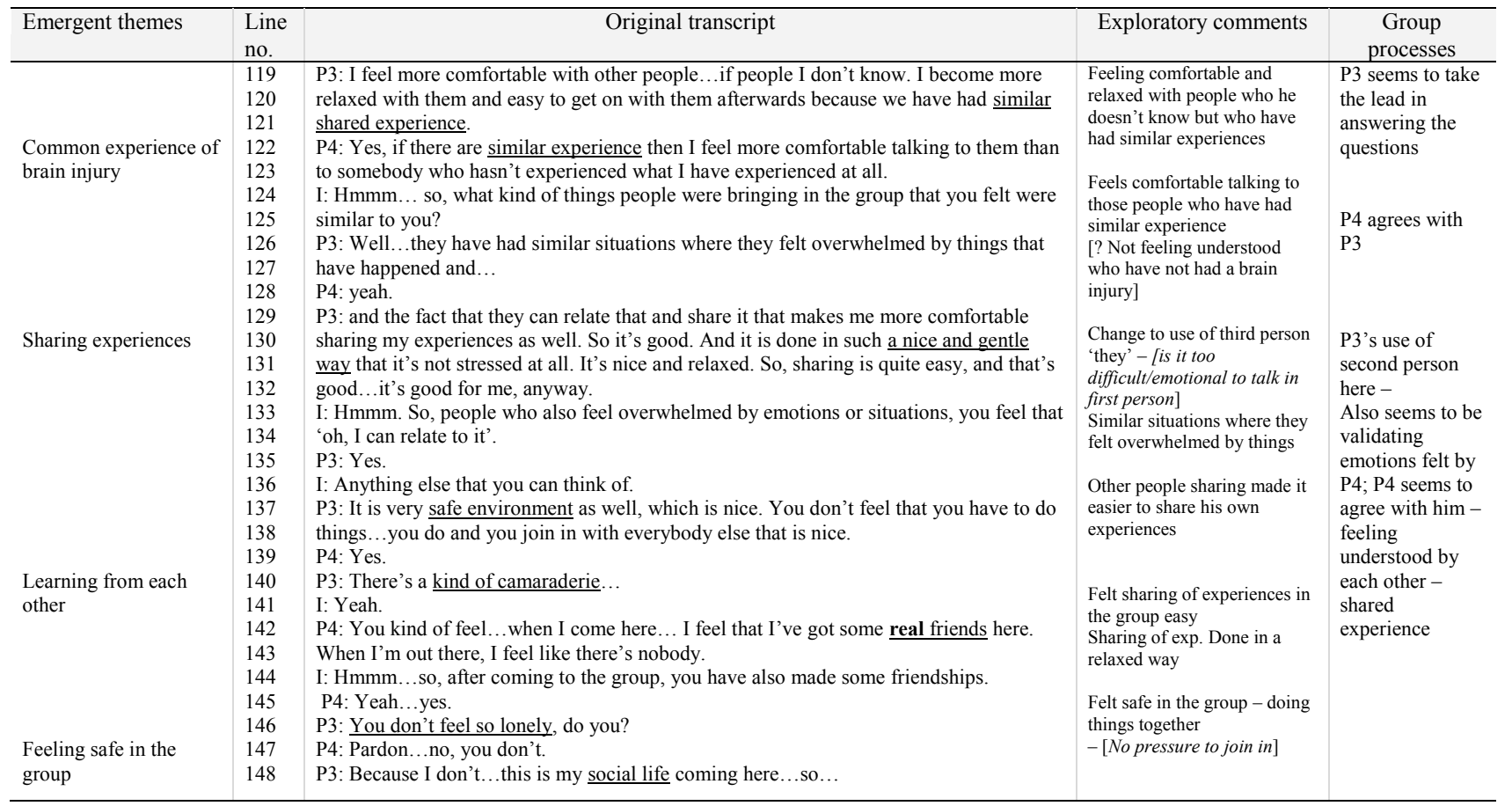




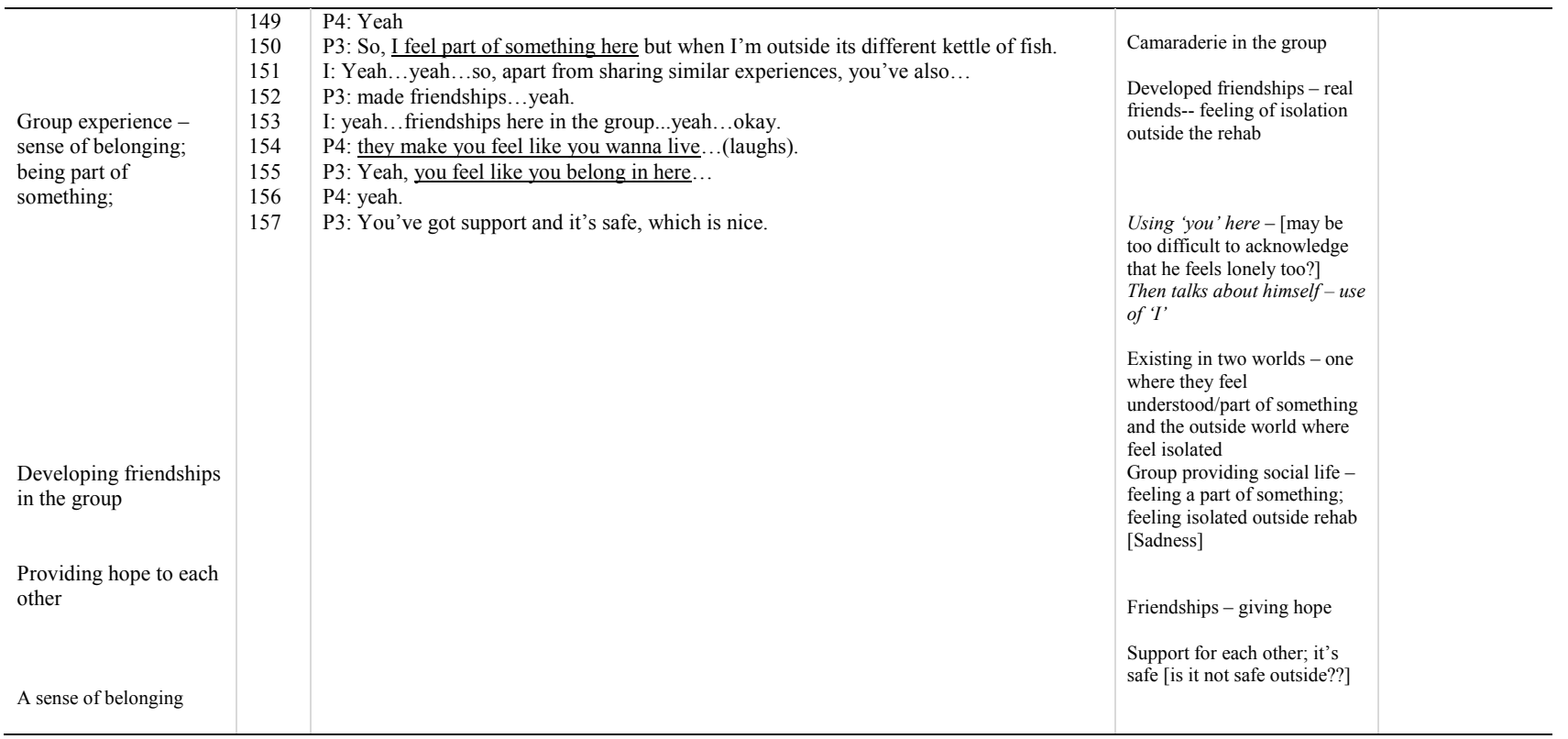




\section{Appendix 11. Emergent Themes from Focus Group - 2}

\begin{tabular}{|c|c|c|}
\hline Emergent Themes & $\begin{array}{l}\text { Participant } \\
\& \text { line no. }\end{array}$ & Keywords from transcript \\
\hline Initial scepticism & $\begin{array}{l}\mathrm{P} 4,14 \\
\mathrm{P} 3,27\end{array}$ & Thought similar to relaxation group \\
\hline $\begin{array}{l}\text { Expectations from Group: } \\
\text { Emotional regulation }\end{array}$ & $\begin{array}{l}\mathrm{P} 4,23 \\
\mathrm{P} 3,33\end{array}$ & To be able to contain emotions \\
\hline $\begin{array}{l}\text { Overcoming initial } \\
\text { scepticism }\end{array}$ & $\mathrm{P} 3,47$ & Glad not like relaxation \\
\hline Mindfulness as a technique & $P 3,55,64$ & Technique to develop focus \\
\hline Feeling relaxed & $\mathrm{P} 3,73$ & Action involved but can get relaxed \\
\hline $\begin{array}{l}\text { Discovering own } \\
\text { techniques }\end{array}$ & $\mathrm{P} 4,79$ & Shadow focusing \\
\hline $\begin{array}{l}\text { Using Mindfulness in other } \\
\text { activities }\end{array}$ & $\mathrm{P} 4,85$ & When drawing \\
\hline Taking a step back & $\mathrm{P} 4,88$ & $\begin{array}{l}\text { Using when feeling overwhelmed to } \\
\text { calm down }\end{array}$ \\
\hline $\begin{array}{l}\text { Common experience of } \\
\text { brain injury }\end{array}$ & $\begin{array}{l}\mathrm{P} 3 \& \mathrm{P} 4 \\
120\end{array}$ & Have had similar shared experiences \\
\hline Sharing experiences & P3, 129 & Relate to other's experiences \\
\hline Learning from each other & $\mathrm{P} 3,133$ & $\begin{array}{l}\text { Other people feeling overwhelmed with } \\
\text { emotions }\end{array}$ \\
\hline Feeling safe in the group & P3, 137 & Safe environment \\
\hline $\begin{array}{l}\text { Group experience - sense } \\
\text { of belonging }\end{array}$ & $\begin{array}{l}\text { P3 \& P4, } \\
152\end{array}$ & Feel part of something \\
\hline $\begin{array}{l}\text { Developing friendships in } \\
\text { the group }\end{array}$ & $\mathrm{P} 4,144$ & Real friends here \\
\hline $\begin{array}{l}\text { Providing hope to each } \\
\text { other }\end{array}$ & $\mathrm{P} 4,156$ & They make you feel like you wanna live \\
\hline A sense of belonging & $\mathrm{P} 4,157$ & Feel like you belong in here \\
\hline $\begin{array}{l}\text { Comparing mindfulness } \\
\text { with relaxation }\end{array}$ & P4, 168 & $\begin{array}{l}\text { Mind drift-off in relaxation but focus on } \\
\text { something in mindfulness }\end{array}$ \\
\hline $\begin{array}{l}\text { Benefits of mindfulness: } \\
\text { helping to reduce stress }\end{array}$ & $\mathrm{P} 3,171$ & Feel less stressed \\
\hline $\begin{array}{l}\text { Mindfulness bringing } \\
\text { improvement in } \\
\text { concentration }\end{array}$ & $\begin{array}{l}\text { P3, 181, } \\
196\end{array}$ & Become less distractful \\
\hline $\begin{array}{l}\text { Increased awareness of } \\
\text { changing values }\end{array}$ & P3, 192 & More considerate of others \\
\hline $\begin{array}{l}\text { Benefits of mindfulness: } \\
\text { improvement in } \\
\text { concentration }\end{array}$ & P3, 202 & $\begin{array}{l}\text { Focused on what I'm supposed to be } \\
\text { doing }\end{array}$ \\
\hline $\begin{array}{l}\text { Benefits of mindfulness: } \\
\text { emotional wellbeing }\end{array}$ & $\begin{array}{l}\mathrm{P} 4,206, \\
214\end{array}$ & Feeling less emotional now \\
\hline $\begin{array}{l}\text { Scepticism about } \\
\text { mindfulness as an } \\
\text { intervention }\end{array}$ & $\mathrm{P} 4,211$ & Takes everything with a pinch of salt \\
\hline Comparing mindfulness & $\mathrm{P} 4,231$ & In mindfulness given a task \\
\hline
\end{tabular}




\begin{tabular}{|c|c|c|}
\hline with relaxation & & \\
\hline $\begin{array}{l}\text { Learning the technique - } \\
\text { Object acts an anchor }\end{array}$ & P4, 238 & Easier to shut mind down \\
\hline $\begin{array}{l}\text { Increased awareness of } \\
\text { distractions - taking a step } \\
\text { back }\end{array}$ & $\mathrm{P} 3,250$ & $\begin{array}{l}\text { Internal as well as external distractions - } \\
\text { put them in a place }\end{array}$ \\
\hline $\begin{array}{l}\text { Benefits of being in the } \\
\text { group }\end{array}$ & P3, 257 & Easier to learn and practice mindfulness \\
\hline $\begin{array}{l}\text { Benefits of mindfulness: } \\
\text { improvement in } \\
\text { concentration }\end{array}$ & P3, 279 & More focused \\
\hline $\begin{array}{l}\text { Noticing improved } \\
\text { concentration in other tasks }\end{array}$ & P4, 291 & Helps with drawing \\
\hline $\begin{array}{l}\text { Mindfulness helping to } \\
\text { control distractions }\end{array}$ & $\mathrm{P} 3,310$ & $\begin{array}{l}\text { Skill helping with focusing on what is } \\
\text { necessary }\end{array}$ \\
\hline $\begin{array}{l}\text { Group experience - sharing } \\
\text { experiences and learning } \\
\text { from each other }\end{array}$ & $\mathrm{P} 3,317$ & Able to relate to others \\
\hline $\begin{array}{l}\text { Group bringing } \\
\text { improvement in self-esteem }\end{array}$ & $\mathrm{P} 3,325$ & Makes you good about yourself \\
\hline $\begin{array}{l}\text { Integrating practice into } \\
\text { daily life }\end{array}$ & $\begin{array}{l}\mathrm{P} 3,336 \& \\
340\end{array}$ & Daily activity for me \\
\hline $\begin{array}{l}\text { Seeing the benefits } \\
\text { encourages to carry on the } \\
\text { practice }\end{array}$ & $\mathrm{P} 3,361$ & $\begin{array}{l}\text { Seeing the benefits encourages to carry } \\
\text { on }\end{array}$ \\
\hline $\begin{array}{l}\text { Integrating practice into } \\
\text { daily life }\end{array}$ & P3, 364 & Practice until it becomes a habit \\
\hline $\begin{array}{l}\text { Owning responsibility to } \\
\text { continue practice }\end{array}$ & $\mathrm{P} 3,373$ & It's down to me \\
\hline $\begin{array}{l}\text { Barriers to continuing } \\
\text { practice }\end{array}$ & $\begin{array}{l}\text { P3 \& P4, } \\
408\end{array}$ & Crisis in life \\
\hline $\begin{array}{l}\text { Barriers to continuing } \\
\text { practice }\end{array}$ & P3, 428 & Extreme pain \\
\hline $\begin{array}{l}\text { Reinforcer to continuing } \\
\text { practice }\end{array}$ & $\mathrm{P} 3,454$ & Remembering the benefits \\
\hline $\begin{array}{l}\text { Non-judgemental ethos of } \\
\text { group }\end{array}$ & $\mathrm{P} 4,470$ & Feeling understood and not judged \\
\hline
\end{tabular}


Appendix 12. Master Table of Themes by Focus Groups

\begin{tabular}{|c|c|c|c|c|c|c|}
\hline \multirow[t]{2}{*}{ Themes } & \multicolumn{6}{|c|}{ Focus Groups } \\
\hline & FG-1 & FG - 2 & FG - 3 & $\mathrm{FG}-4$ & FG - 5 & FG - 6 \\
\hline $\begin{array}{l}\text { 1. DEVELOPMENTAL } \\
\text { LEARNING PROCESS }\end{array}$ & & & & & & \\
\hline $\begin{array}{l}\text { 1.1 Overcoming initial } \\
\text { scepticism }\end{array}$ & $X$ & $X$ & $X$ & $\mathrm{X}$ & $X$ & $X$ \\
\hline $\begin{array}{l}1.2 \text { "Mindfulness is a bit of a } \\
\text { technique to get used to" }\end{array}$ & $X$ & $\mathrm{X}$ & $\mathrm{X}$ & $X$ & $X$ & $X$ \\
\hline 1.3 "It's become part of me" & $X$ & $\mathrm{X}$ & $X$ & $X$ & $\mathrm{X}$ & $\mathrm{X}$ \\
\hline $\begin{array}{l}\text { 2. GROUP AS A } \\
\text { SUPPORTIVE } \\
\text { ENVIRONMENT FOR } \\
\text { LEARNING }\end{array}$ & & & & & & \\
\hline $\begin{array}{l}\text { 2.1 Sense of belonging - "I am } \\
\text { not the only one" }\end{array}$ & $X$ & $X$ & $X$ & $X$ & $X$ & $\mathrm{X}$ \\
\hline 2.2 Learning from each other & $X$ & $X$ & $X$ & $\mathrm{X}$ & $X$ & $X$ \\
\hline $\begin{array}{l}\text { 3. INCREASED } \\
\text { AWARENESS }\end{array}$ & & & & & & \\
\hline 3.1 Taking everything in & $X$ & $\mathrm{O}$ & $\mathrm{O}$ & $\mathrm{X}$ & $X$ & $X$ \\
\hline 3.3 Taking a step back & $\mathrm{X}$ & $\mathrm{X}$ & $\mathrm{X}$ & $X$ & $X$ & $X$ \\
\hline $\begin{array}{l}3.2 \text { "Stopping my thoughts to } \\
\text { go and run everywhere" }\end{array}$ & $X$ & $X$ & $X$ & $X$ & $X$ & $\mathrm{X}$ \\
\hline $\begin{array}{l}3.4 \text { Increasing awareness of } \\
\text { self-to-self relationship and } \\
\text { increasing self-compassion }\end{array}$ & $X$ & $X$ & $X$ & $\mathrm{O}$ & $X$ & $X$ \\
\hline $\begin{array}{l}\text { 4. BENEFITS OF } \\
\text { MINDFULNESS }\end{array}$ & & & & & & \\
\hline $\begin{array}{l}\text { 4.1 Mindfulness bringing } \\
\text { improvement to sleep and pain }\end{array}$ & $X$ & $\mathrm{O}$ & $X$ & $X$ & $X$ & $X$ \\
\hline $\begin{array}{l}4.2 \text { Mindfulness bringing } \\
\text { improvement in memory and } \\
\text { concentration }\end{array}$ & $\mathrm{O}$ & $X$ & $X$ & $\mathrm{O}$ & $X$ & $X$ \\
\hline $\begin{array}{l}4.3 \text { Mindfulness bringing } \\
\text { improvement in emotional } \\
\text { well-being }\end{array}$ & $X$ & $X$ & $X$ & $X$ & $X$ & $X$ \\
\hline
\end{tabular}


Appendix 13. Master Table of Themes and Location by Participant in Each Focus Group

\begin{tabular}{|c|c|c|c|c|c|c|c|c|c|c|c|c|c|c|c|c|c|c|}
\hline \multirow[t]{3}{*}{ Themes } & \multicolumn{18}{|c|}{ Participants and line no. } \\
\hline & \multicolumn{2}{|c|}{ FG - 1} & \multicolumn{2}{|c|}{ FG - 2} & \multicolumn{3}{|c|}{ FG - 3} & \multicolumn{2}{|c|}{ FG - 4} & \multicolumn{3}{|c|}{ FG - 5} & \multicolumn{6}{|c|}{ FG - 6} \\
\hline & Linda & Tracey & Ian & Miriam & Mark & Yusuf & Miriam & Joanne & Anna & Chris & Tanya & Raj & Paul & Sam & Simon & Chris & Tanya & Anna \\
\hline \multirow[t]{4}{*}{$\begin{array}{l}1.1 \text { Overcoming initial } \\
\text { scepticism }\end{array}$} & 91 & & 30 & 16 & 8 & 31 & 71 & 12 & 38 & 47 & 14 & 64 & 7 & & & 207 & 49 & \\
\hline & 126 & & 45 & 165 & 16 & & & 18 & & & 18 & & 210 & & & 73 & 209 & \\
\hline & 131 & & 47 & 225 & 32 & & & 54 & & & & & & & & & & \\
\hline & & & & & & & & 109 & & & & & & & & & & \\
\hline & & & & & & & & & & & & & & & & & & \\
\hline \multirow[t]{5}{*}{$\begin{array}{l}1.2 \text { "Mindfulness is a bit } \\
\text { of a technique to get used } \\
\text { to" }\end{array}$} & 99 & 494 & 55 & 79 & 24 & 44 & & 68 & 261 & 458 & 300 & & & 54 & & 56 & 132 & \\
\hline & 179 & 101 & 64 & 228 & 189 & 302 & & 450 & & 466 & 529 & & & & & 585 & 269 & \\
\hline & 680 & & 336 & & 181 & & & 432 & & 509 & & & & & & & 59 & \\
\hline & 741 & & 361 & & 24 & & & & & & & & & & & & & \\
\hline & 465 & & 257 & & & & & & & & & & & & & & & \\
\hline \multirow[t]{7}{*}{$\begin{array}{l}1.3 \text { "It's become part of } \\
\text { me" }\end{array}$} & 202 & 491 & 168 & 85 & 418 & 445 & & 136 & & 442 & 33 & & & 546 & 590 & 127 & 507 & 487 \\
\hline & 478 & 493 & 333 & 244 & & & & & & & 432 & & & 550 & 592 & 561 & 366 & 103 \\
\hline & 465 & & 361 & & & & & & & & 436 & & & & & 99 & 391 & 112 \\
\hline & 729 & & 373 & & & & & & & & 443 & & & & & 511 & 510 & 504 \\
\hline & & & 173 & & & & & & & & 524 & & & & & 551 & 556 & \\
\hline & & & & & & & & & & & & & & & & 564 & & \\
\hline & & & & & & & & & & & & & & & & 591 & & \\
\hline \multirow{6}{*}{2.1 Sense of belonging } & 188 & 147 & 120 & 122 & & 123 & & 124 & 144 & 213 & 129 & 96 & & 223 & 220 & & 225 & \\
\hline & 191 & 387 & 129 & 142 & & & & & & & 181 & & & 231 & 390 & & 232 & \\
\hline & 376 & & 133 & 147 & & & & & & & & & & 233 & & & 234 & \\
\hline & & & 148 & 154 & & & & & & & & & & & & & 388 & \\
\hline & & & 155 & & & & & & & & & & & & & & & \\
\hline & & & 157 & & & & & & & & & & & & & & & \\
\hline
\end{tabular}




\begin{tabular}{|c|c|c|c|c|c|c|c|c|c|c|c|c|c|c|c|c|c|c|}
\hline & Linda & Tracey & Ian & Miriam & Mark & Yusuf & Miriam & Joanne & Anna & Chris & Tanya & Raj & Paul & Sam & Simon & Chris & Tanya & Anna \\
\hline \multirow[t]{4}{*}{$\begin{array}{l}2.2 \text { Learning from each } \\
\text { other }\end{array}$} & 208 & 194 & 314 & & 167 & 103 & 89 & 146 & & 113 & 129 & & & 235 & 237 & & 388 & \\
\hline & 228 & 196 & 318 & & 170 & 117 & 94 & & & 154 & 184 & & & 223 & & & & \\
\hline & 380 & & 322 & & & 142 & & & & 175 & 188 & & & & & & & \\
\hline & & & & & & 132 & & & & 188 & & & & & & & & \\
\hline & & & & & & & & & & & & & & & & & & \\
\hline \multirow[t]{6}{*}{3.1 Taking everything in } & 354 & 155 & & & & & & 54 & & 504 & 429 & & & 398 & 500 & & 261 & \\
\hline & 359 & & & & & & & 432 & & & 486 & & & 411 & & & 394 & \\
\hline & & & & & & & & 450 & & & 492 & & & & & & 405 & \\
\hline & & & & & & & & & & & 497 & & & & & & 410 & \\
\hline & & & & & & & & & & & 500 & & & & & & & \\
\hline & & & & & & & & & & & & & & & & & & \\
\hline \multirow[t]{3}{*}{ 3.2 Taking a step back } & 557 & 617 & 88 & & 362 & 384 & 413 & 228 & & 137 & 258 & & 259 & & 312 & 355 & 63 & \\
\hline & & & 193 & & 479 & 294 & & 234 & & 226 & 149 & & 447 & & 155 & & 270 & \\
\hline & & & 199 & & & & & 251 & & & & & & & & & & \\
\hline \multirow[t]{7}{*}{$\begin{array}{l}3.3 \text { "Stopping my } \\
\text { thoughts to go and run } \\
\text { everywhere" }\end{array}$} & 438 & 438 & 310 & & 154 & 64 & & & 260 & & 247 & & 244 & 161 & 153 & 74 & 481 & 362 \\
\hline & & & & & 185 & 289 & & & & & & & 253 & 168 & & 92 & 63 & \\
\hline & & & & & & 302 & & & & & & & 625 & 171 & & 95 & & \\
\hline & & & & & & & & & & & & & & & & 631 & & \\
\hline & & & & & & & & & & & & & & & & 633 & & \\
\hline & & & & & & & & & & & & & & & & 638 & & \\
\hline & & & & & & & & & & & & & & & & & & \\
\hline \multirow[t]{7}{*}{$\begin{array}{l}3.4 \text { Increasing awareness } \\
\text { of self-to-self relationship } \\
\text { and increasing self- } \\
\text { compassion }\end{array}$} & 339 & 311 & 192 & & 475 & 298 & & & & 269 & 248 & 336 & 441 & 407 & 423 & 336 & 187 & \\
\hline & 344 & 293 & 279 & & & 534 & & & & 276 & 288 & & & & 434 & 183 & 469 & \\
\hline & 347 & 301 & & & & & & & & 282 & 398 & & & & 148 & 316 & 450 & \\
\hline & 350 & 237 & & & & & & & & 547 & & & & & 413 & 496 & 456 & \\
\hline & 353 & 346 & & & & & & & & 297 & & & & & 417 & & 466 & \\
\hline & 425 & 285 & & & & & & & & & & & & & 492 & & 518 & \\
\hline & & & & & & & & & & & & & & & 497 & & & \\
\hline
\end{tabular}




\begin{tabular}{|c|c|c|c|c|c|c|c|c|c|c|c|c|c|c|c|c|c|c|}
\hline & Linda & Tracey & Ian & Miriam & Mark & Yusuf & Miriam & Joanne & Anna & Chris & Tanya & Raj & Paul & Sam & Simon & Chris & Tanya & Anna \\
\hline \multirow[t]{3}{*}{$\begin{array}{l}4.1 \text { Mindfulness bringing } \\
\text { improvement to sleep and } \\
\text { pain }\end{array}$} & 214 & & & & & & & & 90 & 54 & & & 285 & & & & & \\
\hline & & & & & & & & & 116 & 383 & & & & & & & & \\
\hline & & & & & & & & & 260 & & & & & & & & & \\
\hline \multirow{6}{*}{$\begin{array}{l}4.2 \text { Mindfulness bringing } \\
\text { improvement in memory } \\
\text { and concentration }\end{array}$} & & & & & & & & & & & & & & & & & & \\
\hline & & & 181 & 291 & 253 & 315 & 244 & & & 255 & & & 295 & 29 & 24 & 642 & & \\
\hline & & & 250 & & 333 & 319 & & & & & & & & & 121 & & & \\
\hline & & & 279 & & & & & & & & & & & & 221 & & & \\
\hline & & & 276 & & & & & & & & & & & & & & & \\
\hline & & & & & & & & & & & & & & & & & & \\
\hline \multirow[t]{6}{*}{$\begin{array}{l}4.3 \text { Mindfulness bringing } \\
\text { improvement in } \\
\text { emotional well-being }\end{array}$} & 258 & & 181 & & 268 & 384 & & 195 & 271 & & 245 & 92 & & 322 & 124 & 78 & 52 & 102 \\
\hline & & & 213 & & 344 & & & 203 & 364 & & & & & & & & 119 & 115 \\
\hline & & & 217 & & 284 & & & 216 & & & & & & & & & 329 & \\
\hline & & & & & 477 & & & 225 & & & & & & & & & & \\
\hline & & & & & & & & 394 & & & & & & & & & & \\
\hline & & & & & & & & 401 & & & & & & & & & & \\
\hline
\end{tabular}

